\title{
Urban Suburbanism: An Architectural Domestic Hybrid,
}

\author{
By \\ Steve Kenyon
}

A thesis submitted to

The Faculty of Graduate Studies and Research

In partial fulfillment of the requirements

For the degree of

Master of Architecture

School of Architecture

Carleton University

Ottawa, Ontario

May 2006

(c) 2006 Steve Kenyon 
Library and

Archives Canada

Published Heritage

Branch

395 Wellington Street

Ottawa ON K1A ON4

Canada
Bibliothèque et

Archives Canada

Direction du

Patrimoine de l'édition

395, rue Wellington

Ottawa ON K1A ON4

Canada
978-0-494-18345-8

Yourfile Votre référence

ISBN:

Our file Notre rerenence

ISBN:
NOTICE:

The author has granted a nonexclusive license allowing Library and Archives Canada to reproduce, publish, archive, preserve, conserve, communicate to the public by telecommunication or on the Internet, loan, distribute and sell theses worldwide, for commercial or noncommercial purposes, in microform, paper, electronic and/or any other formats.

The author retains copyright ownership and moral rights in this thesis. Neither the thesis nor substantial extracts from it may be printed or otherwise reproduced without the author's permission.
AVIS:

L'auteur a accordé une licence non exclusive permettant à la Bibliothèque et Archives Canada de reproduire, publier, archiver, sauvegarder, conserver, transmettre au public par télécommunication ou par l'Internet, prêter, distribuer et vendre des thèses partout dans le monde, à des fins commerciales ou autres, sur support microforme, papier, électronique et/ou autres formats.

L'auteur conserve la propriété du droit d'auteur et des droits moraux qui protège cette thèse. $\mathrm{Ni}$ la thèse ni des extraits substantiels de celle-ci ne doivent être imprimés ou autrement reproduits sans son autorisation.
In compliance with the Canadian Privacy Act some supporting forms may have been removed from this thesis.

While these forms may be included in the document page count, their removal does not represent any loss of content from the thesis.
Conformément à la loi canadienne sur la protection de la vie privée, quelques formulaires secondaires ont été enlevés de cette thèse.

Bien que ces formulaires aient inclus dans la pagination, il n'y aura aucun contenu manquant.

\section{Canadä}


Abstract

This project seeks an architectural prototype that is a hybrid of urban and suburban domestic values. It is predicated upon the present-day merging of the traditional notions of city and suburb, and it rejects the type of built fabric that typically results from this convergence. Instead, it proposes an urban infill development de signed to address certain suburban notions as well. The particular aspects of suburbia this thesis focuses on are still elusive in the city, and they are: the expectation of affordability, the desire for contact with open green space, and the desire for a detached, private home. As such, this is an urban design project examining the nature of suburbia, its history, its current state, and how it fits into the changing condition of today's urban realm. 


\section{Acknowledgements}

Gratitude and admiration go to my wife Kathryn Armstrong for her undying patience and support. To her, as well as my parents and all the family and friends who've helped me throughout my education in architecture, I am so thankful.

Many thanks go to my advisor Paul Kariouk for his interest and commitment to this project. His critical insight and wisdom were invaluable throughout this process.

Steve Kenyon 


\section{Table of Contents}

Abstract

ii

Acknowledgements

iii

Table of Contents

iv

Index of Images

Index of Works Cited

$\mathrm{V}$

$\mathrm{xi}$

1.0 Introduction

1.1 Project Premise

1.2 Terms of Reference

1

1.3 Project Scope

2.0 Research

2.1 Introduction

20

2.2 The Dichotomy of City and Suburb

20

2.3 Selected Case Studies

3.0 Design Project

3.1 Choice of Site

3.2 Design Project Introduction

84

3.3 Project Documentation

89

4.0 Conclusions

130

4.1 Re-statement of Argument

4.2 Project Summary

4.3 Project Conclusions 


\section{Index of Images}

page

\section{Section 1.0}

Image 1.1.1 The distinct notions of city and suburb. Aerial photographs from the OttawaGatineau region. Image comprised of digital air photos obtained from the Maps, Data, and Government Information Department at Carleton University's MacOdrum Library. Other manipulation by author. City of Ottawa. Surveys and Mapping. Air Photos, Spring 2002: 1:15,000. 360050200 and 360050300 [computer files]. Ottawa, City of Ottawa, 2004.

Image 1.1.2 Typical contemporary development. Aerial photograph of Nepean, Ottawa. Image comprised of digital air photos obtained from the Maps, Data, and Government Information Department at Carleton University's MacOdrum Library. Other manipulation by author. City of Ottawa. Surveys and Mapping. Air Photos, Spring 2002: 1:15,000. 360050200 [computer file]. Ottawa, City of Ottawa, 2004.

\section{Section 2.0}

24 Image 2.2.1 Central Park by Ashcroft Homes. Ottawa. Aerial photo, 2002. City of Ottawa. Surveys and Mapping. Air Photos, Spring 2002: 1:15,000. 360050200 [computer file]. Ottawa, City of Ottawa, 2004.

Image 2.2.2 Model Home in Central Park, Ottawa 2003. Photograph by author.

25 Image 2.2.3 First floor plan. David M. Blakely Architect and Ashcroft Homes. Model: Burgundy. Floorplan obtained from the Ashcroft Homes sales centre at Central Park on Merivale Rd.

28 Image 2.3.1.1 London, England during the industrial revolution. Photo is public domain.

29 Image 2.3.1.2 Clapham Common outside London, England 1800. Robert Fishman, Robert. Bourgeois Utopias: The Rise and Fall of Suburbia (New York: Basic, 1991) 118.

30 Image 2.3.1.3 Paris, France. (1862) Map showing one portion of the reconstruction project at L'Opera. Anthony Sutcliffe, The autumn of central Paris: the defeat of town planning, 1850-1970 (London: Edward Arnold, 1970) 201.

31 Image 2.3.1.4 The Parisian Apartment House type. Façade and layout for Haussmann's new boulevards. (circa 1858) Anthony Sutcliffe, The autumn of central Paris: the defeat of town planning, 1850-1970 (London: Edward Arnold, 1970) 246.

32 Image 2.3.1.5 The General Plan of Riverside, Illinois. (Olmsted and Vaux, 1869) Robert Fishman, Robert. Bourgeois Utopias: The Rise and Fall of Suburbia (New York: Basic, 1991) 124.

33 Image 2.3.1.6 925 Park Ave. New York. 1909-10 (perspective drawing, Delano \& Aldrich) Robert A. M. Stern. New York 1900 (New York: Rizzoli, 1983) 359.

34 Image 2.3.1.7563 Park Ave. New York. 1909-10. Elevation and typical floor plan. Robert A. M. Stern. New York 1900 (New York: Rizzoli, 1983) 358. 
36 Image 2.3.1.9 Sketch of the Golden Lane Housing proposal at the urban master plan scale. Alison and Peter Smithson. Ordinariness and Light. (Cambridge: M.I.T. Press, 1970) 48.

37 Image 2.3.1.10 Golden Lane Housing. View of upper deck. Alison and Peter Smithson. Ordinariness and Light. (Cambridge: M.I.T. Press, 1970) 39.

38 Image 2.3.1.11 Typical house and family at Levittown, NY. (1949) Berhard Hoffman, Life Magazine, 1950. Time Inc.

Image 2.3.2.1 Habitat '67, Montreal. View from the ground. Moshe Safdie. For Everyone a Garden. Judith Wolin Ed. (Cambridge: M.I.T. Press, 1974) 62.

39 Image 2.3.2.2 Habitat '67, Montreal. View of private gardens. Moshe Safdie. For Everyone a Garden. Judith Wolin Ed. (Cambridge: M.I.T. Press, 1974) 85.

43 Image 2.3.2.3 Highrise of Homes, 1981, by SITE (James $N$. Wines). View of building within urban context. James N. Wines. (foreword) SITE. New York: Rizzoli, 1989) 54.

43 Image 2.3.2.4 Highrise of Homes. View of stacked residential properties. James N. Wines. (foreword) SITE. New York: Rizzoli, 1989) 131.

45 Image 2.3.2.5 Suburbanism of Mass Customization, 2000, by Lewis. Tsurumaki.Lewis (New York). Sectional drawing showing tract housing above large scale commercial space. Paul Lewis, Marc Tsurumaki, and David J. Lewis, "Suburbanism of Mass Customization," The Cornell Journal of Architecture 7. (Ithica: Cornell U P, Spring 2003) 41.

Image 2.3.2.6 Suburbanism of Mass Customization, 2000, by Lewis.Tsurumaki.Lewis. (New York). Perspectival images (partially sectional) showing residential landscape above commercial space. Paul Lewis, Marc Tsurumaki, and David J. Lewis, "Suburbanism of Mass Customization," The Cornell Journal of Architecture 7. (Ithica: Cornell U P, Spring 2003) 42 and 41.

\section{Section 3.0}

56 Image 3.1.1 Aerial photo of central Ottawa showing 4 considered site locations. City of Ottawa. Surveys and Mapping. Air Photos, Spring 2002: 1:15,000. 360050200 and 360050200 [computer files]. Ottawa, City of Ottawa, 2004. Other manipulation by author.

57 Image 3.1.2 Photograph of site \#1. Photograph by author.

61 Image 3.1.3 Site plan of site \#1. Image created by author with files from the Maxwell MacOdrum Library: City of Ottawa. 1:2000 Scale Topographic Mapping. [computer file] Ottawa: 2003.

62 Image 3.1.4 Aerial photograph of site \#1. City of Ottawa. Surveys and Mapping. Air Photos, Spring 2002: 1:15,000. 360050200 [computer file]. Ottawa, City of Ottawa, 2004. 
Image 3.1.5 Building program type diagram for site \#1. Image created by author with files from the Maxwell MacOdrum Library: City of Ottawa. 1:2000 Scale Topographic Mapping. [computer file] Ottawa: 2003.

64

Image 3.1.6 Photograph of site \#2. Photograph by author.

Image 3.1.7 Site plan of site \#2. Image created by author with files from the Maxwell MacOdrum Library: City of Ottawa. 1:2000 Scale Topographic Mapping. [computer file] Ottawa: 2003.

Image 3.1.8 Aerial photograph of site \#2. City of Ottawa. Surveys and Mapping. Air Photos, Spring 2002: 1:15,000. 360050200 [computer file]. Ottawa, City of Ottawa, 2004.

Image 3.1.9 Building program type diagram for site \#2. Image created by author with files from the Maxwell MacOdrum Library: City of Ottawa. 1:2000 Scale Topographic Mapping. [computer file] Ottawa: 2003.

Image 3.1.10 Photograph of site \#3. Photograph by author.

Image 3.1.12 Site plan of site \#3. Image created by author with files from the Maxwell MacOdrum Library: City of Ottawa. 1:2000 Scale Topographic Mapping. [computer file] Ottawa: 2003.

Image 3.1.13 Aerial photograph of site \#3. City of Ottawa. Surveys and Mapping. Air Photos, Spring 2002: 1:15,000. 360050300 [computer file]. Ottawa, City of Ottawa, 2004.

Image 3.1.14 Building program type diagram for site \#3. Image created by author with files from the Maxwell MacOdrum Library: City of Ottawa. 1:2000 Scale Topographic Mapping. [computer file] Ottawa: 2003.

Image 3.1.15 Photograph of site \#4. Photograph by author.

7mage 3.1.16 Site plan of site \#4. Image created by author with files from the Maxwell MacOdrum Library: City of Ottawa. 1:2000 Scale Topographic Mapping. [computer file] Ottawa: 2003.

Image 3.1.17 Aerial photograph of site \#4. City of Ottawa. Surveys and Mapping. Air Photos, Spring 2002: 1:15,000. 360050300 [computer file]. Ottawa, City of Ottawa, 2004.

Image 3.1.18 Building program type diagram for site \#4. Image created by author with files from the Maxwell MacOdrum Library: City of Ottawa. 1:2000 Scale Topographic Mapping. [computer file] Ottawa: 2003.

1 Image 3.1.19 Excerpt from the City of Ottawa's Zoning By-Law, PART VII "Commercial Zones."

Image 3.1.20 Excerpt from the City of Ottawa's Zoning By-Law, PART VII "Commercial Zones."

Image 3.1.21 Site Comparison Chart. Chart prepared by author.

Image 3.2.1 Section drawing through Rideau Street looking south. The proposed development is shown within the surrounding context which ranges from 2 to 17 storeys in height. Image by author.

Image 3.2.2 Sketch of initial building scheme. Diagram conveys a vertical layering of programmatic uses and the possible re-creation of a ground plane for private residences above commercial spaces. Image by author. 
88 Image 3.2.3 Early design sketch. Section cut shows retail and office space below a re-created residential ground plane. In this arrangement of programmatic elements, common green spaces are oriented towards Rideau Street. Stacked private residences are accessed via vertical circulation along the south side of the building. Image by author.

88 Image 3.2.4 Photograph of massing model. Private homes stacked at rear, green space facing Rideau Street. Photograph by author.

90 Image 3.3.1 Street-level view of the building design showing the immediate context along Rideau Street. Image by author.

91 Image 3.3.2 View of the south-facing façade showing common landscaped areas and private gardens. Image by author.

$92 \quad$ Image 3.3.3 Exploded perspective drawing showing programmatic elements. Image by author.

94 Image 3.3.4 Ground level entry conditions for 3 building elements: Offices space, Private Home Residential, and Condominium Residential. Image by author.

95 Image 3.3.5 Private residential housing configuration: Individual units and addresses. Semipublic access-ways along the north façade facing Rideau St. Image by author.

101 Image 3.3.6 Partial section through front facade. The street-front includes an indoor retail promenade under the second floor office space. Private residential units, accessed off of street-facing walkways are protected by a continuous barrier of glazing. Image by author.

102 Image 3.3.7 Partial section through rear of building. Private residential yard space and common green space sit above the ground level retail space. Image by author.

$103 \quad$ Image 3.3.8 Perspective view of private garden space in between private residential units. Image by author.

103 Image 3.3.9 Sectional view of parking garage, laundry, and landscaped areas at ground level. Image by author.

104 Image 3.3.10 Perspective view of rear green space in winter. Condominium tower and enclosed green space in background. Image by author.

105 Image 3.3.11 Parking levels two and three at a scale of 1:400. Floor plans by author.

106 Image 3.3.12 Parking level one and ground level floor plan at a scale of 1:400. Floor plans by author.

$107 \quad$ Image 3.3.13 First level and second level floor plans at a scale of 1:400. Floor plans by author.

108 Image 3.3.14 Third level and fourth level floor plans at a scale of 1:400. Floor plans by author.

$109 \quad$ Image 3.3.15 Fifth level and sixth level floor plans at a scale of 1:400. Floor plans by author.

$110 \quad$ Image 3.3.16 Seventh/Eighth and Ninth level floor plans at a scale of 1:400. Floor plans by author. 
112 Image 3.3.17 Chart showing the distribution household sizes in the Ottawa-Gatineau region, 2001. Chart prepared by author with data from Statistics Canada, Census of Population, 2001. http://www40.statcan.ca/l01/cst01/ famil53f.htm

$113 \quad$ Image 3.3.18 Chart showing the decrease in Canadian household size since 1961. Chart prepared by author with data from Statistics Canada, Census of Population, 2001. http://www40.statcan.ca/cgi$\mathrm{bin} / \mathrm{getcans} /$ sorth.cgi?lan $=$ eng \&dtype $=$ fina\&filename $=$ famil66. htm \&sortact $=2 \&$ sortf $=7$

116 Image 3.3.19 Section detail of an intensive green roof assembly. Image by author.

118 Image 3.3.20 Comparison image of the typical suburban floor plan and all three unit plans at the same scale. Image by author. Claridge Homes floor plan obtained from sales center at Morgan's Grant development, Kanata.

119 Image 3.3.21 Exterior view of private residential unit \#1 showing garden and exterior finishes. Image by author.

$120 \quad$ Image 3.3.22 First floor plan of private residential unit \#1. Image by author.

121 Image 3.3.23 Second floor plan of private residential unit \#1. Image by author.

122 Image 3.3.24 Exterior view of private residential unit \#2 showing garden and exterior finishes. Image by author.

123 Image 3.3.25 First floor plan of private residential unit \#2. Image by author.

$124 \quad$ Image 3.3.26 Second floor plan of private residential unit \#2. Image by author.

125 Image 3.3.27 Exterior view of private residential unit \#3 showing garden and exterior finishes. Image by author.

126 Image 3.3.28 First floor plan of private residential unit \#3. Image by author.

127 Image 3.3.29 Second floor plan of private residential unit \#3. Image by author.

\section{Section 4.0}

139 Image 4.2.1 Chart showing construction values by type of construction. Chart prepared by author.

$141 \quad$ Image 4.2.2 Chart showing areas and total construction costs for the building design. Chart prepared by author.

143 Image 4.2.3 Image showing " a typical suburban development on the Rideau Street site." The site would fit five typically-sized suburban homes accessed directly off of Rideau Street. Image created by author with files from the Maxwell MacOdrum Library: City of Ottawa. 1:2000 Scale Topographic Mapping. [computer file] Ottawa: 2003

144 Image 4.2.4 Chart showing the cost scenario for a typical suburban development on the Rideau Street site. Chart prepared by author.

145 Image 4.2.5 Image showing " a typical urban development on the Rideau Street site." This type of building is a maximization of the allowable building envelope, and floor-space index. There would be approximately 120 residential units of various sizes. Image created by author with files from 
the Maxwell MacOdrum Library: City of Ottawa. 1:2000 Scale Topographic Mapping. [computer file] Ottawa: 2003.

146 Image 4.2.6 Chart showing the cost scenario for a typical urban development on the Rideau Street site. Chart prepared by author.

148 Image 4.2.7 Urban Suburbanism. This development option provides for 5000 square feet of office space, 6000 square feet of retail space, a full parking garage, 15 units of private dwellings, and 18 dwelling units within a condominium tower. Image created by author with files from the Maxwell MacOdrum Library: City of Ottawa. 1:2000 Scale Topographic Mapping. [computer file] Ottawa: 2

149 Image 4.2.8 Chart showing the "year one" cost scenario for a the building design this project proposes. Chart prepared by author.

150 Image 4.2.9 Chart showing the long term cost scenario for the building design this project proposes. Chart prepared by author. 


\section{Index of Works Cited}

Chow, Renee Y. Suburban Space: The Fabric of Dwelling. Berkeley: U of California P, 2002.

Duaney, Andres, Elizabeth Plater-Zyberk, and Jeff Speck. Suburban Nation: The Rise of Sprawl and the Decline of the American Dream. New York: North Point P, 2001

Earth Pledge Foundation. Green Roofs: Ecological Design and Construction. Atglen, PA: Schiffer, 2005.

Ferguson, John H. ed. Hanscomb Yardsticks For Costing 2005: Cost Data for the Canadian Construction Industry; Metric and Imperial. Markham: Robert S.Means Co, 2005.

Fishman, Robert. Bourgeois Utopias: The Rise and Fall of Suburbia. New York: Basic, 1991.

Garreau, Joel. Edge City: Life on the New Frontier. New York: Doubleday, 1991

Jacobs, Jane. Dark Age Ahead. New York: Random House, 2004.

Kunstler, James Howard. Home from Nowhere: Remaking Our Everyday World for the Twenty-First Century. New York: Simon and Schuster, 1996.

Le Corbusier. The Radiant City. New York: Orion P, 1967.

Lewis, Paul, Marc Tsurumaki, and David J. Lewis, "Suburbanism of Mass Customization," The Cornell Journal of Architecture 7. Spring 2003.

National Capitol Commission. "Greenbelt Master Plan: A Summary" Planning the Capital Region. 11 June 2003. <http://www.canadascapital.gc.ca/ corporate/plan_reg/todays_plan/greenbelt_master_e.asp> 
O'Toole, Randal. "Dense Thinkers" Reason Magazine. January 1999.

Phillips, Rhys. "An Eye for Neighbourhoods" Capital Style Magazine. Fall 2003 Ed. $<$ http://www.capitalstyle.ca/fall03/home_story.html>

Reevely, David. "Smarting from Smart Growth" The Ottawa Citizen 09 May 2002: B3.

Riis, Jacob A. How the other half lives; studies among the tenements of New York. Sam Bass Warner, Jr. Ed. Cambridge: Harvard U P, 1970.

Safdie, Moshe. Beyond Habitat by 20 Years. Montreal: Tundra, 1987.

Soja, Edward W. Postmetropolis: Critical Studies of Cities and Regions. Oxford: Blackwell, 2000.

Statistics Canada. "Selected Dwelling Characteristics." 25 Dec. 2005 <http://www40.statcan.ca/101/cst01/famil09a.htm?sdi=type\%20dwelling>

Tanner, Frances. "Central Park: More than Just Homes" The Carlington Summit. September 1997.

The American Heritage Dictionary of the English Language, Fourth Ed. Boston: Houghton Mifflin, 2000. <http://dictionary.reference.com>.

Vidoto, Marco. Alison and Peter Smithson Works and Projects. Barcelona: Gustavo Gili, 1997.

Wines, James N. "Growing Up," Artforum. October 2003.

Wright, Gwendolyn. Building the Dream: A Social History of Housing in America. Cambridge: MIT 1983. 


\subsection{INTRODUCTION}

The cities will be part of the country; I shall live 30 miles from my office in one direction, under a pine tree; my secretary will live 30 miles away from it too, in the other direction, under another pine tree. We shall both have our own car.

We shall use up tires, wear out road surfaces and gears, consume oil and gasoline. All of which will necessitate a great deal of work... enough for all. ${ }^{1}$

Le Corbusier, The Radiant City (1967)

\subsection{Project Premise}

In the urban environment that defines many of North America's cities, the areas known traditionally as 'downtown' are suffering. Today, fewer people are living and working in city centers because jobs and homes have shifted to the urban periphery. ${ }^{2}$ Similarly, areas once known simply as 'suburbs' are disappearing today because they themselves are becoming more urban: these places are complete with copious amounts of commercial space and office space, in addition to all of the housing in immense subdivisions. ${ }^{3}$ This type of urban development, referred to here as the 'contemporary urban realm,' occurs at a much lower density than the traditional city. Filled with sprawling office campuses, huge swaths of retail's new 'big-box store' format, and endless subdivisions, these places are in the middleground between the traditional suburb and the traditional city. In this modern merging of city and suburb, the built density that had formerly defined the city is lost. The privacy and quiet isolation of the suburbs is also lost. 
The purpose of this project is not to malign development in the present day urban or suburban realm. In fact, this project embraces the ongoing merging of city and suburb but argues instead for the hybridization of the two. All of the work that follows is predicated on one basic observation: the contemporary urban realm qualifies neither as city nor suburb, and the present-day merging of these two entities has resulted in a decentralized, medium-density built fabric where the positive aspects of the 'truly urban' and the 'truly suburban' are lost.

In response to this condition, this thesis project asks: in recognition of the ongoing merging of city and suburb, is there an architecture that can successfully hybridize the urban and suburban realms?

In the urban morphology of the city of Ottawa, distinct examples of each of these development scenarios can be found. Ottawa has a true downtown where the central business district and various urban residential districts combine to form an area of town that is clearly centralized and more densely populated than its environs. ${ }^{4}$ This city also has its suburbs: places of primarily residential uses that are removed from the urban core. The aerial diagrams below (Images 1.1.1 \& 1.1.2) are all of the greater Ottawa area and show differing areas of town at the same scale. It is the condition shown in the third image that this project is essentially a reaction to; the 'contemporary urban realm' is a sprawling, medium density type of development that is largely designed around the space required for automobile traffic. Does development have to occur in this fashion? Can a city be inclusive of commercial 


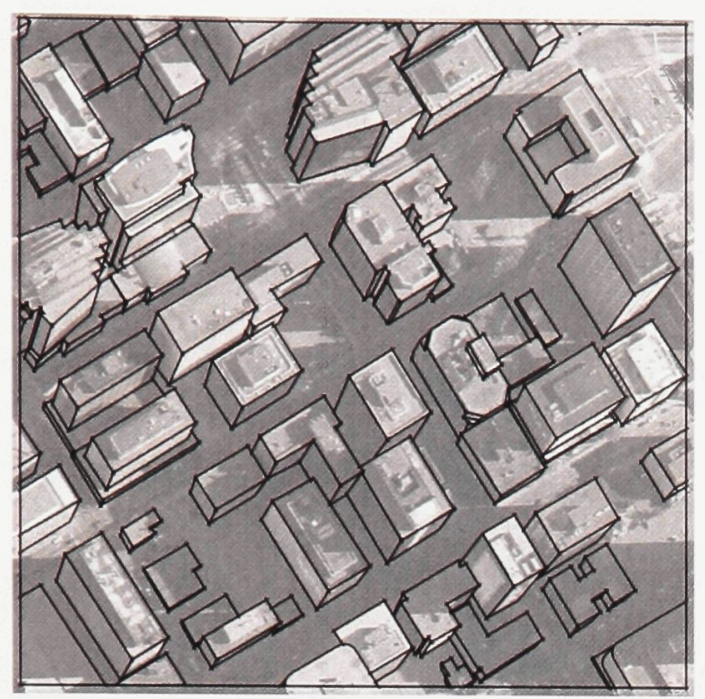

city

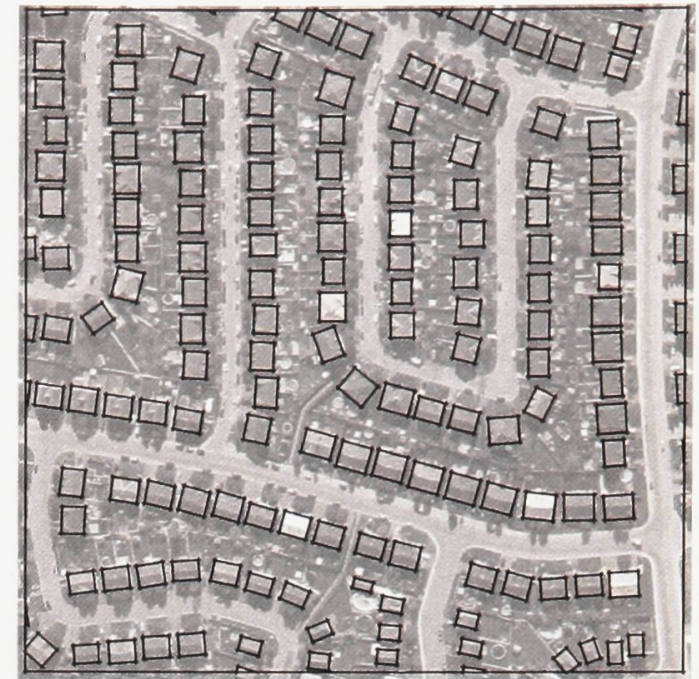

suburb

Image 1.1.1 The distinct notions of city and suburb. Aerial photographs from the Ottawa-Gatineau region.

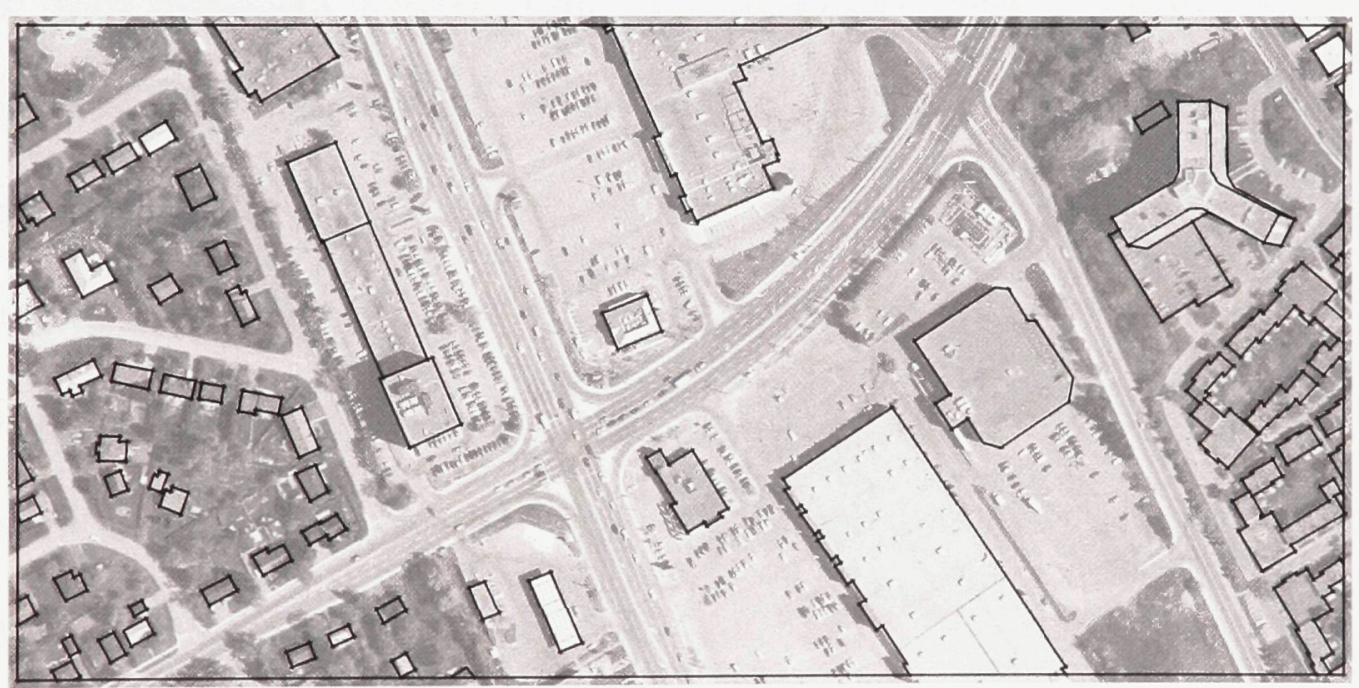

contemporary urban realm

Image 1.1.2 Typical contemporary development. Aerial photograph of Nepean, Ottawa. 
space, office space and residential space without taking this form? If not, is there another type of development that could address both urban and suburban values? What would this building type look like, and where should it be situated?

This premise has been formed around the descriptions of the urban realm given by the following authors: first and foremost, Robert Fishman's Bourgeois Utopias provides a historical review of the rise (and supposed fall,) of suburban development. ${ }^{5}$ Other writers (journalists and architects) have written about the contemporary urban condition, including Joel Garreau who wrote Edge Cities: Life on the New Frontier, a book about the growing phenomenon of suburbs becoming a new type of city. ${ }^{6}$ Also, Andres Duaney, Elizabeth Pater-Zyberk and Jeff Speck - the authors of Suburban Nation: the Rise of Sprawl and the Decline of the American Dream, provide a thorough account of the effects of urban and suburban sprawl. ${ }^{7}$ These texts were the most influential in the preparation of this document.

Amongst the vast number of projects that address the dichotomy of city and suburb, this project is unique in a few ways. First, the design exploration is situated in the context of the city of Ottawa, on a real site in the urban core. To the knowledge of the author, it is the only project that surveys recent development patterns in this city and proposes a comprehensive alternative. In addition, this work is one of only a handful of projects that does not reject either the urban or suburban realm in favour of the other. Instead, it identifies the type of development that has typically resulted from the contemporary merging of these two realms - a condition that does exist in Ottawa, and rejects that in favour of a more accurate hybrid. The alternative building type presented here fully embraces the notions of city and 
suburb. Finally, in the context of the projects that merge urban and suburban notions, this work is fairly unique in that here, aspects of the suburbs are brought into the city, whereas in most comparable projects, the city is brought into the suburbs.

\subsection{Terms of Reference}

The concepts that are of greatest importance in this text can be understood in multiple ways. The need to define these terms is imperative. For example, how exactly is something 'suburban'? How are complex notions of 'public' vs. 'private' space referred to in this text? The usages of the main terms are crucial in the argument and design project description to come. It must be conceded that some of these words are used in numerous contexts in the following document and that some 'grey areas' where contrasting definitions will bleed into each other do exist. However, every effort is made to be consistent throughout this thesis as these concepts are examined.

\section{Urban and Suburban}

cit $\mathbf{y} n .\left(\mathrm{s}_{\mathrm{l}}^{\prime} \overline{\mathrm{e}}\right) 1$ A center of population, commerce, and culture; a town of significant size and importance. ${ }^{8}$

sub urb n. (sŭb' ûrb) 1 A usually residential area or community outlying a city. ${ }^{9}$

These two terms, once entirely divergent, are becoming less-and-less distinct in contemporary development. This thesis takes as its premise that the traditional concepts of 'urban' and 'suburban' have merged and, as such, these definitions are 
somewhat obsolete. However, it is the dichotomous relationship between these two archetypal forms of development that is the basis of this project, and as such, they are defined here as opposites.

Henceforth, the term 'urban' refers to anything characteristic of the traditional city. For the purposes of this project, the three main qualities that have traditionally characterized the city are built density, convenience, and connectivity. Other facets of the city such as age, established character, infrastructure, and social diversity are important, but are more difficult to discuss because they are not as universal. The traditional city, which differs quite a lot from today's largest 'metropolitan centers,' refers to the urban areas that existed before the rise of suburban development. A 'traditional city' could refer to industrial London in the mid 1800 's,${ }^{10}$ or any of the great American cities like Chicago, Philadelphia or New York that eventually spawned the first railroad suburbs. ${ }^{11}$ These places were metropolises in the truest sense of the word. The traditional urban realm was flawed from the standpoint that saw it as crowded, dangerous, and the source of many society's ills, ${ }^{12}$ but it also offered its inhabitants a lot of advantages. Urban dwellers live in close proximity to many other people, to entertainment, to shopping, to recreation, and, more often than not, to their places of employment. It is the density of the urban built fabric that subsequently offers convenience and connectivity to the inhabitants. The city is also traditionally recognized as a heterogeneous place, where multiple uses are entwined. Commercial space mixes with residential space, and places used for recreation and entertainment are not far from a person's place of work. For the purposes of this 
work, the city is place of convenience and connectivity, where a dense population and heterogeneous built fabric create an intense, efficient environment.

In stark contrast with this description of the city as given is the entire notion of the 'suburb.' The etymology of the term points to these places as simply being 'not quite urban. ${ }^{13}$ The suburban realm began as a reaction against the urban realm, and the original suburbs were places designed as a retreat from the industrial city. Historian Robert Fishman points to an ideological shift in the mindset of uppermiddle-class merchants in London, England that entailed the separation of work and family life. ${ }^{14}$ The pastoral land at the edges of the city became a safer and more clean place to which the head of the household was now morally obligated to send the family. The private home in the countryside became an ideal to many urban dwellers, and by the end of the First World War it was the central tenet of the American Dream. ${ }^{15}$ At this point in the history of suburban development, these communities were almost entirely residential; almost everyone who lived there would commute to the urban core for work, shopping, and entertainment. It was not until the 1970's that North American suburbs became inclusive of more than just houses, as elements of cities crept out to where the people lived. ${ }^{16}$ Within this text, the term 'suburb' refers to a type of development that is distinct from the city. Where the 'traditional notion of suburbia' is mentioned in this text, this refers to an almost extinct type of community that is primarily residential and quite removed from the urban core.

This project deals more extensively with particular aspects of suburbia than it does with others. As is discussed later in the Project Scope of this thesis, there are 
many issues at play in the complex and far-reaching topic of 'suburbia' that could each be the basis of their own thesis investigation. This project focuses strictly on three issues that continue to separate the suburbs from the city: first, the suburban desire for contact with open green space; second, the suburban expectation of affordability; and third, the popularity of the single-family, fully-detached private home. These are the central traits that define the 'suburb' as it pertains to this thesis.

This project uses the terms 'urban' and 'suburban' to convey two opposing urban typologies, each offering what the other does not. The marks of the urban realm are density, connectivity and convenience, while the suburban realm is sought after for its affordability, private homes, and open green space.

\section{Public and Private Space}

pub lic: adj. (pu-blik) 1 a: exposed to general view b: accessible to or shared by all members of the community ${ }^{17}$

pri vate: adj. (prI-vat) $1 \mathrm{a}$ : intended for or restricted to the use of a particular person, group, or class ${ }^{18}$

For this project, private space refers to areas that are meant for the members of a single household, while public spaces are the parts of the built environment that are shared by all persons. These are simple definitions, as there are obviously many zones in between a totally private and a totally public area. Transitional zones are referred to here as either 'semi-public' or 'semi-private.' An illustration of this transition can be provided by the typical suburban layout of a single-family home on a private lot. Beginning at the edge of the roadway, which is a totally public zone shared by everyone, is a curb and the beginning of a front lawn. Often, this is also 
the property line, and as such it signifies the beginning of a more private space. However, this space is also public where there exists a sidewalk. The entire front yard of the home must be considered semi-public because it is owned by one homeowner, but shared visually and physically with members of the public who pass by. The front porch or veranda is a good example of an area best described as semiprivate, because although it is an exterior space, it seems to be part of the private space of the home. Side-yards and back-yards are semi-private because they are most often bound by fences meant to delineate property, and, of course, give privacy, but they are still exterior spaces. The interior of the home is generally considered a private space, although certain rooms in a house are historically regarded as more private than others. Large windows in rooms facing the street can also make certain interior spaces more public than private. Rooftop patios, balconies, and enclosed verandas are - despite their clear connection by way of sightlines to public zones considered as semi-private aspects of the home.

One term that is used at length in this document is 'private home.' A suburban private home is completely separate from the other homes that fill the neighbourhood. There is typically no sharing of walls, roofs, driveways, or even yard spaces. This arrangement is very common in suburban development whereas in the city, a 'private' dwelling is often a part of a larger building. Urban residences are accessed through a common entry, elevator or stair, and hallway. Walls, roofs, and buildings systems are shared. Even in condominium-style arrangements, where true ownership is offered as opposed to renting, fees are charged for up-keep and maintenance of systems and common areas. Condominiums are private dwellings, 
but in comparison with the detached suburban home, they appear as only a part of a collection of similar dwellings within the framework of a larger building. In the rest of this text, the term 'private home' refers to the detached house type that is typically found in suburban development, not the condominiums or apartment dwellings that exist within an urban high-rise. This distinction is more important later as two forms of residential space are introduced in the building design: one is of the typical urban 'condominium' format; the other is a reconstitution of the suburban 'private home.'

\section{Other Terms}

Other terms that are central to this project that must be clarified are 'affordability,' 'green space,' and the 'contemporary urban realm.'

The suburban expectation of 'affordability' has already been listed as a defining trait of the suburban realm. When used in this sense, the phrase refers to the fact that a suburban home generally costs less than a comparable home within the city limits. Larger homes on larger lots have historically been available in the suburban developments, ${ }^{19}$ and the same is generally true in the suburbs of greater Ottawa. 'Affordability' here, is a measure of financial performance, often comparing methods of building or types of development. In the investigations that follow, 'affordability' and 'value' are used interchangeably at times, depending on whether the issue is definite (quantitative) or less strictly defined (qualitative). For example, a building type might be less 'affordable' because it is expensive, but offer other 'valuable' amenities like a convenient location or a functional floor plan. 
As far as the notion of 'green space' is presented here, this does not refer to 'nature' in the sense of nature as the 'untouched organic environment.' This project deals primarily with urban and suburban spaces, neither of which can be described as having any true characteristics of the 'wilderness.' Even in the suburbs, rural space may be nearby, but the 'subdivision' is a place that was created by plowing over whatever countryside existed in order to construct those homes. It is ironic that most suburbs have names that describe the places that were destroyed in order to build them: "Oak Park," "Cedar Grove," etc. But it is this popular recognition of suburban development as being inherently closer to nature that has fueled its growth since the beginning, ${ }^{20}$ and this project does not attempt to deconstruct this mindset. The suburbanite's desire for contact with open green space is simply an indispensable trait no matter how suspect this green space may be. It is the suburban conception of 'green space' that is examined in this project, which refers to the piece of property upon which a suburban home sits, and that usually includes a front and back yard, sod, and a few token trees.

The concept of the 'contemporary urban realm' was described earlier as what typically results from the merging of 'city' and 'suburb'. This is a reductive definition that fails to exclude any aspect of our built environment. The fact is that many of today's so-called 'urban centers' in North America are inclusive of all types of development from the dense urban core, to the medium density periphery, to the sprawling suburbs. Some cities still exist in clearly defined concentric rings where built density decreases as one travels away from the centre. Some cities have become 'multi-centered,' as they include multiple smaller towns that have amalgamated. 
What is different about the 'contemporary urban realm' (as it is most often referred to in the text,) is that it has no true centre - it is a place of medium density throughout. Journalist and author Joel Garreau has written the most extensively on the rise of this urban form. His book, Edge Cities: Life of the New Frontier, attempts to quantify this phenomenon as it flourishes throughout the United States. ${ }^{21}$ Other authors have called this phenomenon the "technoburb" or "superburbia" or "exopolis." Garreau describes 'edge city' as the result of suburbanites wanting the city to come to them - as suburban enclaves with massive retail areas and massive amounts of office space. In edges cities, the gigantic geographic scale at which all of these types of areas occur is of little concern because everyone has a car; the distances traveled through them are long, but the traditional commute to the city was further. For clarity, this document refers to the edge city phenomenon as the contemporary urban realm. This type of medium density development has become commonplace across the continent, Ottawa included.

\subsection{Project Scope}

The need for finite boundaries and goals became a necessary component of this project as it became obvious that urban planning and the sub-genre of 'suburbia' were too broad for one project, unless it was focused very categorically. For example, in a project examining suburbia, which of the many facets of it are worthy of concentration? If only suburban housing is examined, then is one concerned with its esthetics or the economics? Is one redesigning the space inside or out? Is the 
project concerned with historical suburbia or with what the suburbs have become today? These types of questions forced the refocusing of this project's scope at the beginning and at various points throughout. This is a design project based upon observations of the contemporary urban realm, specifically within Ottawa.

This thesis project seeks an urban building type that is expressive of not only its context in the city, but of particular suburban notions at the same time. Predicated upon a simple rejection of typical contemporary development patterns, this design project seeks an alternative: one in which the result is an in-fill development where a vacant downtown site is utilized for an architecture that is a hybrid of urban and suburban typologies. Other exercises are subsequently part of this endeavor, and they include site research, economic comparisons, as well as basic construction cost evaluations.

In the hybridization of suburban and urban typologies that this project proposes, the pursuit of clarity also requires that the notions of 'urban' and 'suburban' are distilled down to a few hallmark characteristics. As already described in the Terms of Reference, the 'urban' qualities that this project seeks are multi-use, built density, efficiency and connectivity. While research on the suburban phenomenon was extensive, in the end only the most conspicuous aspects of the suburban realm are relevant to this project. Specifically, the suburban expectation of 'affordability,' the suburban desire for contact with open 'green space,' and the suburban desire for a detached, 'private home' represent the three surviving issues that form the driving themes of the 'suburban' portion of this design project. 
Defined in this manner, this project is certainly not a re-design of suburbia, nor does it propose a resolution of the so-called 'suburban problem;' Neither does it seek a singular answer to the problems facing major North American cities. Situated on an urban site in Ottawa, this thesis has produced a building designed specifically for its site. Therefore, the design does not necessarily provide a building type that can be exported to another urban context, though it provides the conceptual foundation for the planning of other urban sites.

\section{Project Goals}

In order to arrive at a simultaneous expression of certain urban and suburban building ideas, this design project must convey the central traits of city and suburb already discussed. The 'urban' realm, as stated, is signified by built density and multi-use, but how will those traits be made obvious in this design project? Similarly, how are the suburban ideas of green space, the private home, and affordability provided for in the design? The goals of this design project, and the reasoning behind them, are stated below.

The urban trait of 'multi-use' is expressed through the provision of commercial and residential space in direct juxtaposition. Both retail and office space are to be present in comparable amounts so that one type of commercial development does not overpower the other, as there is no preference on the part of the author toward one type of commercial usage over the other. The total square footages of each of the retail and office spaces should be equal to the amount of space that would be offered by a one-storey development on the site chosen. This 
amount would equal to the leasable space offered if a simple, ground-level building were built instead of a multi-use development. On the site at the east end of Rideau Street, this would amount to approximately 5000 square feet of usable space because the rest of the site would be used by surface parking. Residential space should be provided as an expression of both of the typical 'urban' and 'suburban' forms. Here, the typical 'urban' residential type is the slab apartment building, also known as the 'high-rise.' The built density of this type of building is obviously high, and all of the individual residential units are contained within the envelope of a simple slab structure. The residential units inside this portion of the building should be of comparable size and price with other urban condominium projects in the city of Ottawa. Furthermore, the commercial spaces and urban residential spaces should be accessed directly off of the street, as they normally would be in the urban core. Where possible, retail space should connect directly with the street front.

With regards to the suburban notions of 'green space,' the 'private home' and 'affordability' this project sets the following goals: first, suburban lawn will inevitably be reconfigured if it is to exist as part of a hybrid. The goal is not to provide the literal idea of suburban green space, or a verbatim transfer of the sod-covered areas that exist in typical suburban developments. Rather than pander to the preconceived notions of suburban yard space, the goal here is simply to provide a useful garden space adjacent to each dwelling unit - a space that could be used literally as a garden, and, as such, must consist of suitable amounts of soil, irrigation, and sunlight. This project seeks also to provide a reconstituted version of the suburban 'private home' separate from the residences already described as part of the 'urban' 
aspects of the design. Predicated on an observation of the spaciousness of the typical suburban home as wasteful and not particularly representative of demographics, the private dwellings this project seeks are distilled down their most essential requirements. As such, the total square footages of these 'private' dwellings should be greatly reduced back down to the average sizes of the homes in the original postwar suburbs. Subsequently, these homes must be cheaper than their suburban counterparts. The specifics of the proposed building program include:

- 5,000 square feet of leasable retail space at the ground level, accessed directly off of the street.

- 5,000 square feet of leasable office space.

- A minimum of 30 dwelling units, where approximately half of the total number of units are of the 'suburban' private home type, (at a minimum of 800 square feet each,) and the other half are part of the 'urban' high rise condominium.

- Parking in the amount of 1 space per dwelling unit, and at least 1 full level (approx. 30 spaces) of underground parking meant for use by patrons of the retail and office space.

As a Masters-level thesis in architecture, this project is required to not only address its chosen topic in a thorough, concise, and thoughtful manner, but also produce a building design that reacts to the criteria set out in the written document.

The building design shown in Section 3 is intended to clearly express the chosen aspects of suburbia without compromising the urban quality of its context in the city. It must adhere to the specifics of municipal zoning and its own programmatic requirements. The design must also adhere to the economic realities of building on the chosen site and be demonstrated as a feasible and profitable development project. Specifically, the building design must work within the height, setback, area, and 
usage restrictions defined in the local by-laws. It must also be a building project that, assuming full sales of the dwelling units and full leasing of the retail and office space, could recuperate the full construction costs in the first post-construction year, going on to achieve a $100 \%$ profit over-and-above the initial investment value within five years of construction completion. 


\section{Endnotes Section 1.0}

${ }^{1}$ Le Corbusier, The Radiant City, (New York : Orion P, 1967)

In addition, Le Corbusier proposed various urban designs during his career including the Contemporary City (1922) and plan Voisin for Paris (1925), and the Radiant City of 1933-1935. For a review of Le Corbusier's urban planning ideas, read chapter seven of: The Ideas of Le Corbusier on Architecture and Urban Planning by Jacques Guiton.

${ }^{2}$ Andres Duaney, Elizabeth Plater-Zyberk, and Jeff Speck. Suburban Nation: The Rise of Sprawl and the Decline of the American Dream. (New York: North Point P, 2001) 9.

${ }^{3}$ Joel Garreau, Edge City: Life on the New Frontier (New York: Doubleday, 1991) 6-7.

${ }^{4}$ For an image of the area of Ottawa being considered as the central core, refer to image 3.1.1. Also, the city of Ottawa's central area and inner road network schedule shows an area that is bordered on the east by the Rideau River, on the North by the Ottawa River, on the west by a rail line near Preston Street, and on the south by the Queensway. The Ottawa 20/20 Plan is currently available online at: http://www.ottawa.ca/city_services/planningzoning/2020/op/index_en.shtml

${ }^{5}$ Robert Fishman, Bourgeois Utopias: The Rise and Fall of Suburbia (New York: Basic, 1991). This text is regarded as one of the most complete writings on the origins of suburban development, and the most often referred-to source in this text.

${ }^{6}$ Garreau's text is an essential part of the difficult description of this new type of urban fabric. His "Edge Cities" are what Robert Fishman identified as being the "fall of suburbia," because with them, suburbs as they had been known, would no longer exist.

${ }^{7}$ Duaney, Plater-Zyberk and Speck's text is essentially a manifesto for the New Urbanist Movement, but it provides a thorough discussion of the distinctions between traditional and contemporary forms of development.

8 "City," The American Heritage Dictionary of the English Language, Fourth Ed. (Boston: Houghton Mifflin) 2000. <http://dictionary.reference.com/search? q=city>. $? \mathrm{q}=$ suburb $>$.

9 "Suburb," The American Heritage Dictionary, <http://dictionary.reference.com/search

${ }^{10}$ Fishman, 19. Robert Fishman describes the urban growth situation in Britain by saying: "The modern suburb was a direct result of this unprecedented urban growth. It grew out of a crisis in urban form that stemmed from the inability of the pre-modern city to cope with explosive modern urban expansion."

${ }^{11}$ Fishman, 127-8,142-3, and 158. Fishman outlines the development of the earliest American suburbs as they were made possible by the railroad and its direct connection to the city.

${ }^{12}$ Fishman, 35. The powerful evangelical movement affecting $18^{\text {th }}$ century London had identified the city as the source of most of society's ills. Here, Fishman points to a leading Evangelical author who in 1787 stated that the city was the enemy of family life. 
${ }^{13}$ Fishman, 6. The base term is actually "suburbe" which Fishman says is defined as a "place of inferior, debased, and especially licentious habits of life."

${ }^{14}$ Fishman, 7-9.

${ }^{15}$ Gwendolyn Wright, Building the Dream: A Social History of Housing in America (Cambridge: MIT 1983) 195.

${ }^{16}$ Garreau, 4-15.

17 "Public," The American Heritage Dictionary, <http://dictionary.reference.com/search $? \mathrm{q}=$ public $>$.

18 "Private," The American Heritage Dictionary, <http://dictionary.reference.com/search $? \mathrm{q}=$ private $>$.

${ }^{19}$ Wright, 242-248. The beginnings of suburban "affordability" a really due to war veterans mortgage assistance programs offered after WWII. In both the USA and Canada, these initiatives allowed potential homeowners to borrow the entire value of the home without a down payment.

${ }^{20}$ Wright, $104-8$

${ }^{21}$ Garreau 4-16. Joel Garreau is often criticized for its broad designations of what makes up the phenomenon of "Edge City." He uses blanket statements that are so inclusive that it is at times difficult to discuss what is not a part of "Edge City". 


\subsection{RESEARCH}

\subsection{Introduction}

Research for this thesis was conducted with an intentionally narrow focus because the breadth of projects that could have been studied seemed endless. This thesis project is a humble contribution to the larger discipline of urban planning and design, and it draws heavily from the wealth of historical examples of suburban development and urban reform as it develops the design response presented later in this text. In particular, this project was concerned with the historical examples of architecture where the conflicting issues of the city and the suburbs seemed to clash. As will be shown, this entailed the study of the original suburbs that existed as a rejection of the metropolis. It also involved the study of some more contemporary urban design projects that embody the aspects of both city and suburb that are still so sought after today.

\subsection{The Dichotomy of City and Suburb}

The title of this thesis refers to an architectural hybrid of city and suburb. This hybridization can only occur if the two contrasting ideas can somehow co-exist without one cancelling the other. The central question here then becomes: how can suburban ideals be embodied in a architecture that does not compromise urban ideals? This may not be entirely possible, as will be shown in the case studies to come.

The concepts of city and suburb each fulfill differing sets of desires. Both offer their own advantages and disadvantages, and the pull between them is the basis 
of this thesis exploration. As discussed in the premise, this project identifies the fact that a lot of contemporary development occurs in a manner that attempts to be both urban and suburban. It rejects this type of development because the environment that typically results from qualifies as neither; it is a compromised urban form. The contemporary urban realm is, although flawed, a reflection of the dichotomy of city and suburb.

\section{The New Urbanism and Smart Growth}

The ongoing struggle between urban and suburban development types is manifest today in the form of two identifiable movements in architecture and urban planning: first, the New Urbanism has existed for more than twenty years. ${ }^{1}$ It is referred to by other names such as: neo-traditional design, transit-oriented development, and traditional neighborhood development. Simply put, New Urbanist theory argues for a return to a traditional form of urban development that is mixed-use, intense, and more pedestrian oriented. New Urbanist documents are starkly anti-suburban in the sense that they point towards low-density development as causing our dependence on automobiles and the lack of affordability and livability in our built environment. ${ }^{2}$ This type of development is still growing in popularity even though critics have exposed it as not being entirely practical. New Urbanist design is said to subordinate modern aspects of city planning in favour of an urban design dogma that focuses more on nostalgic aesthetics. ${ }^{3}$ It has also been criticized for not actually creating pedestrian-oriented environments; in North American society, the reality is that these places fall victim to our habitual use of automobiles. Even in a densely laid-out 
neighbourhood, most North Americans will still drive to where they're going, and then complain about a lack of parking. These types of towns are denser and more thoughtfully designed than most suburban developments, but they still result in an urban environment that is lower in density than a traditional downtown. In addition, the majority of New Urbanist designs are for greenfield sites; few of them are reconfigurations of existing development. New Urbanist principles of multi-use and urban infill are certainly at play in this thesis project, but this is not intended as an exercise in New Urbanism.

One of the basic premises of Smart Growth is the adaptive re-use of urban buildings and urban sites. In this way, Smart Growth differs slightly from the main focus of the New Urbanism even though these two popular movements are often seen as being one-and-the-same. Smart Growth is predominantly an environmentalist response to urban sprawl, arguing for the re-use of existing structures and spaces in ways that would invigorate the urban realm. New Urbanism on the other hand, focuses primarily on the esthetic and spatial quality of new built fabric. This project is not an argument for environmentally-sustainable building types per se, and it does not consider itself a 'Smart Growth' design exploration; this project does, however, argue for the utilization of urban sites and urban infrastructure as opposed to building anew outside the city.

\section{The Dichotomy of City and Suburb in Ottawa}

The dichotomy of city and suburb is an ongoing issue in metropolitan areas across North America, but this thesis is meant to address this topic as it relates to local conditions. In the context of the greater Ottawa area, there are likely many 
examples of the pull between the central core and the many suburban communities that could be discussed, but one development stands out in particular. The development known as Central Park is located in Nepean north, not far from downtown Ottawa. It is a large subdivision of suburban style housing despite being marketed as something very different. In relation to this project, Central Park offers a recent local example of the conflicting notions of city and suburb.

Central Park was built by Ashcroft Homes, an Ottawa development company, between 1999 and 2004. After purchasing this site from the city of Ottawa 1997, Ashcroft submitted a proposal for a four-phased development of primarily residential buildings on the ninety-acre site. The development proposal was highly scrutinized by the City of Ottawa because this piece of land represented one of the last undeveloped properties within the central part of Ottawa, and, as such, the city wanted it used wisely. ${ }^{4}$ Specifically, Ashcroft was granted development approval on the condition that the project would follow the City's new growth and development guidelines which were meant to curb urban and suburban sprawl. Dense urban infill projects were being encouraged, and restrictions were being put on building in Ottawa's suburban and rural areas. ${ }^{5}$ From a marketing point of view, Central Park was actually targeted towards urban dwellers that were looking for a home in a more community-oriented environment. The development plan for Central Park included a wide variety of building types including single-family detached homes, townhomes, shops with loft space, and mid-rise apartment buildings. 


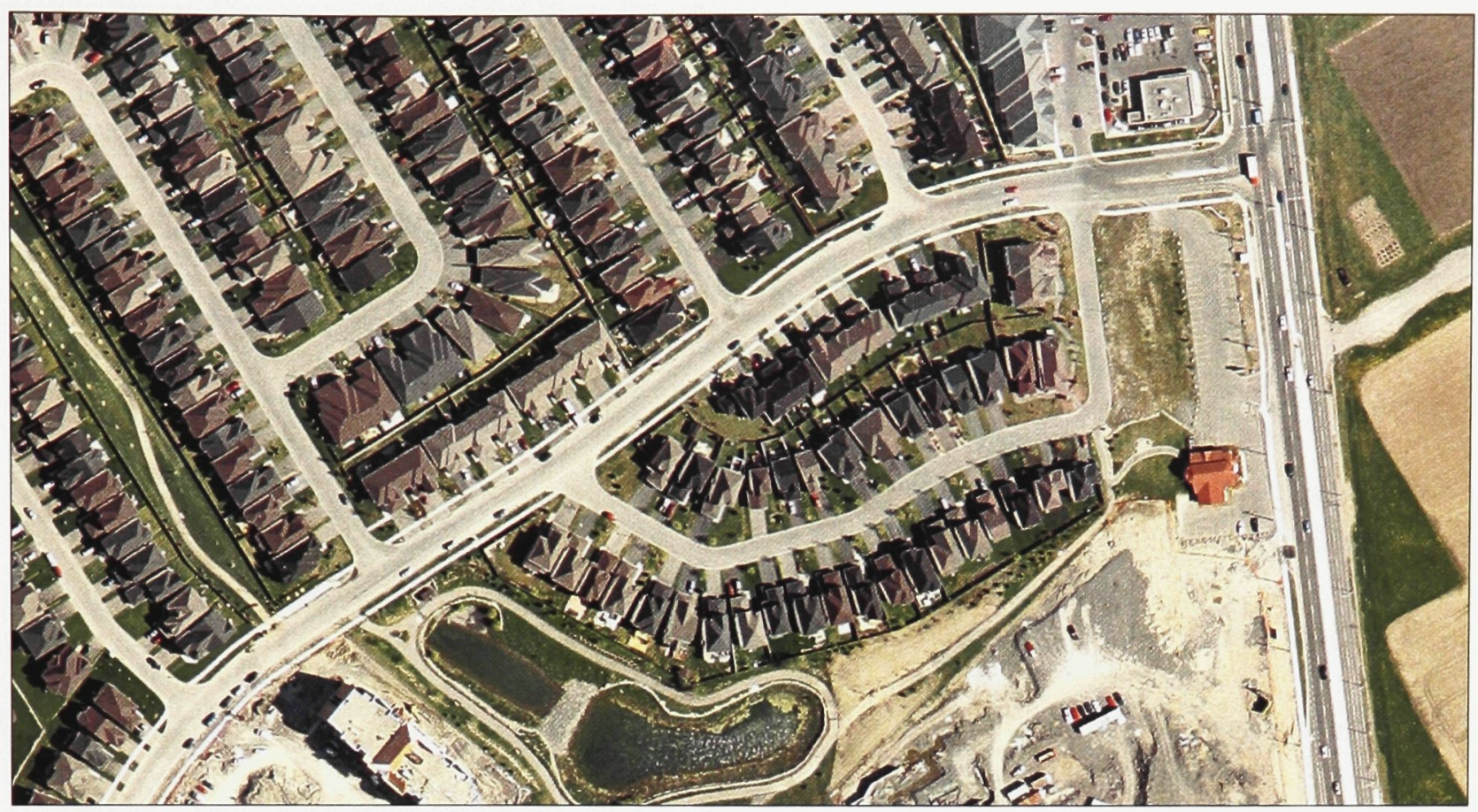

Image 2.2.1 Central Park by Ashcroft Homes. Ottawa. Aerial photo, 2002.

At Central Park, individual lot sizes are slenderized and yard space is reduced in favour of a large common green space complete with playgrounds and a soccer field. Ashcroft Homes did in fact deliver a development with a higher density than most suburban developments, and they included some retail space at the entrance to the subdivision off of Merivale Road. In these ways, the project is a model of New Urbanist principles.

There were problems that arose during the realization of Central Park. Many of the so-called New Urbanist design principles got edited out of the project as it progressed. In the end, a far larger proportion of the homes ended up being built as fully detached, single-family homes. The mid-rise apartment blocks turned into a pair of high-rise towers. All of the commercial buildings were grouped together into one area off of Merivale Road, instead of spacing them throughout the community. Furthermore, shoddy construction, poor project delivery, and many unhappy 
homeowners started to expose Ashcroft Homes' apathy for the quality of the community. ${ }^{6}$ The reason that more single-family homes were built was because they would sell, and could be sold at a higher price than a townhome. The slender lot sizes were simply a maximization of street frontage to allow for more homes to be built. Disguised under the slogan of a "more dense community in keeping with Ottawa's urban infill plans," Central Park is in reality a condensed form of suburban sprawl, where profiteering has compromised the original vision.

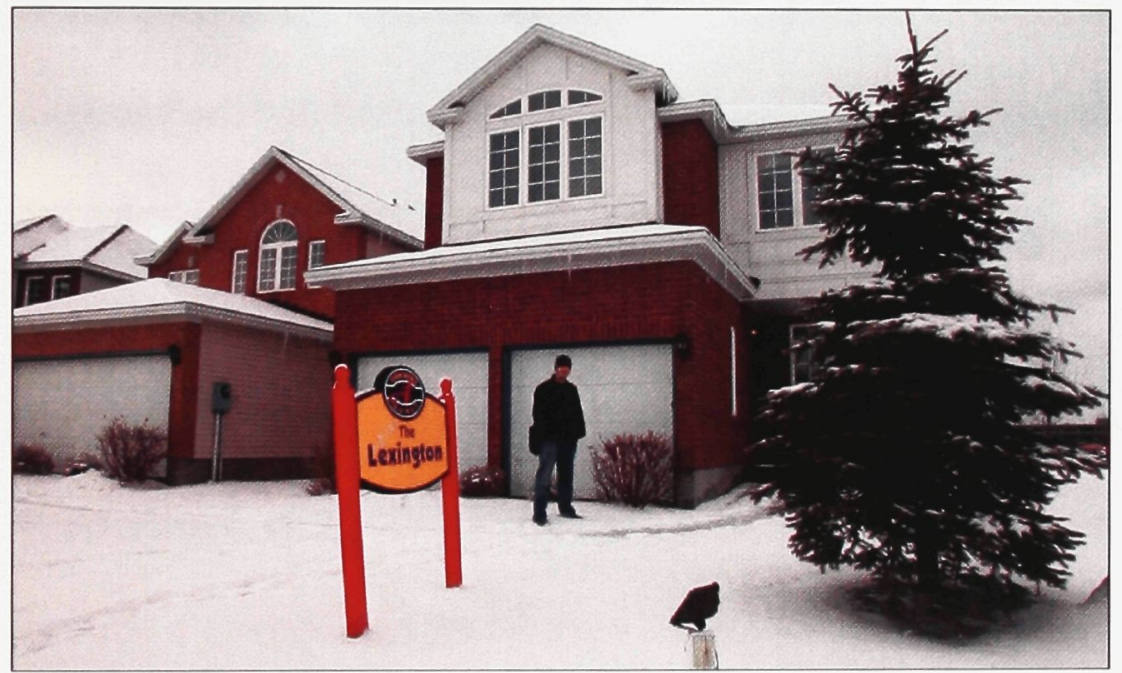

Image 2.2.2 Model Home in Central Park, Ottawa 2003.

Image 2.2.3 First floor plan. David M. Blakely Architect and Ashcroft Homes. Model: Burgundy.

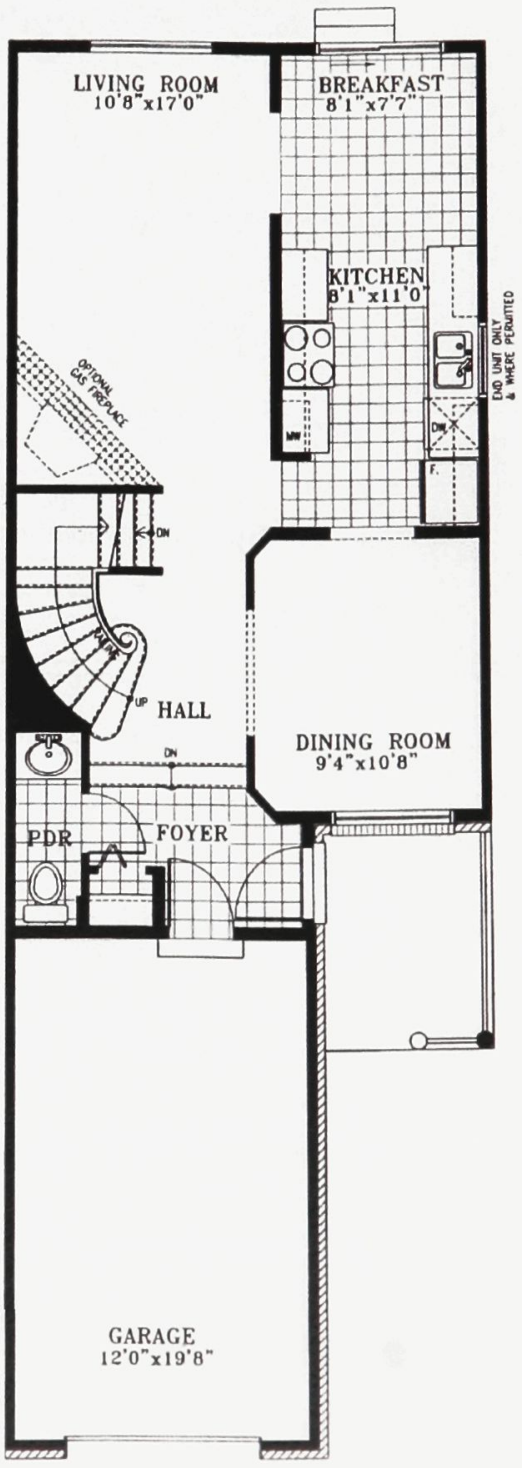


Central Park offers a local example of the urban-suburban dichotomy to this thesis. In Ottawa, it is one of the few examples of an urban site that was used for a suburban form of development. That is, despite the fact that the project was marketed toward urban dwellers, a very typical type of suburban homes was provided. As this thesis project endeavors to provide a true hybrid of urban and suburban building types, Central Park stands as an example of how a method of development can qualify neither as urban nor suburban. It fails as an urban development because of the building typology used: it is composed of mainly singlefamily private homes on private lots. It also falls short as a truly suburban development because of the crowded nature of those same homes. Yard space in Central Park has been reduced beyond even the typical standards of today's most crowded subdivisions.

In addition, Central Park shows that private homes of all sizes are saleable in the city of Ottawa. Homes range in size between 1500 and 3700 square feet in Central Park, with the average being about 2100 square feet. ${ }^{7}$ These homes always include a garage and most often have dining rooms and at least three bedrooms. The slenderized footprints of the homes in Central Park are tiny in comparison with the spacious house plans popular in many suburbs ${ }^{8}-$ and yet these homes still sold. In fact, sizeable profits were reported upon resale only a couple of years after construction. ${ }^{9}$ The design project presented in Section 3 of this document is certainly not an homage to the homes in Central Park, but the fact that small homes in a reduced spatial configuration would sell in Ottawa was influential. The slenderized housing units in Central Park formed a precedent for the private houses created later. 


\subsection{Selected Case Studies}

The wealth of architectural projects, both theoretical and in built-form, that broach the issues of suburbia and urban sprawl are too numerous to be described here. However, several projects that deal directly with the co-existence of urban and suburban types need to be discussed. They in turn form precedents for the design project shown in Section 3.

For the sake of organization, these projects are categorized into groups that are roughly chronological. This is because they exhibit differences that are really only comparable if they are explained as being from the same era. For example, the text begins with a brief survey of housing types in the pre-First-World-War era. By comparison, this was a time when a vastly different set of social influences were determining the composition of the urban realm than the post-war era that followed. ${ }^{10}$ The projects presented here as 'post-war' date from after the Second World War and they exemplify differing reactions to the need for housing in Europe and North America.

These case studies are also categorized according to larger themes. In analyzing these examples, it became obvious that the early projects were reactions to the metropolis, while the latter projects (1960 and onward,) are actually reactions to urban sprawl and the contemporary urban realm. To explain, the first set of projects conveys housing typologies that arose out of the European industrial cities of the seventeenth and eighteenth century where crime, crowding and pollution were major problems. Similarly, suburban developments like Riverside, IL. or Levittown, NY. are 
early examples of the flight from the metropolis in North America. By the late postwar era, the urban realm had evolved to the point where the metropolis no longer existed in its original form, and many projects are based instead upon observations of the 'exopolis' or what is referred to in this text as the contemporary urban realm. These latter grouping of projects are categorized differently because they are hardly reactions to the pre-war industrial city; instead, they examine modern examples of urban and suburban sprawl.

\subsubsection{Reactions to the Metropolis}

\section{Pre-war examples: London and Paris}

During the industrial revolution of the $18^{\text {th }}$ and 19th century, the city of London, England had grown immensely from its pre-industrial origins.

Urban growth was occurring due to the availability of factory jobs in the urban core, and in 1880 the population of greater London was already over 3.8 million. Poverty was rampant, and the average number of inhabitants in a dwelling was 7.9. ${ }^{11}$

Factories and mills contributed air pollutants to an

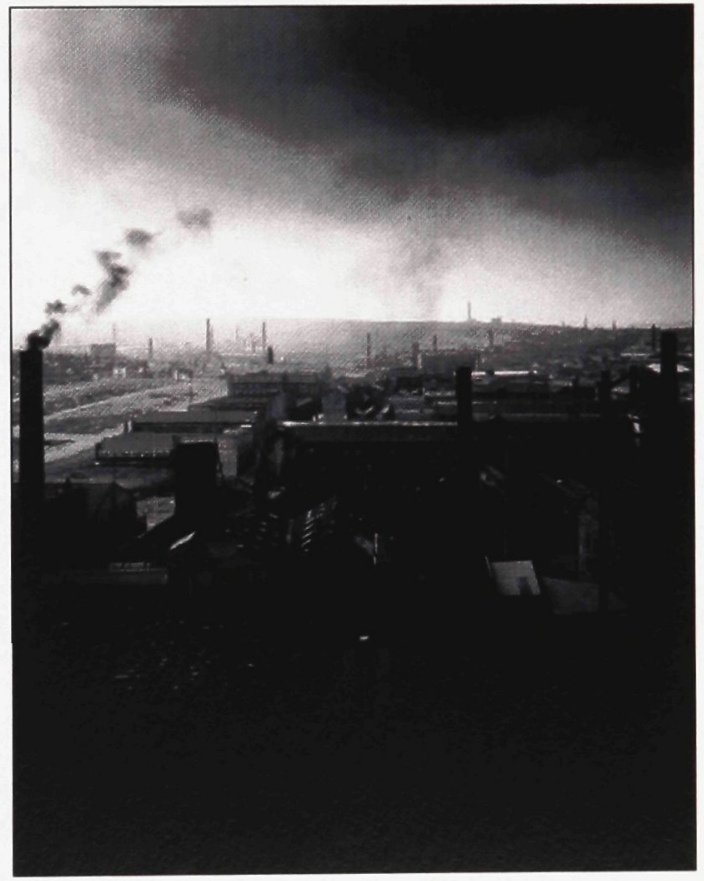

Image 2.3.1.1 London, England during the industrial revolution. urban environment already compromised by overcrowding and a lack of sanitation infrastructure. Most people - even the rich lived in cramped residences that were most often above the family business; as such, 
there was no real separation of business and family life. ${ }^{12}$ A popular and influential religious movement of evangelical Christians identified (among other things) the city as a source of society's problems. As result many upper and middle-class families shifted their family life out of the city. The urban realm had become synonymous with crime, pollution, and crowding, while the countryside came to be seen as a clean and safe alternative. According to Robert Fishman, London is the "birthplace of suburbia" because the merchant middle class developed a view of the areas on the outskirts of the city as better than life in the city. ${ }^{13}$

One of the earliest suburbs was called Clapham. This settlement at the edge of London included private homes on large pieces of property. These homesteads surrounded an expansive shared park land at the centre. This type of alternative living arrangement soon became more common and what initially were just humble shacks in the countryside meant for weekend use soon became full-time residences.

The most notable aspect of the original suburbs is that londoners reacted to the problematic nature of the urban realm at the time by leaving it altogether. Everyone who could afford to leave did leave, and in doing so they

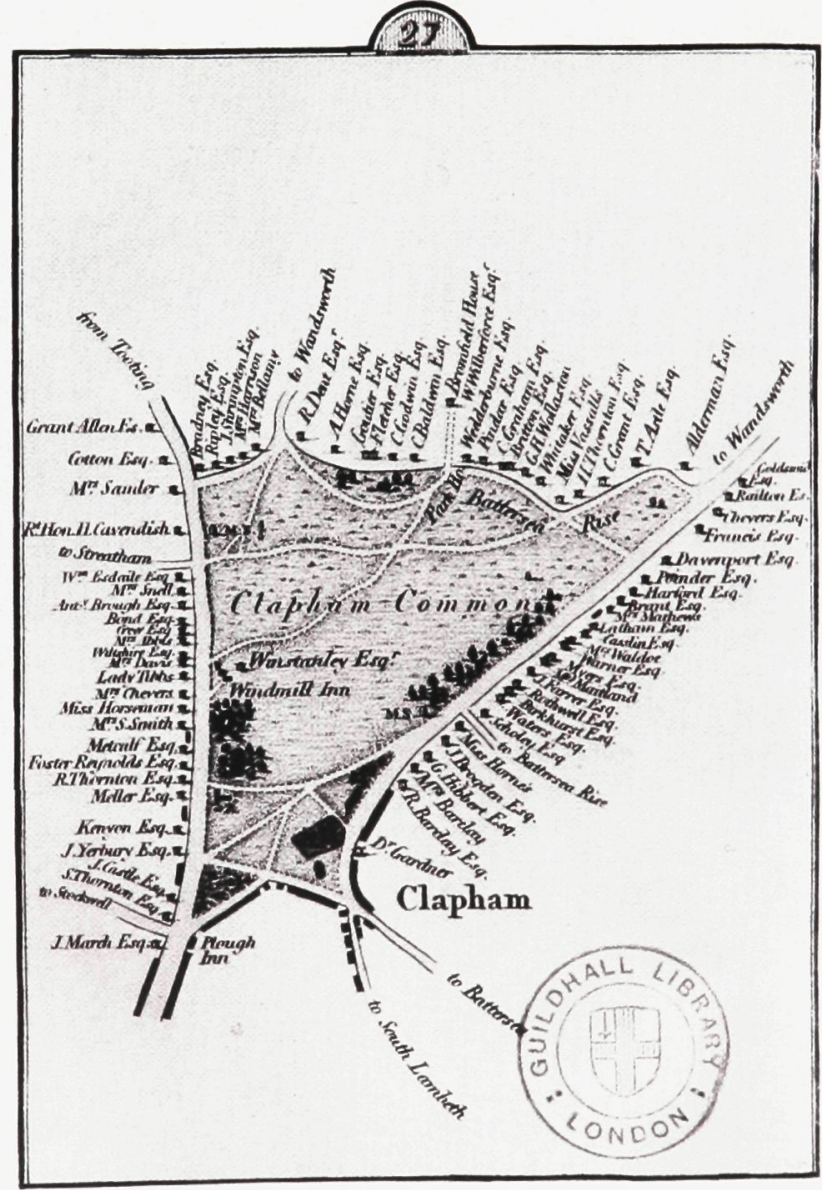

Image 2.3.1.2 Clapham Common outside London, England 1800. 
popularized the private home in the countryside as an ideal setting for family life.

In contrast with the scenario of industrial London is that of Paris, France. Similar problems faced Paris as did London: crowding and pollution threatened the lives of its urban inhabitants in the sense that they had been victimized by disease and crime. ${ }^{14}$ The street and alleyway network of Paris was difficult to navigate and it showed a lack of planning. In 1853, Napoleon III named Baron Haussmann Prefect of the Seine. This gave Haussmann near dictatorial powers, and he razed parts of Paris in order to create larger, more open and picturesque boulevards. This involved the destruction of many thousands of homes over the nearly two decades that the project took to complete. ${ }^{15}$

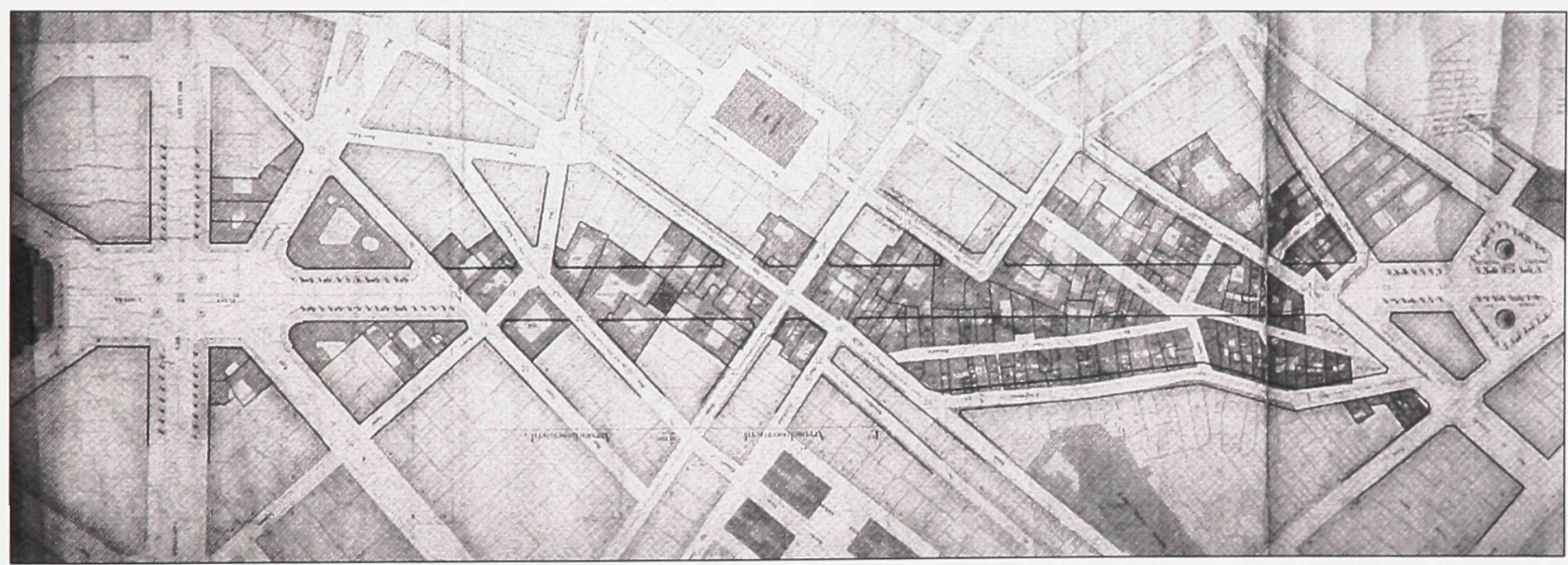

Image 2.3.1.3 Paris, France. (1862) Map showing one portion of the reconstruction project at L'Opera.

The new streets and vistas created throughout Paris meant not only that there would be more logic and openness to the street network, but that new housing could be built along the edges of these new boulevards. The building type that typically 
filled Paris was already a multi-storey, multi-unit dwelling, but the new buildings would be grander and more luxurious than what was torn down. ${ }^{16}$

These five to six-storey buildings were continuous along the street front, and the value of each dwelling would decrease as the inhabitant ascended the stairs, ensuring the wealthiest had the most convenient access to the street. As a reaction to urban blight, the emergence of the Parisian 'urban villa' house type is a significant example of an urban population that reconfigured their urban fabric instead of spreading out into the countryside. As reactions to the 'metropolis' the reformed urban streetscapes of $19^{\text {th }}$ century Paris were to upper and middle-class Parisians as the suburbs like Clapham were to londoners of the same era.

Image 2.3.1.4 The Parisian Apartment House type. Façade and layout for Haussmann's new boulevards. (circa 1858)

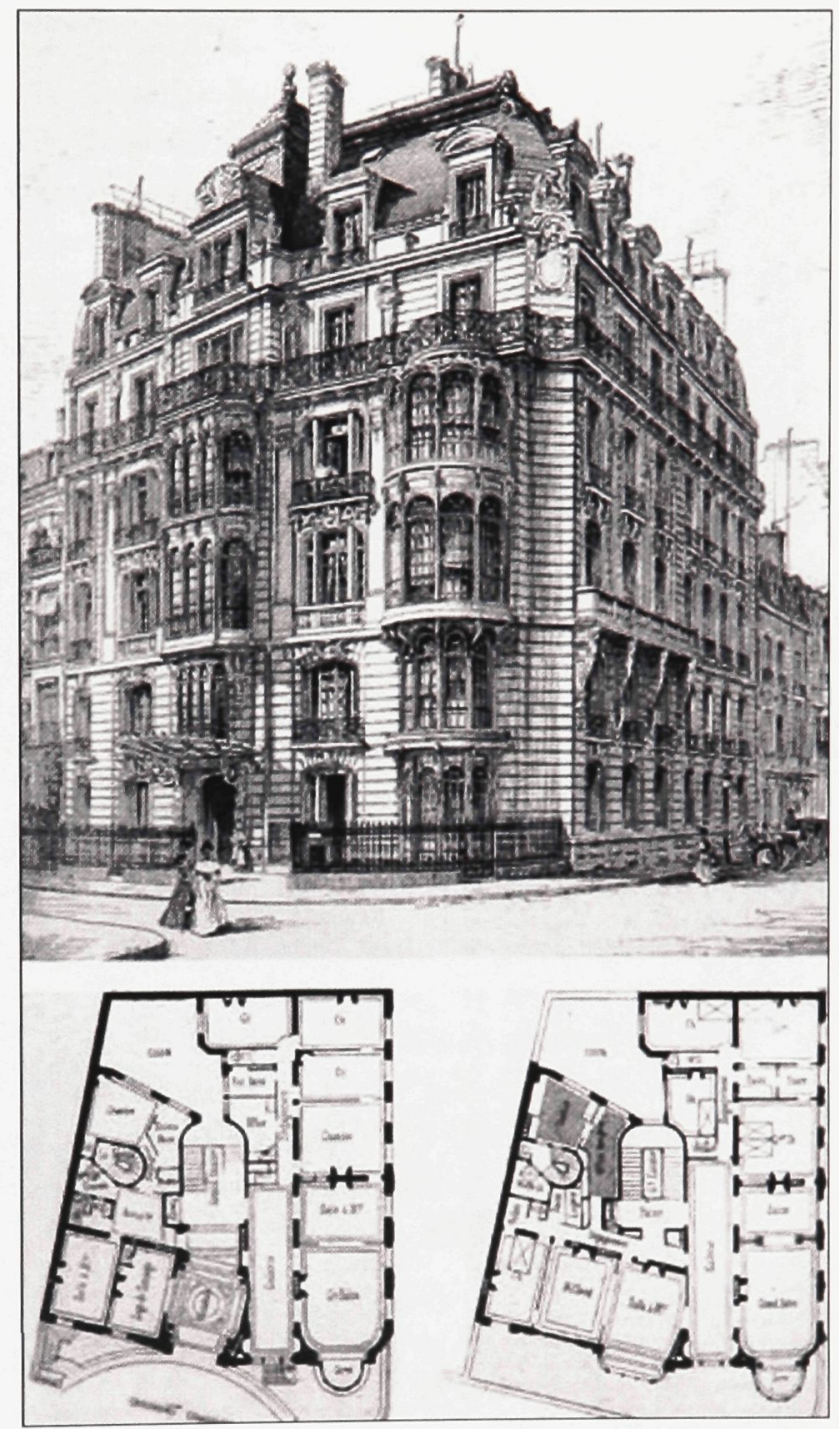




\section{Pre-war examples: Chicago and New York}

A North American parallel can be drawn from the European examples just discussed. The pre-First World War era in the United States had resulted in similar problems for major urban centers in America. In Chicago, Illinois, urban growth had begun to spawn what were called 'railroad suburbs.'

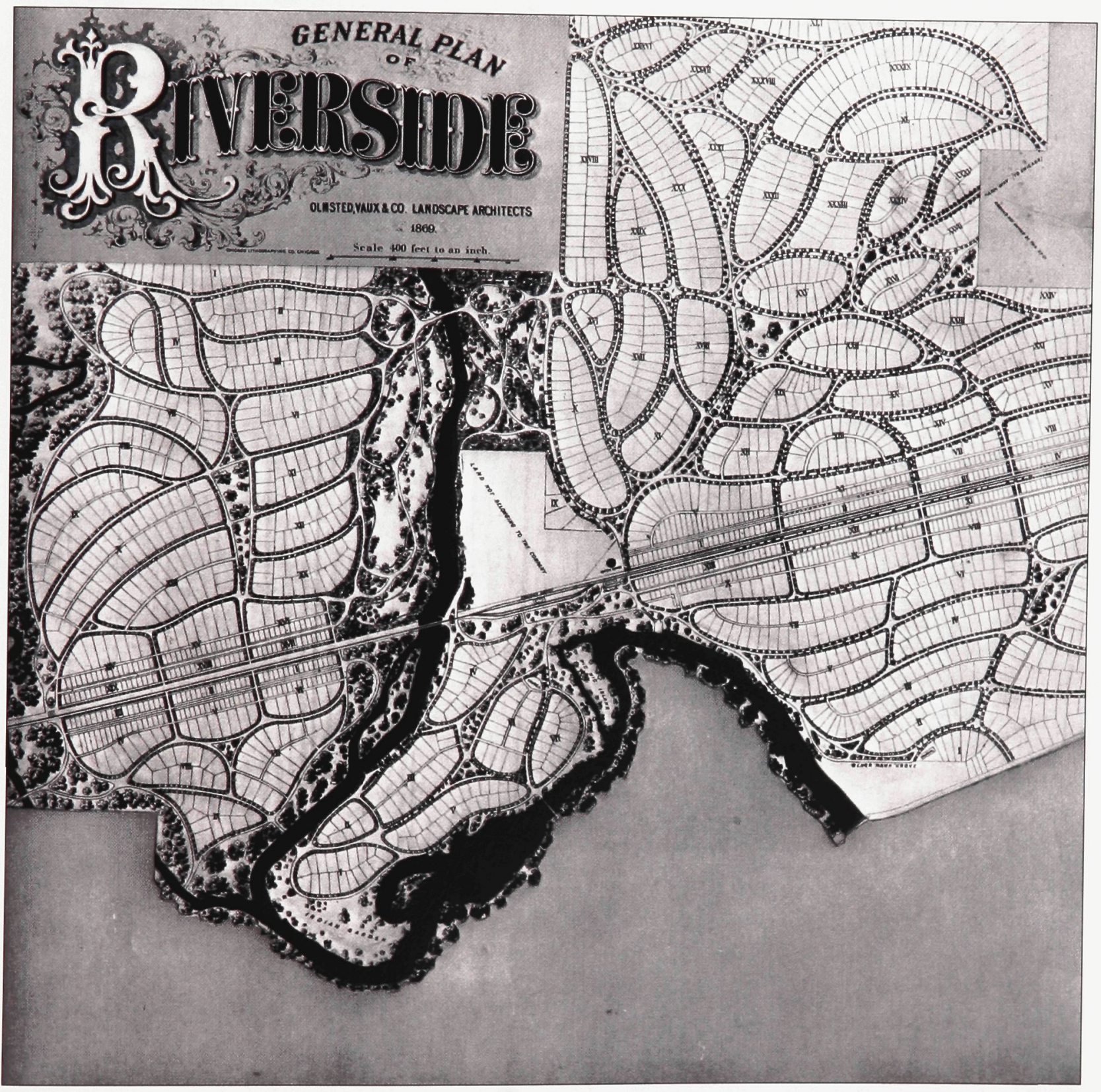

Image 2.3.1.5 The General Plan of Riverside, Illinois. (Olmsted and Vaux, 1869) 
These places were removed from the city but connected by a railroad meant to bring goods and urban workers into town from the countryside. One such place was called Riverside designed by Frederick Law Olmsted and Calvert Vaux. The most distinguishing characteristic of Riverside is the extent to which it is landscaped to provide a picturesque living environment; far more premeditation and effort went in to the design of this suburban community than most others that existed at the time. ${ }^{17}$ Riverside is one of the primary examples of the early picturesque movement in landscape design, where no road or garden's edge is straight because the undulating forms were perceived as 'natural' and more 'pleasing to the eye. ${ }^{\text {18 }}$ The example that Riverside provides to this project is of an American urban area that spawned a new, separate type of community, much like that of London. Although small by some of today's standards, the homes at Riverside were large for their time as fully-detached, private dwellings meant for single families.

In New York City circa 1900, a contrasting reaction to the metropolis can be found. Similar pressures faced the city of New York as those faced by the other major urban centers already discussed: crime, crowding, pollution, and an overloaded urban infrastructure for sanitation and traffic and housing. ${ }^{19}$ In the same way that Parisians ended up

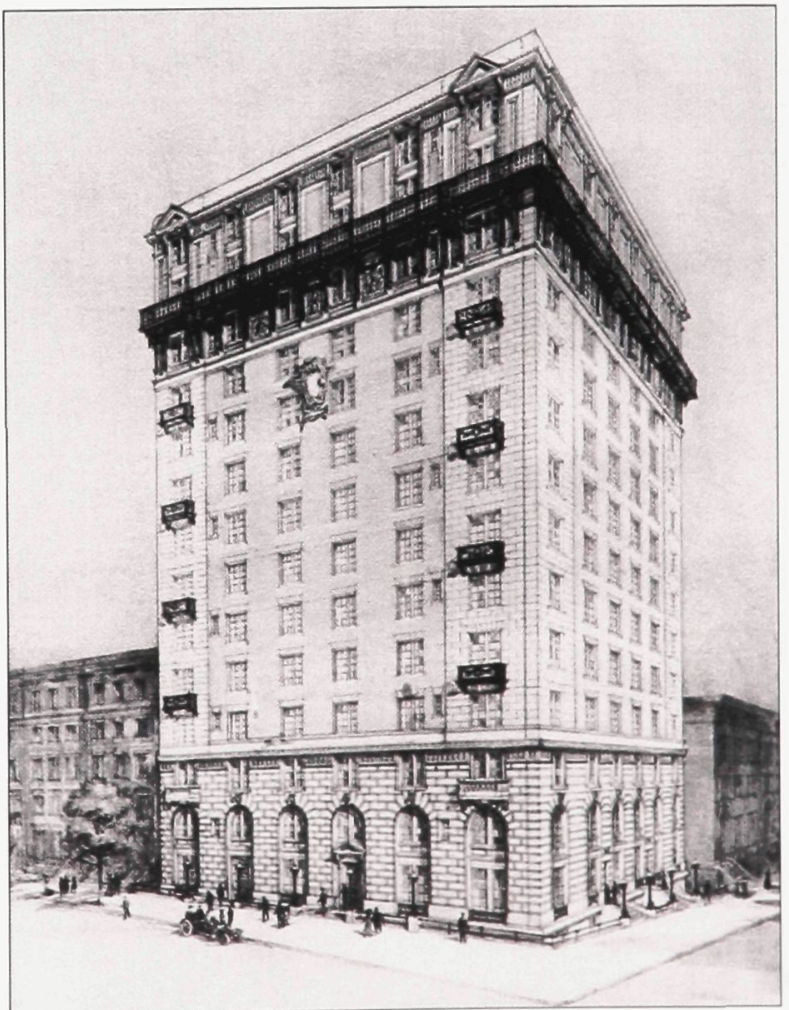

Image 2.3.1.6 925 Park Ave. New York. 1909-10 (perspective drawing, Delano \& Aldrich) 
staying within the city as opposed to moving out, the wealthiest of New Yorkers created a new type of luxurious and spacious type of dwelling within the city. Lavish new high-rises were constructed to suit families who could afford to occupy these expensive and high-profile dwellings. In some cases, these apartments would total more than twenty rooms and occupy an entire floor. Large rooms were provided for the purpose of entertaining, and there were also living quarters for residents as well as servants.
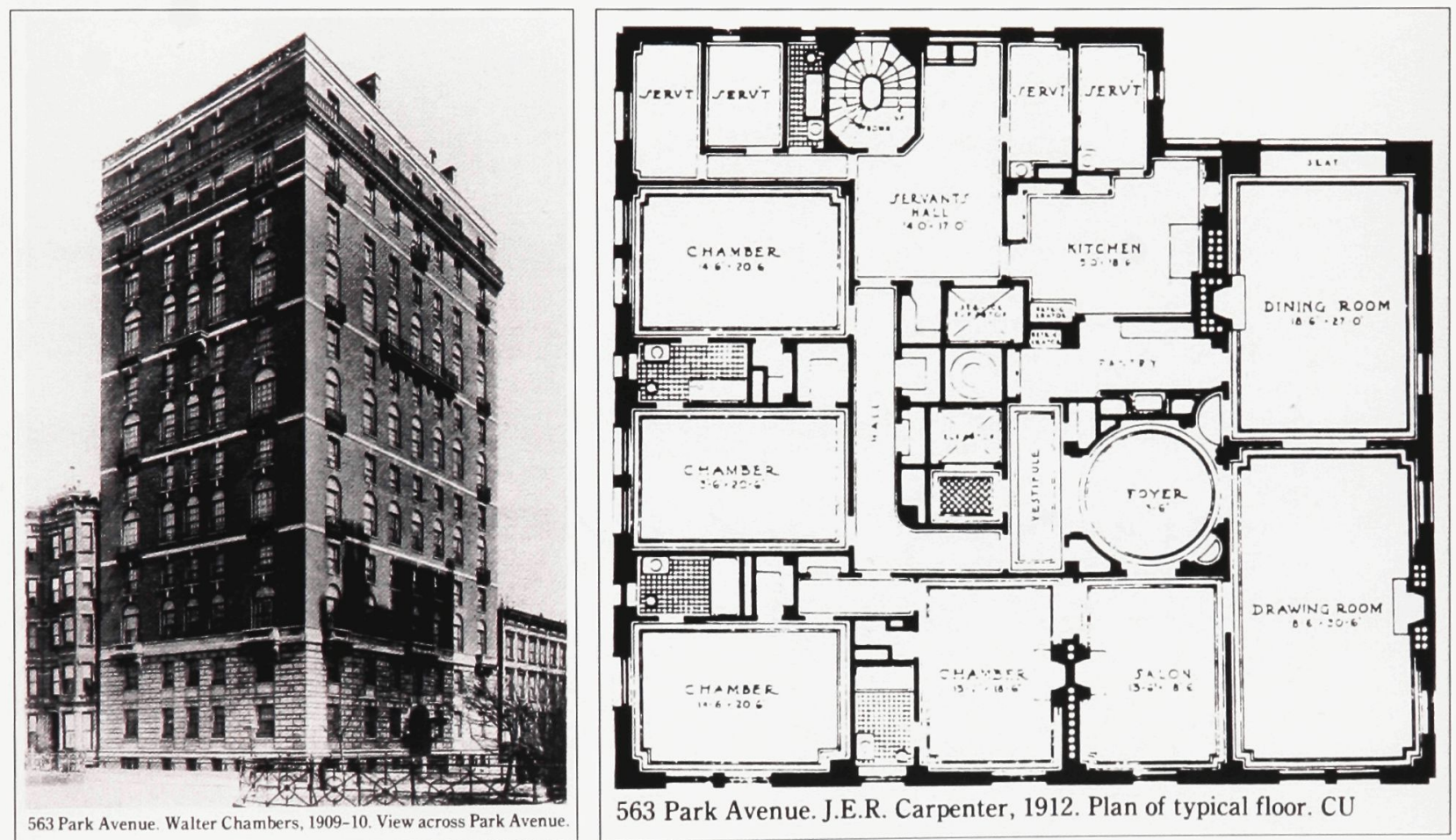

Image 2.3.1.7 563 Park Ave. New York. 1909-10. Elevation and typical floor plan.

As a response to urban blight, this is another example where the inhabitants of an urban area chose to stay and live in the city rather than leave for the spacious suburbs. This is a high-end alternative to the luxury that was being sought out in new developments outside of the city, and in relation to this project, it is a precedent for in-fill development. Luxuriousness aside, this type of building affirms the value 
that urban inhabitants attribute to the location of their places of residence. To live in close proximity with business life and to all the other aspect of life that the city offered was a catalyst for this type of domestic arrangement in New York City at the time, and it could also mean the same thing for Ottawa today. These high-end urban high-rises offered aspects of the suburbs and urban amenities (such as connectivity and convenience,) by virtue of their location. By addressing the dichotomy of city and suburb in this way, these buildings in New York are exemplary of the strategy employed in this design project.

In the post World War II era, the design of domestic space was influenced by a new set of social realities. In Europe, many cities were faced with the need to rebuild due to extensive destruction during the war. In North America, a severe housing shortage confronted the masses of returning soldiers and their families. The following examples address the conflicting notions of city and suburb in different ways, and, similar to the pre-war examples given, they occur both inside and outside the city. 
Post-war examples: Golden Lane Housing, London. Alison and Peter Smithson

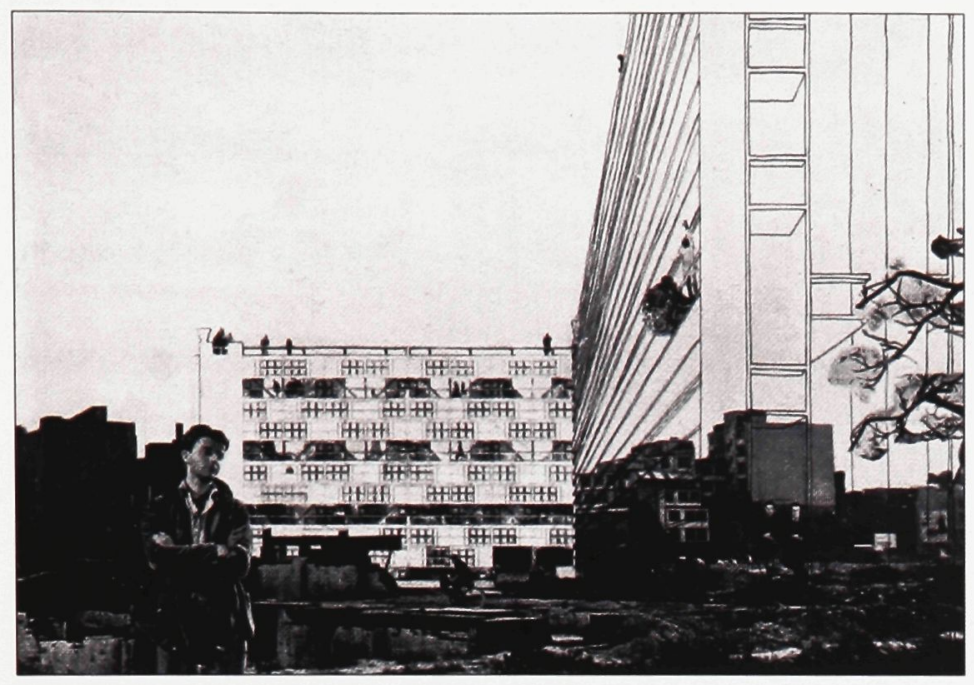

Image 2.3.1.8 Ground level view of Golden Lane Housing.

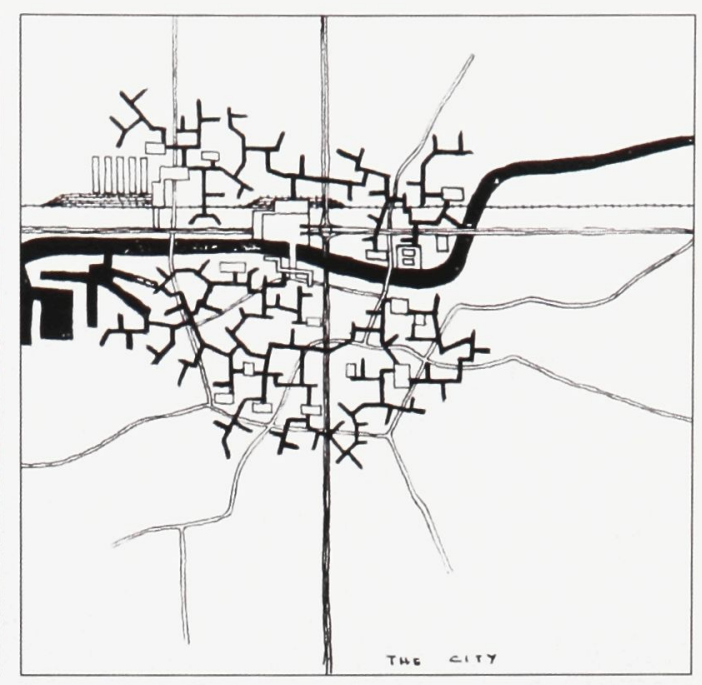

Image 2.3.1.9 Sketch of the Golden Lane Housing proposal at the urban master plan scale.

Alison and Peter Smithson were modernist architects who submitted this design as part of the Golden Lane Housing Competition. It was an affordable housing design initiative aimed at re-building London after the Second World War. ${ }^{20}$ Within their proposal, large slab structures would snake through London, leaving much of the formerly-crowded ground plane as un-built green space, or, at least, to exist at a lower built density. The buildings themselves were to rise above the street level and recreate that street on every third level on what the Smithson's called public 'decks.' Off of which, people would enter their private dwellings where each had a private rear garden space, as well as living space above and below the deck level.

This project was never constructed as originally proposed, but in the versions of it that do exist, the idea of the urban street has not been effectively re-created. The Smithson's re-configured upper streets or 'decks' were one-sided and removed from the ground. This arrangement did not produce the lively results their renderings 
showed because of a lack of population at each level, and a severe lack of reasons for anyone other than a resident to be there. At Golden Lane, the notion of the individual dwelling becomes completely lost within the larger context of the building, and the massive constructions themselves would have had a divisive effect on the remaining built fabric below because they did not follow the logic of any existing topographic features or existing built infrastructure.

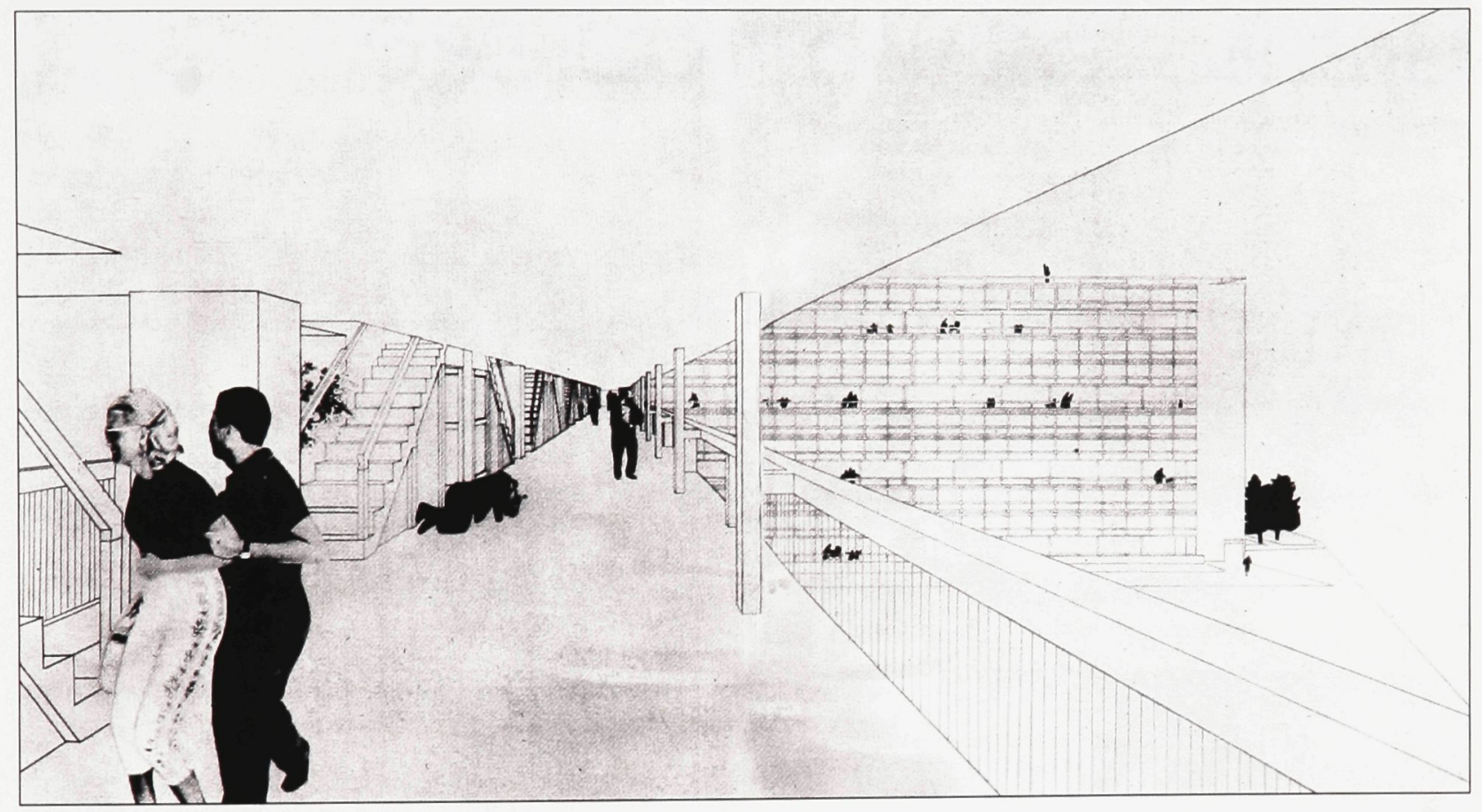

Image 2.3.1.10 Golden Lane Housing. View of upper deck.

This thesis project takes the position that the Golden Lane proposal, although inherently flawed, set a historical precedent for so-called 'private housing' in the urban context. It presented an inventive dwelling arrangement of private homes as part of a larger structure, but simultaneously proved that the scale of that structure and the lack of differentiation for each home could cause the scheme to fall short. 
Post-war examples: Levittown. Long Island, New York, 1948. William Levitt and Sons.

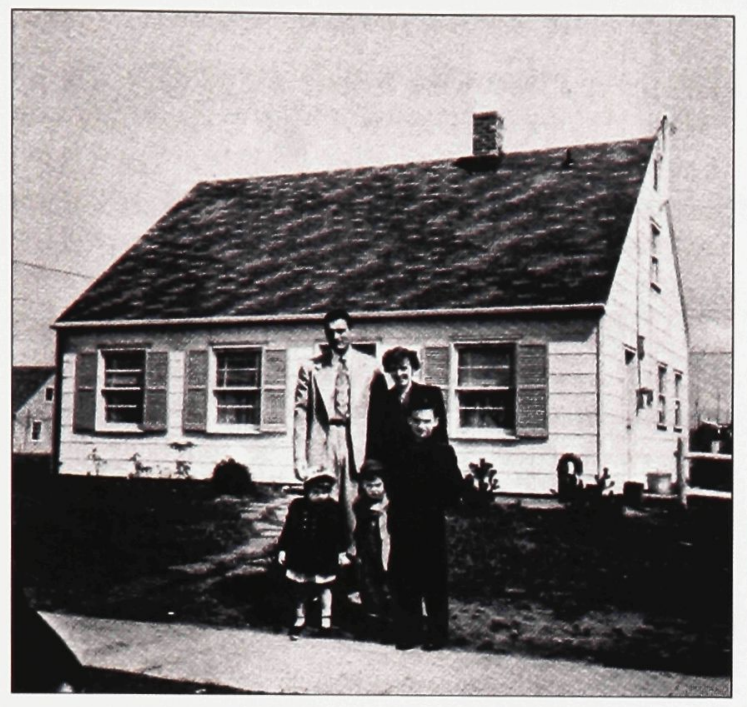

Image 2.3.1.11 Typical house and family at Levittown, NY. (1949)

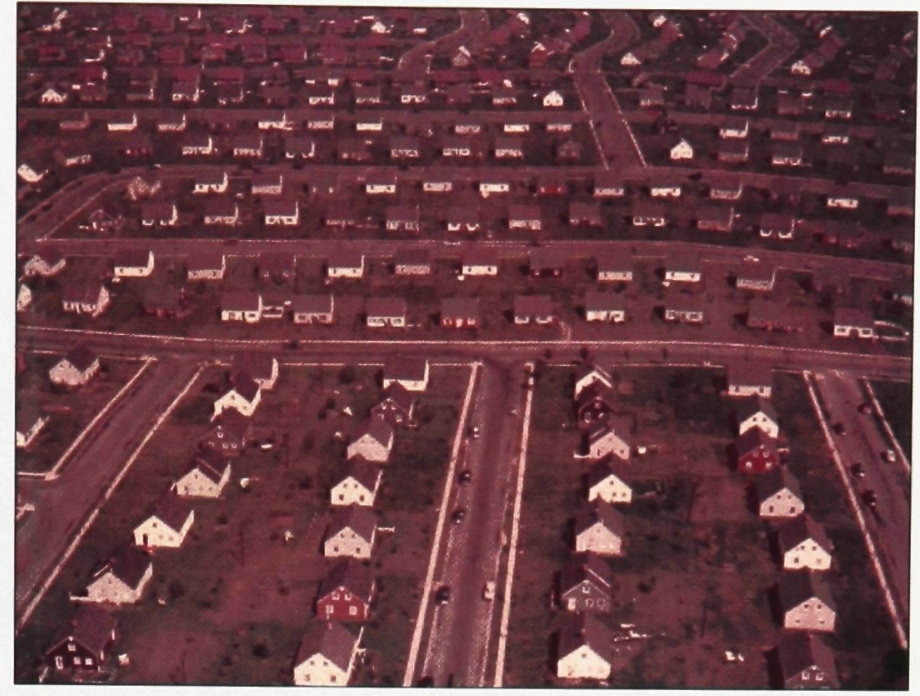

Image 2.3.1.12 Aerial view of Levittown, NY. (1950)

Levittown, NY. was the first truly mass-produced suburban residential community and it is widely regarded as the archetype of post-war suburbs in North America. In 1947 the developer Levitt and Sons built began building sprawling residential communities of easily constructed homes. Each home offered appoximately 800 square feet of usable space inside. ${ }^{21}$ The first such development was near Long Island, New York, but other similar developments were completed by Levitt in New Jersey and Pennsylvania. These places provided an answer to a housing shortage that followed World War II and the homes were also affordable enough to allow the potential homeowner to qualify for veteran's assistance programs offered to returning soldiers. ${ }^{22}$

Levittown also became the target for critics who noted its repetitiveness and homogeneity. Although extremely popular, these types of developments also became known for their blandness and racial exclusivity. Still, Levittown became 
the symbol for post-war suburbia and secured the notions of private land ownership and the private detached home as central facets of the American Dream.

At Levittown and Golden Lane, the cognition of the private dwelling as it relates to the city seems reversed. In one instance, the metropolis is being reconfigured, while in the other instance the inhabitants choose to settle in the 'countryside.' This trend, as already discussed, began in eighteenth-century-Europe where the London and Paris exhibited a similar set of opposite responses. These precedents exist as reactions to the metropolis and they exemplify the ongoing dichotomy of city and suburb.

\subsubsection{Reactions to the Contemporary Urban Realm}

\section{Habitat '67, Montreal}

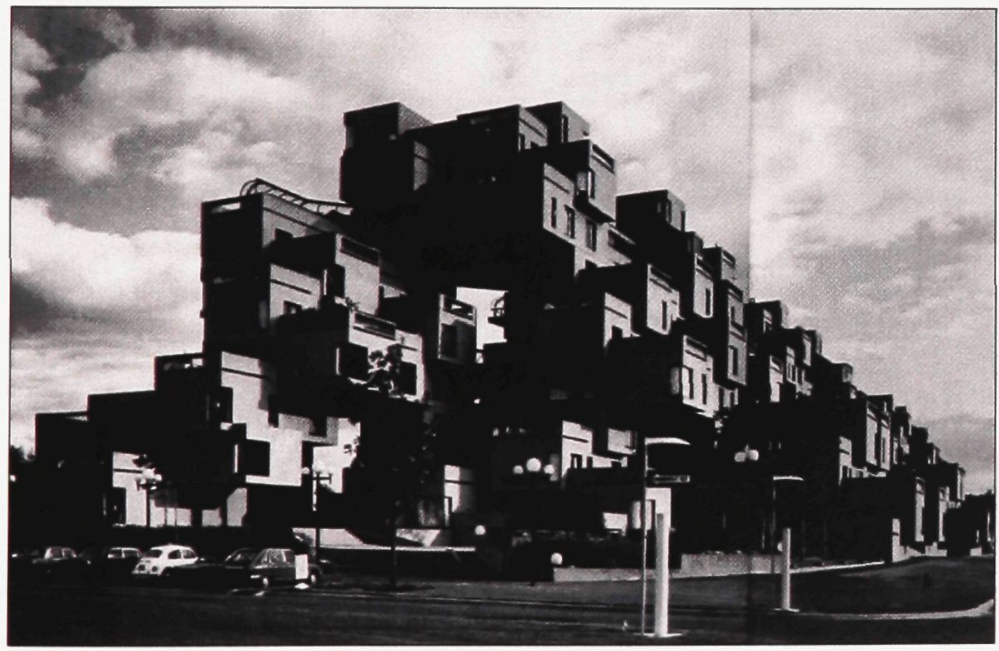

Image 2.3.2.1 Habitat '67, Montreal. View from the ground.

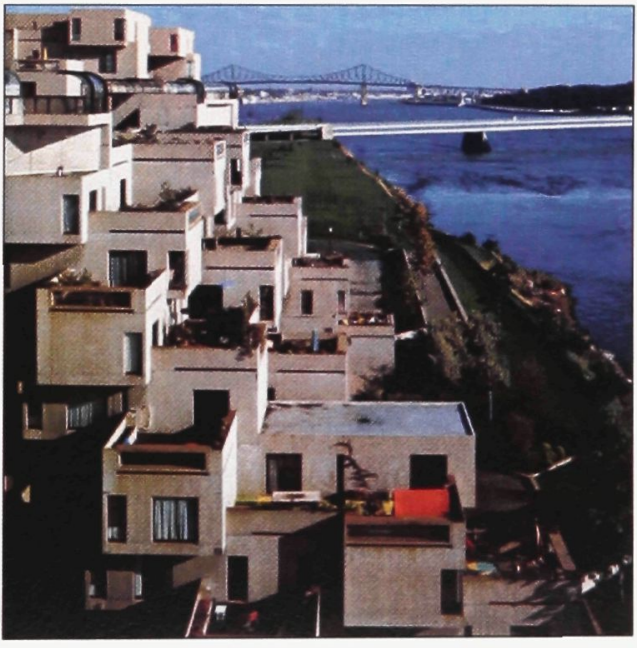

Image 2.3.2.2 Habitat' 67 , Montreal. View of private gardens. 
Habitat ' 67 by Moshe Safdie became known worldwide for its inventive use of modular construction and other modern construction technologies as well as its distinct formal arrangement. Moshe Safdie was a recent graduate of McGill University where he had written a thesis entitled A Three Dimensional Modular Building System which won the commission for a housing project to be part of the 1967 World Expo. Habitat is a type of vertical community whose form is largely dictated by its composition of dwellings and gardens in relation to sunlight, as well as the desire to express the identity of the individual house within the group. ${ }^{23}$ Houses of varying sizes are created by the stacking of structural concrete modules at rightangles with each other. The resultant multi-level building creates common spaces in the void below at the ground and at intermediate spaces throughout the structure. Access to each private unit occurs off of a shielded public corridor connected to common vertical circulation cores.

Habitat is often used as a successful example of an urban housing prototype where a high density is achieved without entirely sacrificing sunlight or direct contact with exterior space. In relation to this thesis work, it can also be seen as a reintegration of suburban notions of housing into the city. In comparison with a typical mid-to-high-rise apartment building, Safdie's Habitat makes obvious efforts to preserve the appearance of each unit as a distinct entity. Despite the physical contact that each dwelling has with its immediate neighbours, each unit can be spoken of as a visibly differentiated object. This is hardly the conception of the single-family, fully-detached house that is so typical in suburban development, but it is a clear departure from the high-rise apartment building where the individual unit is reduced 
to appear only as a window on a continuous façade of the same window. This thesis design project drew heavily from Habitat's provision of individual homes as part a larger building.

The building design presented later does not utilize the modular design principles displayed in Habitat per se, nor does it subscribe to the Metabolist theory of which Habitat is so expressive. Metabolist architecture utilizes a built framework for the connecting any number of individual units. This strategy, where each unit is like a cell that helps form a larger organism, offers inhabitants and personal living space as part of larger building where circulation and all other amenities are communal. In the context of this design project, Habitat simply provided an example of a dense, urban interpretation of private housing. It also represents a formidable attempt at the re-creation of private green space. The large balconies referred to as 'gardens' offer the inhabitant a private space that is in direct contact with greenery and the exterior environment. Safdie speaks about greenery and the modern city in his book Beyond Habitat:

The early twentieth century industrial city, which virtually eliminated plant life, is only a temporary nightmare. Even though the nature of plant life in the city is quite different from that in the open country, it has its rightful place. In a typical Mexican town like Taxco, plant life is integrated with the buildings. It gives colour and shade and texture to the town. In the industrial city we have eliminated soil by massive paving and construction. Now as the city becomes three-dimensional, as we build it up on many levels, we create a new kind of environment where the plant can only exist if manmade structures make a place for it. ${ }^{24}$ 
Habitat is certainly not the only Canadian building that attempts a reintegration of plant life back into the urban realm. As modern building technologies meant to sustain plant life are becoming commonplace, more-and-more buildings are making use of the positive effects of plant life within buildings both aesthetically and environmentally. For the purposes of this project however, Moshe Safdie's Habitat in Montreal is the best Canadian example of a successful residential building that makes provisions for green space and private amenity space, and it provides for the notion of a private home as part of a larger urban building type.

One way in which Habitat ' 67 differentiates from this thesis project is in its choice of site. It is located in the city of Montreal whose population was 3.2 million people in 2001, almost four times the population of Ottawa. ${ }^{25}$ However, Habitat sits on a site that is fairly disconnected from the densest areas of Montreal. Situated on an outcropping of land away from the urban core, Habitat is not - and was not subject to any pre-existing constraints such as land values that can be excessive in the downtown or to a limited zoning envelope that results from the crowding of an established urban fabric. Though it is technically situated on an 'urban' site, Habitat is fairly inconvenient to access, being almost completed surrounded by water and segregated from much of the downtown. For its inhabitants, the building's relationship with the city is actually one of isolation rather than inclusion. In this way, this thesis finds fault with Habitat ' 67 : it is not a truly urban building because it is not situated within, nor connected with the urban core. Although it is an example of an alternative urban building type, it fails to contribute to the urban fabric because it is physically removed. 
Highrise of Homes, 1981. (un-built)

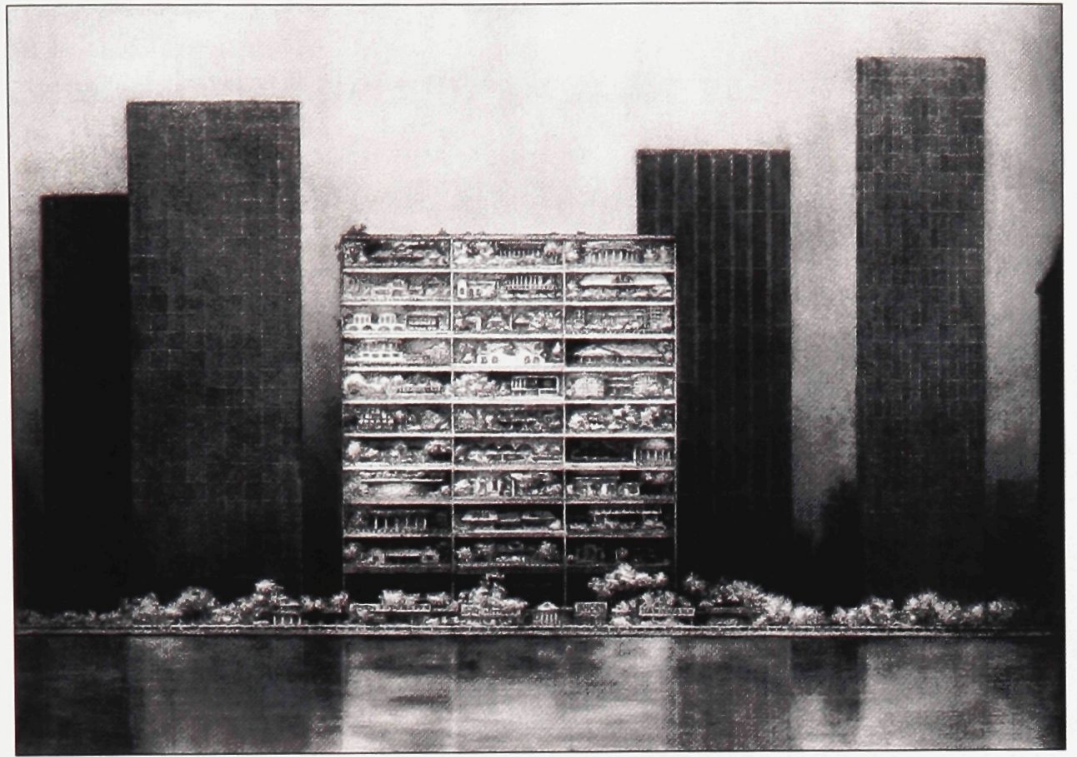

Image 2.3.2.3 Highrise of Homes, 1981, by SITE (James N. Wines). View of building within urban context.

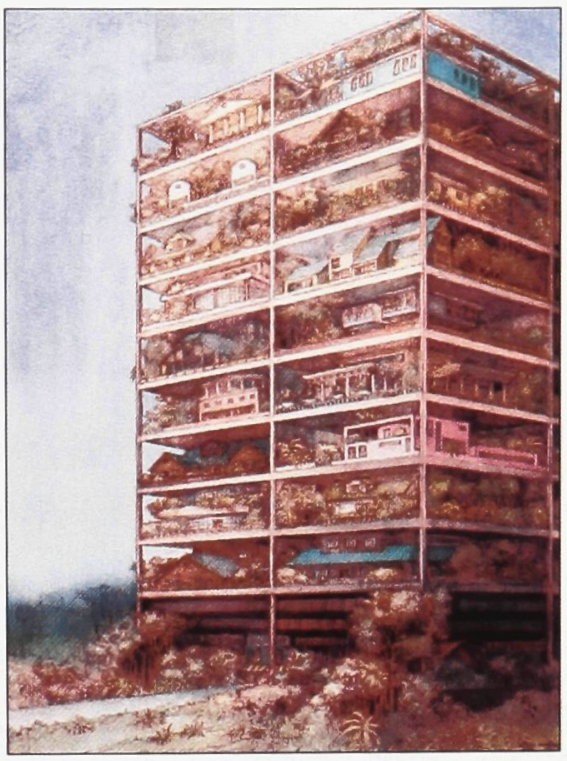

Image 2.3.2.4 Highrise of Homes. View of stacked residential properties.

The Highrise of Homes project by James Wines of S.I.T.E. is perhaps the most simplistic approach to the notion of private housing in the city, and it is also the most impractical. It is in some ways a caricature of the collision of suburbia and the city, where homesteads are shown stacked into a skyscraper form. Essentially it is a highrise, consisting of a simple structural grid system that creates a cul-du-sac's worth of private home on individual lots at each level of the building. A central vertical circulation core allows access to each level for the residents, and the bottom two floors are given to commercial space.

This project is a straightforward attempt to answer to the question: what happens when suburban homes are transferred into an urban context? Economic pressures and land values within a major urban centre would prevent a single level 
with four or five fully-detached homes from being built, so the ground plane gets multiplied $\mathrm{x}$-number of times up into the sky. This (theoretically) allows for a high economic yield from the given site, while still allowing the ever-popular, fully-private home - complete with a white picket fence in many cases. James Wines says:

The fundamental concept of this housing project is based on the assumption that individuals need the territorial definition of house and garden, even though they live in the city. The U-shaped configuration of the building is a steel and concrete matrix which supports a vertical community of private homes and gardens - stylistically each is the choice of the inhabitants - clustered into distinct villagelike streets on each floor. All levels provide flexible platforms which can be purchased by tenants in the manner or real estate land parcels (or "plots in the sky"), complete with earth infill. ${ }^{26}$

Although the project is experimental, Wines speaks of the design as being realistic and build-able. His notion of the re-created ground plane is underdeveloped here, but it became a starting point for the design work shown in Section 3. Wines's project's provision of completely autonomous houses is also valuable. Despite how unrealistic his design is from an economic feasibility and livability point-of-view, he has acknowledged the popular conception of the single family, fully-detached home and the fact that no less than a completely detached house is ever conceived as 'private.' The Highrise of Homes would not allow suitable sunlight, wind blockage, or the waste and circulation infrastructure required in order to be feasible.

Furthermore, the amount of structure, drainage, and heating required to support a recreated ground plane in this manner would be impracticable. As an extreme and largely theoretical proposition, the Highrise of Homes offers some truths: first, it 
emphatically states that the notion of the urban high-rise residential building could be broken up, to exist at a lower density with fewer actual units. It also proposes an integration of green space back into the urban realm. In the imagery there are views of Manhattan that show rooftop gardens and recreated green space as opposed to typical roofs made-up of tar and gravel that contribute to heat gain and poor air quality in the urban core. The Highrise of Homes is, if nothing else, a project that very clearly and simplistically confronts the conflicting notions of city and suburb.

\section{Suburbanism of Mass Customization, 2000. (un-built)}

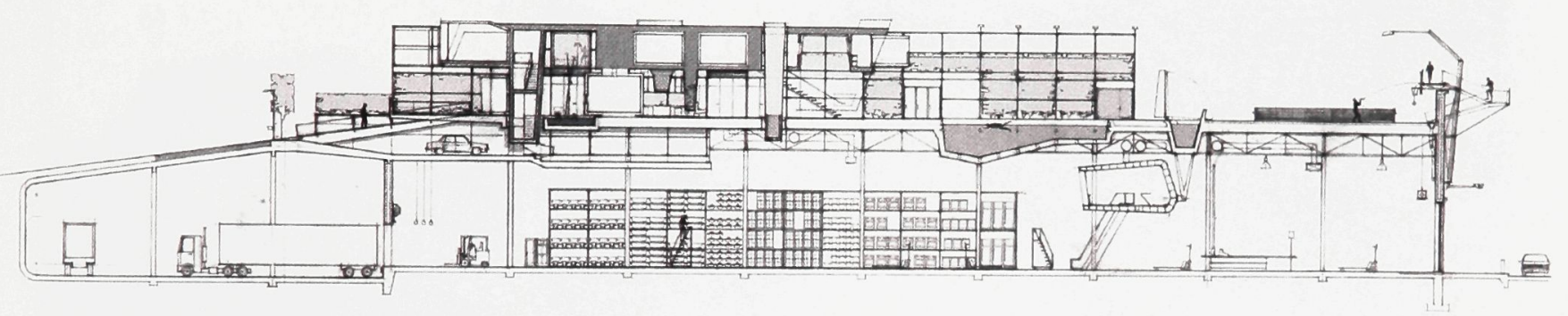

Image 2.3.2.5 Suburbanism of Mass Customization, 2000, by Lewis. Tsurumaki.Lewis (New York). Sectional drawing showing tract housing above large scale commercial space.

Another un-built project that confronts the problems with private housing in the context of today's urban realm is called Suburbanism of Mass Customization by Paul Lewis, Marc Tsurumaki and David J. Lewis of L.T.L. Architects (New York). This project observes current 'big box' commercial developments and the ongoing popularity of tract housing throughout suburbia in North America and proposes a reconstitution of these normally-separate entities. The rooftop space above the 
warehouse-style form of today's typical retail space is utilized for a new ground plane allowing for private homes and a new type of streetscape.

Lewis Tsurumaki Lewis have created a new form of development that accepts yet improves upon contemporary development patterns in the contemporary urban realm. They embrace the automobile culture that has in turn given rise to large scale commercial development (big box stores), and they also see the value of private homes that come complete with yard space and space for recreation. However, they reject the current suburban by-laws that specify 'single-use zoning' in favour an overlapping of the commercial and residential zones. What is perhaps most
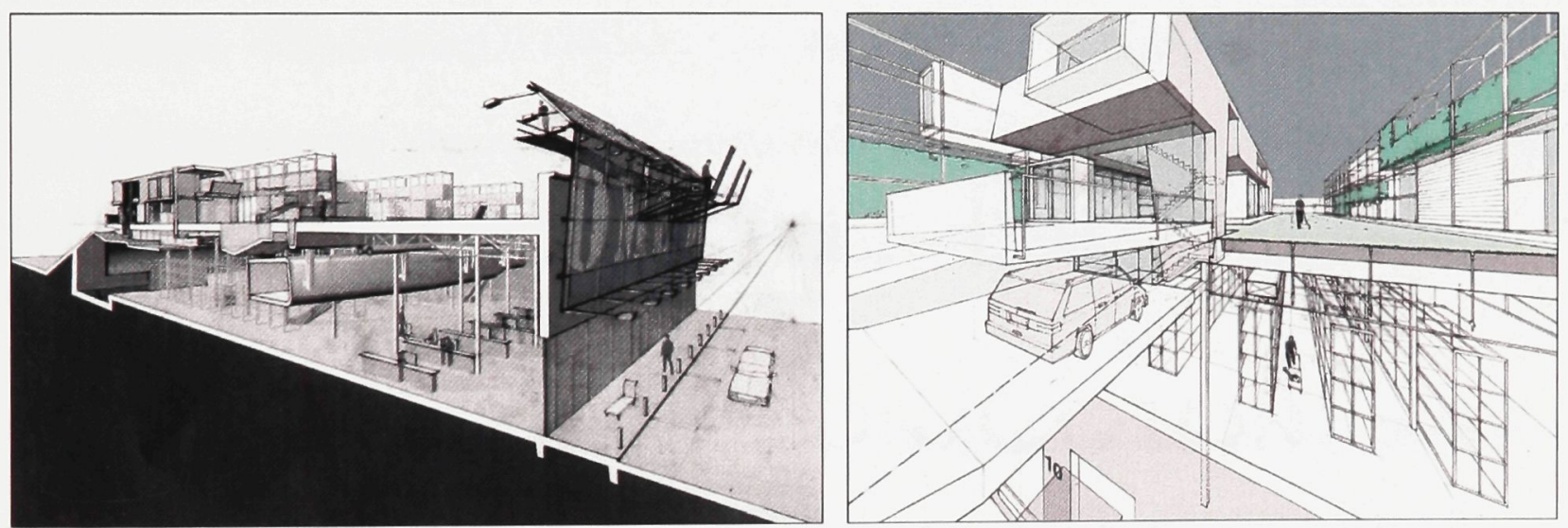

Image 2.3.2.6 Suburbanism of Mass Customization, 2000, by Lewis. Tsurumaki.Lewis. (New York). Perspectival images (partially sectional) showing residential landscape above commercial space.

important about this project is that it takes both the consumerist desire for massive retail space and the popular conception of the private home and actually made improvements on each. In the drawings of this project, the commercial space is given ample sales space, delivery access, and customer parking. The residential landscape above is complete with spacious lot sizes, sizeable housing layouts, and copious amounts of greenery. There are recreational facilities including a 
neighbourhood lap pool, jogging track, and playing fields. Another positive aspect of this arrangement is the clear separation of the world of the pedestrian from the world of the automobile. L.T.L. has acknowledged the environment that arises from this contemporary form of commercial development. Malls and big box stores bring with them the need for not only massive parking lots, but for widened roads, for larger intersections, and even for new highway interchanges. Some of these roadways are treacherous for motorists, let alone the brave pedestrian willing to attempt a crossing. The solution here is not to dismiss the dominance of the automobile, but to accept it and simply relegate cars (and, subsequently, the type of stores they bring about) to the level below. The idyllic world of homes, lawns and play-space is lifted to a safer level above. This strategy is different than the High-rise of Homes shown previously because the layering of uses shown here is only one layer deep. In the multiple slabs in James Wines' project, each residential level is overshadowed by the level above and cut off from the sky.

The creators of this project speak of it as being appropriate for any suburban enclave in contemporary North America. In the similarity that many suburban realms share with each other due to repetitiveness and common by-laws, a radical reconstitution such as this would be equally appropriate in any of them. Paul Lewis says:

The excessive parking that typically surrounds big-box stores is now just another space under the vast ground/roofscape. Without the parking moats, the scale of downtown USA is reclaimed - the signage of the big-box stores recreating in mutated form the image of Main Street. In New Suburbanism, latent desires of suburbia are exploited, lamentable redundancies are absolved, and new sectional matings are established in continued pursuit of the American Dream. ${ }^{27}$ 
This type of development does require an empty and extremely sizable site. Although Suburbanism of Mass Customization would re-use the rooftops of big-box stores, those buildings, as they exist today, would have to be re-configured to support the development they propose. As such, this project is not about an adaptation of existing buildings or traffic networks. It is a speculative solution to the problems associated with big box stores and tract housing, but it would not fix the pre-existing suburbs afflicted with this type of development. It could replace them, but this project is essentially a proposal for the future, is a not a current resolution of a problematic suburban situation.

The influence of this project within this design thesis is such that it inspired an attempt to accept certain pre-existing contexts. Certain aspects of the Suburbanism of Mass Customization can be seen in the building presented in Section 3, such as the sectional juxtaposition of multiple types of programs and the recreation of green space above the ground plane. Where this thesis project differs from the LTL project begins with the selection of a real site - a site which is also part of the dense urban core of Ottawa. In doing so, the constraints of a single building site set within a preexiting neighbourhood context prevent the proposal of such an all-encompassing solution. The design presented in this project reflects a reaction to a much more specific set of site issues. 


\section{Endnotes Section 2.0}

${ }^{1}$ The first and most well known New Urbanist development was Seaside in Florida. Construction began in 1981, and by 1988 it was already being featured in magazines and architecture periodicals even though parts if it were not yet built.

${ }^{2}$ Duaney, Andres, Elizabeth Plater-Zyberk, and Jeff Speck. Suburban Nation: The Rise of Sprawl and the Decline of the American Dream (New York: North Point P, 2001) 91-91, 115-133.

${ }^{3}$ Randal O'Toole, “Dense Thinkers” Reason Magazine, January 1999.

This article is a scathing review of the results that "New Urbanist" developments have had during and after construction completion. Most problems are related to failed traffic management attempts and development types that have left the developers bankrupt. 1997.

${ }^{4}$ Frances Tanner, "Central Park: More than Just Homes" The Carlington Summit September

${ }^{5}$ The introduction of the National Capitol Greenbelt was meant to increase density and development within the new city limits and discourage suburban sprawl. Refer to the following web page for a summary of this municipal initiative:

National Capitol Region - Planning the Capital Region 11 June 2003. "Greenbelt

Master Plan: A Summary" 11 June $2003<$ http://www.canadascapital.gc.ca/

corporate/plan_reg/todays_plan/greenbelt_master_e.asp $>$

${ }^{6}$ David Reevely, "Smarting from Smart Growth" The Ottawa Citizen 09 May 2002: B3.

${ }^{7}$ These totals represent the authors own research based on floor plans of all models offered by Ashcroft Homes, and the frequency at which they were constructed in Central Park.

${ }^{8}$ Paul Lewis, Marc Tsurumaki and David J. Lewis, "Suburbanism of Mass Customization," The Cornell Journal of Architecture 7 (Spring 2003) 35.

${ }^{9}$ Reevely, B3. In defense of this development, Ashcroft Homes CEO David Choo was quoted describing successful re-sales of Central Park homes with profits between $\$ 50,000$ and $\$ 150,000$.

10 This statement goes almost without saying, but for a thorough review of the societal precursors leading to the original suburbs, refer to Robert Fishman's Bourgeois Utopias. (Particularly chapters 1 and 4.)

11 Jacob A. Riis, How the other half lives; studies among the tenements of New York. Sam Bass Warner, Jr. Ed. (Cambridge: Harvard U P, 1970) Appendix (1).

${ }^{12}$ Fishman, 32. The co-existence of the family place of business and the living space in one building caused a lack of separation and privacy. In many cases, a compromised family life was the result. Business partners and employees would often be invited to stay, causing a displacement in the otherwise closed family circle.

${ }^{13}$ Fishman, 38.

${ }^{14}$ Fishman, 107. 
${ }^{15}$ Fishman, 111-113. This daring overhaul of Paris is often referred to as "Hausmannization" for the audacious nature of its overseer, and the sheer scope of the project.

${ }^{16}$ Fishman, 113-114.

${ }^{17}$ Fishman, 129-130. Olmsted took a featureless landscape at the Des Plaines River and created an extensively manicured environment at Riverside. Fishman says:

"As with Central Park, Olmsted had no ready-made picturesque features to work with. Design alone

had to create both landscape and community."

${ }^{18}$ Fishman, 126-133. The development at Riverside, Illinois is exemplary of Olmsted and Vaux's devotion to picturesque design. Fishman quotes Olmsted as saying:

"...tree lined roads that contrast with the ordinary directness of the city streets through their gracefullycurved lines, generous spaces, and the absence of sharp corners, the idea being to suggest and imply

leisure, contemplativeness, and happy tranquility." (129-130).

${ }^{19}$ Riis, Appendix (1). 1997) 34

${ }^{20}$ Marco Vidoto, Alison and Peter Smithson Works and Projects. (Barcelona, Gustavo Gili.,

${ }^{21}$ Renee Y. Chow, Suburban Space: The Fabric of Dwelling. (Berkeley: U of California P, 2002) 23-25.

${ }^{22}$ Gwendolyn Wright, Building the Dream: A Social History of Housing in America (Cambridge: MIT 1983) 240-246.

${ }^{23}$ Moshe Safdie, Beyond Habitat by 20 Years. (Montreal: Tundra, 1987) 104.

${ }^{24}$ Safdie, 122.

${ }^{25}$ According to 2001 federal census data, the post-amalgamation populations of Montreal and Ottawa were $3,215,665$ and 827,854 respectively. The 2001 Census Data is available and searchable online at: <http://www12.statcan.ca/english/census01/home/index.cfm>

${ }^{26}$ James N. Wines, "Growing Up," Artforum October 2003: 47.

${ }^{27}$ Lewis, Tsurumaki and Lewis, 43. 


\subsection{DESIGN PROJECT}

\subsection{Choice of Site}

One of the most critical decisions to be made in this thesis investigation was the choice of an appropriate site. In all, four sites were studied and compared. This section of the document defines the criteria used to evaluate each of the sites studied and briefly describes each of the sites themselves.

The decision to utilize a site within the urban core of Ottawa, rather than one in an adjacent suburban community, was a decisive step. Initially, while conducting research on the history of suburbia and the current state of suburbs in greater Ottawa, it seemed logical to design within the confines of a local suburb such as Kanata. Numerous suburban enclaves around central Ottawa such as Manotick, Stittsville, Kanata, Nepean South, and Orleans were documented for the purposes of this project. The reasoning behind the original choice of a suburban site was simple: I felt that if I addressed the identifiable shortcomings of suburbia with a design project and placed it within the context of typical suburbia, I would heighten its differences (and hopefully its improvements) by direct juxtaposition. The shortcomings I intended to address are linked to issues of economical, environmental, and social sustainability. Contemporary suburban development is wasteful because it occurs at a low density and the social and economic costs of transportation infrastructure at that scale is prohibitive. ${ }^{1}$ Similarly, the space required by millions of private homes on private lots is consuming the North American natural landscape at a rampant pace. ${ }^{2}$ Despite the benevolent intentions behind the original suburbs as places for true sense of community, free from the pressures of the metropolis, ${ }^{3}$ today's suburbs 
often operate as the antithesis of community because they are intensely private places where contact with one's neighbours is actually lessened. The problems seemed to lie within the suburbs, so it was assumed that a solution should be sought there as well.

Inevitably, any single project would have difficulty resolving issues within the suburban phenomenon. The list of inter-connected characteristics that make up what is known today as suburbia is long, and to deal with any portion of them in a single building design project is a daunting, if not impossible, task. Still, this thesis project (naively) set out in hopes of being the first to pull it off: initial design attempts included more dense arrangements of dwellings with a greater focus on green space, commercial space combined with residential neighbourhoods in reaction to singular zoning, and smaller single-family homes on smaller lots with a greater focus on public amenity space. These design attempts were formal reconstitutions of the fabric of typical suburban residential development. This type of work would have been medium density - an improvement upon the wasteful density of typical suburbia, but would still not have been as intense as that of the city. As such, it would have contributed to the ongoing proliferation of the contemporary urban condition where development is neither suburban nor urban. The last thing this project is meant to contribute to is 'exopolis, ${ }^{4}$ or the medium density urban sprawl that continues today on the periphery of most major North American cities.

As these initial attempts were abandoned, it became clear that what began as a 'suburban project' had become an urban planning effort aimed at addressing this issue of the continued merging of city and suburb. The principal question of this 
thesis became: what is the clearest, simultaneous architectural expression of suburban ideals (as mythic as they might be) and urban typologies? That is, if these two divergent conditions are meant to coexist in contemporary development, how can one permeate the other without having to compromise its character? Is this possible? Is it better to situate this hybrid in the city or the suburb? These questions are central to this project's choice of a site.

As already set out, the three central 'suburban' traits are: 'contact with green space,' 'private homes,' and 'affordability.' Taken from a long list of items that help qualify a building as part of the suburban realm, those three remain as the most enduring and most imperative. They also happen to be three traits that continue to be the most elusive in the urban context. More importantly, the traits that qualify a building as 'urban' need to be simultaneously considered: What is it that makes an 'urban' building type? Is it its size or number of saleable or rentable units? Is it its usage for office, commercial, or institutional uses? Is there a specific combination of a building's number of floors and usage types that will qualify it as a deserving member of the city's built environment?

This project takes the stance that no single building can qualify as an urban building unless its context is decidedly urban. Even the highest of high-rises designed for the most intense of downtown cores would cease to be effective as an urban building type if it were removed to a rural or extremely suburban site. This is because that building relies upon the inter-connectedness of the city, a high population, and a large amount of development in order to sustain itself. In this sense, it is the characteristics of a building's or a site's context that largely determines 
how 'urban' it is or is not. Therefore, in the search for a sufficiently 'urban' site, this project sets forth the following criteria:

The site must sit next to major traffic and transit corridors. Not only must the site fall within the city of Ottawa's central area boundaries, ${ }^{5}$ but it should also sit directly adjacent to a major traffic thoroughfare. The site may be beside an east-west or north-south running corridor, but proximity to both will help qualify the site as being 'highly connected' with the rest of the city. Also, numerous routes of the public transit system (OC Transpo,) must stop near the site itself. If the urban realm is characterized by connectivity \& convenience, then the chosen site should be conducive to the efficient navigation throughout the rest of the city.

The site's immediate context must be inclusive of commercial, residential, and multiuse building types. The part of the city being considered must be self-sufficient as far as being able to offer numerous opportunities to live, work, and play. Commercial-use buildings such as offices, warehouses, storage, retail outlets, restaurants, and hotels must share the nearby area with various types of residential-use buildings.

Furthermore, where institutional buildings (such as educational, governmental, and healthcare), entertainment buildings (such as theatres and professional sports facilities), and recreational facilities (like gymnasiums, arenas and fitness clubs) also share the neighbourhood, the project will benefit by the heterogeneous nature of its context.

The zoning designation must allow for multi-use buildings of medium to high-rise.

Within the Municipal By-law, the site in question must be described as allowing both commercial and residential uses, so as to not contribute to the 'edge city' phenomenon where single-use zoning eliminates complex and interesting 
neighbourhoods. The site's zoning must also permit buildings to rise higher than that of a single-family detached home, so that more sustainable and larger building types can be proposed. Similarly, a 'Heritage overlay' or similar type of restriction that limits scale of development would detract from the site's appeal.

The site's monetary value must allow for a medium density of development. Some urban sites are so valuable on a cost per-square-foot basis that they put incredible pressures on the development of that site. That is, in order to cover the cost of the property itself, the owner would have to build an enormous amount of sellable / leasable square footage on that property, making the only feasible building type a high-rise 'skyscraper.' For the purposes of this project, which include suburban notions of green space, private dwellings, and affordability, the skyscraper building type is problematic. So, even though high real estate value is often considered an indicator of a site's value to the urban realm, this project needs to find a site that is not exorbitantly expensive. The current market value of the site in question will need to support a medium-density type of development where some of the residential units are partially detached and amenity space exists in larger amounts. As such, the economic profile of the site in question will need to be comparably affordable, where a basic evaluation of costs ${ }^{6}$ will show a $100 \%$ profit for the proposed development within five years of construction completion.

The following images and descriptions convey the reasoning behind the final choice of a site. Where possible, zoning designations assessed values and actual mortgage values are compared. Also, diagrams, maps, and descriptions are used to portray the characteristics of the site's urban context. 




Image 3.1.1 Aerial photo of central Ottawa showing 4 considered site locations. 


\section{Site \#1: The Southwest Corner of Plymouth Street \& Bronson Avenue}

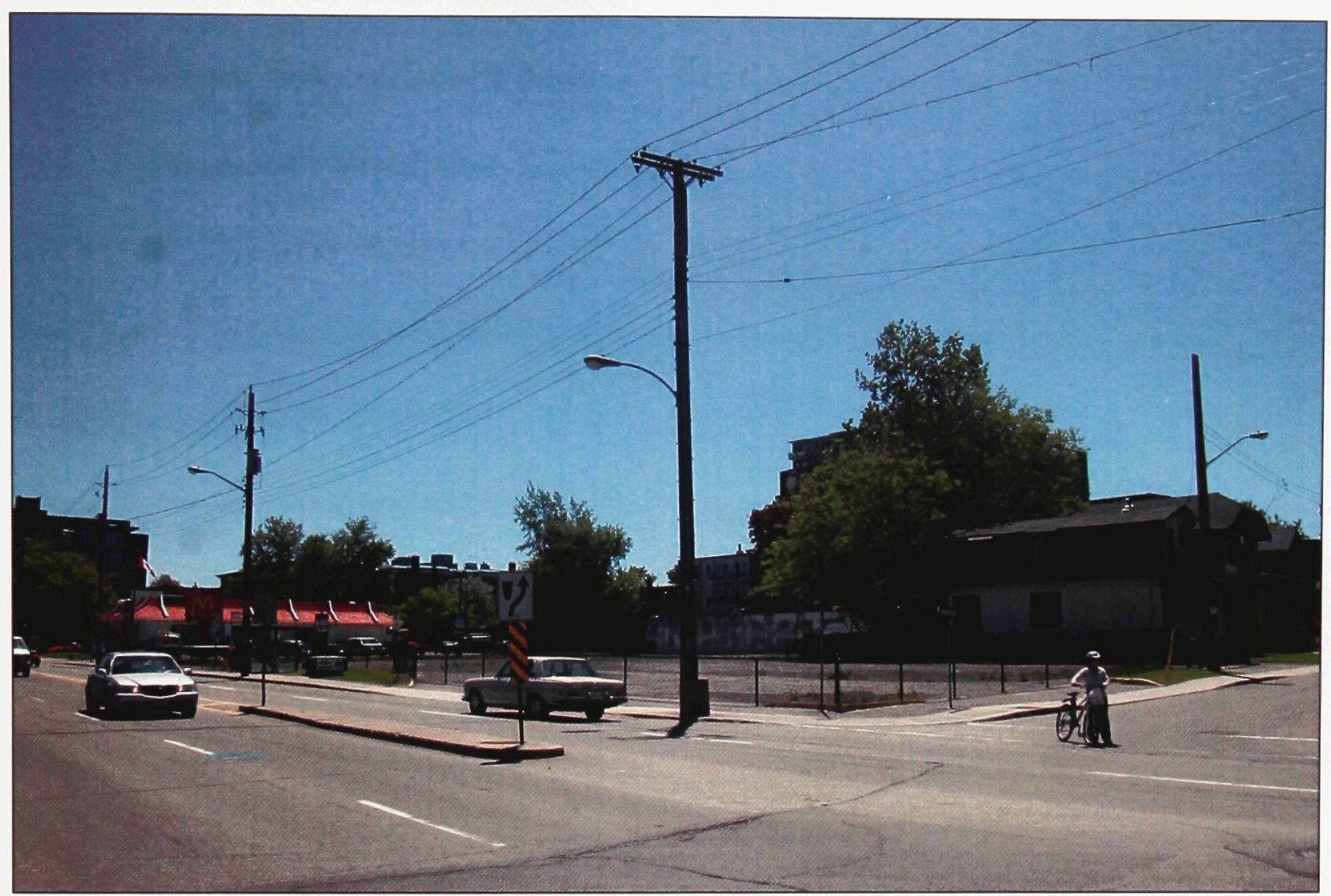

Image 3.1.2 Photograph of site \#1.

This site was initially considered due to its proximity to a major traffic and transit corridor: Bronson Avenue. It sits on a major north/south thoroughfare, but moreover its connectivity to Highway 417 (running east/west, just north of the site), places it at a node in the city of Ottawa's traffic network. Numerous bus routes service the stops on both sides of the street right in front of the site.

The immediate context of the site includes a small warehouse, a gas station, a small office building, and a convenience store on the east side of Bronson Avenue facing the site. Directly to the south sits a McDonald's restaurant and its parking lot, followed by older residential buildings, some of which are currently being used for commercial uses. It is bordered on the west by the concrete wall of a parking 
structure serving a seven-storey apartment building. Two-storey houses line Plymouth Street to the north, and further, across the street sits the slender two-storey Keller-Williams Realty office building.

The greater context of this site includes primarily residential neighbourhoods. On the east side of Bronson is an up-scale residential enclave of the Glebe whose treelined streets and well-aged homes have enjoyed ongoing gentrification over the last thirty years. Bronson Avenue represents the accepted western border of the Glebe, and immediately across the road the housing stock is generally of a lesser quality and value. Along both sides of Bronson Avenue to the north of the site, as it continues toward the downtown central business district, buildings of mixed use (primarily commercial) face the roadway, while housing stock of various sizes can be found immediately behind. Refer to Image 3.1 .5 which describes the building usage in the area around this site.

The second reason for considering this site was its economic profile. It was hoped that its location just outside of the Glebe would make it less economically valuable (and thus, more economically feasible for development) than other available sites in the downtown core. Not far south on the same side of Bronson Avenue, a recent project is offering high-end condominium units in a mid-rise building. The Powell Lofts / Glasgow development is built on the site of an old school and schoolyard. Doug Casey of Charlesfort Developments purchased this property at a reduced price because of its location on the unfavourable side of Bronson Avenue. The project is nearly completed, and its units are selling at a premium price because of their sheer proximity to the Glebe. ${ }^{7}$ Could the same strategy be proposed for this site 
only a few blocks north? The exact value of this 2,657 square meter property cannot be accurately ascertained because no mortgages are currently held on the property, ${ }^{8}$ and the City of Ottawa assessment roles do not accurately reflect the true market value of a property. ${ }^{9}$ However, the extrapolated value of the adjacent site can be discussed for comparison purposes. Being of similar size, the site upon which the McDonald's restaurant now sits is comparable because it has street frontage, equivalent zoning requirements, and an equivalent contextual setting. That property changed hands in 1979 for $\$ 750,000{ }^{10}$ and at an average (although fairly conservative,) real-estate inflation rate of $2 \%$ per year for 25 years, the same site today would be worth almost $\$ 1.25$ million. Assuming the same inflation rate, the open site beside the McDonald's could (by proportion) sell for as much as $\$ 1,650,000$ due to its larger size and the fact that it is a corner lot that allows for frontage and access on both Bronson Avenue and Plymouth Street. Although this comparative reasoning can only produce an approximation, it does illustrate how valuable the site is to its owners, Imperial Oil of Canada Inc., and how misrepresentative the city's assessed value can be. Chart 3.1.21 compares assessed values, extrapolated values, and mortgage values for all the properties being studied. This site seemed promising because in terms of square footage, this site is the largest of the four considered, and hence it could fit a greater number of units making it more valuable from a development point of view. At the same time, the zoning designation applied to this parcel of land encourages multi-use building types, which is the type of development this thesis project argues for. Site \#1 is in a CG zone, which is described in the City of Ottawa's Zoning Bylaw as a "General Commercial Zone." The purpose of the CG 
zone is to allow development that will maximize the compatibility of residential and commercial uses by imposing standards that control the negative impact of commercial buildings. ${ }^{11}$ According to the by-law, numerous residential uses are permitted on this site, in direct adjacency with commercial uses. However, only certain types of commercial uses like small retail stores, small offices, and restaurants are allowed.

Site \#1, at the intersection of Bronson Avenue and Plymouth Street satisfies many of the criteria as a 'sufficiently urban' site. It is highly connected to both traffic and public transit. It also sits in a part of Ottawa that already has a dense fabric of residential and commercial building types, and the surrounding neighbourhoods themselves (the Glebe, Chinatown and Little Italy) already have their own established characters.

This particular site on Bronson Avenue was not chosen because it was too expensive and could not allow for the goal of 'affordability.' Although its location outside of the area known as the Glebe was expected to reduce its economic value, it could not be proven that this was the case. 


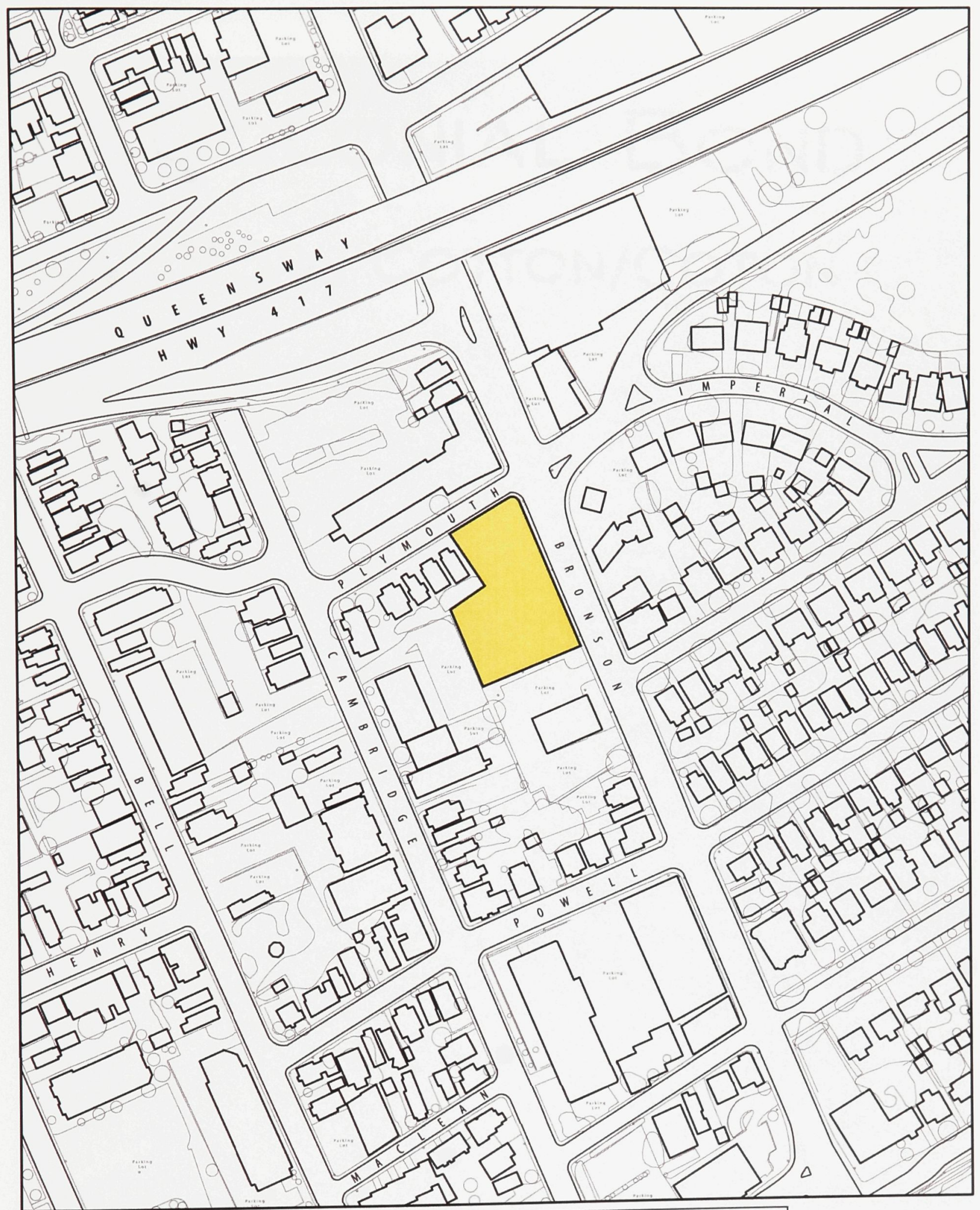

SITE \# 1 southwest corner of Bronson Ave, and Plymouth st. 


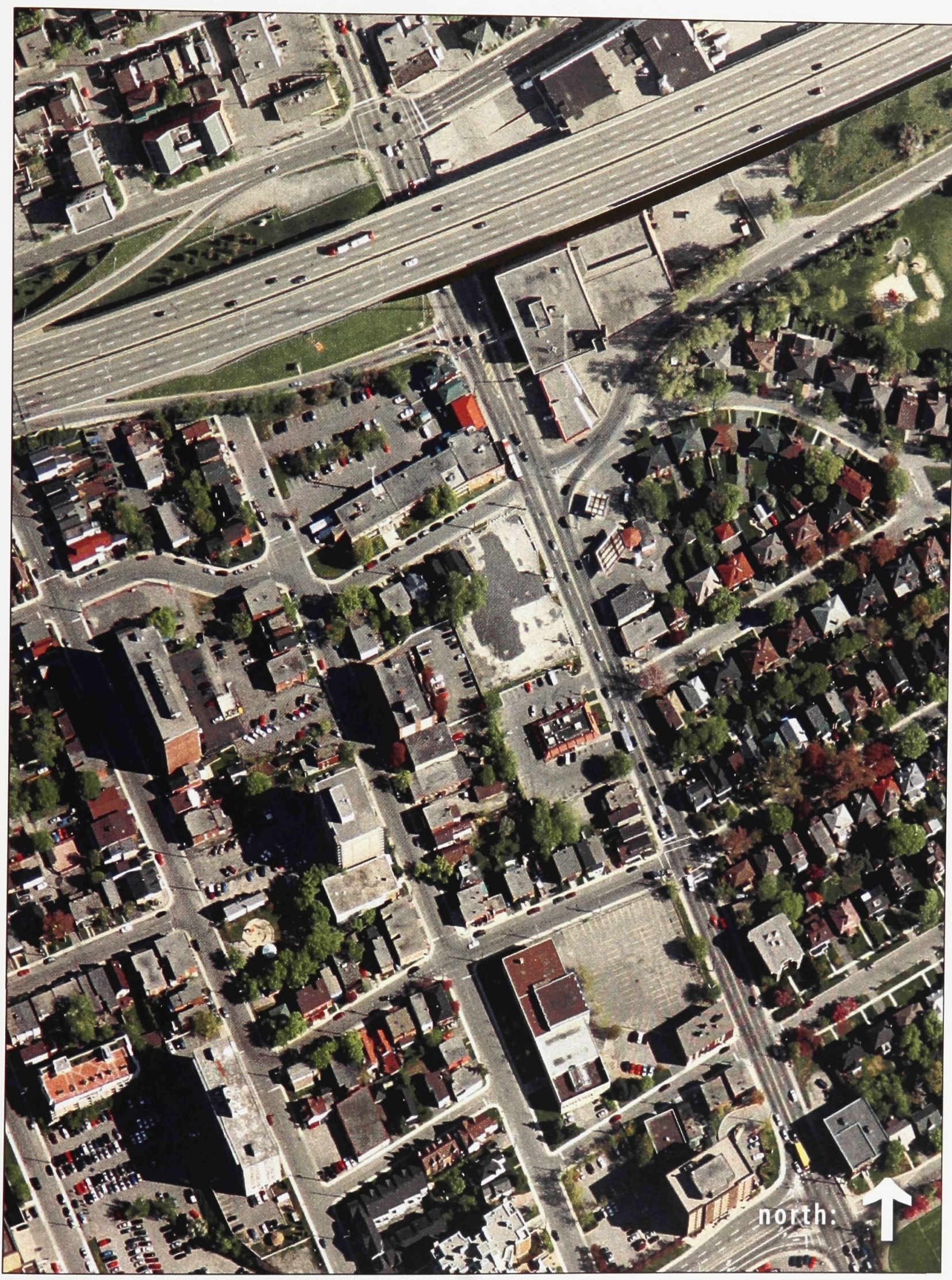

Image 3.1.4 Aerial photograph of site \#1. 
63

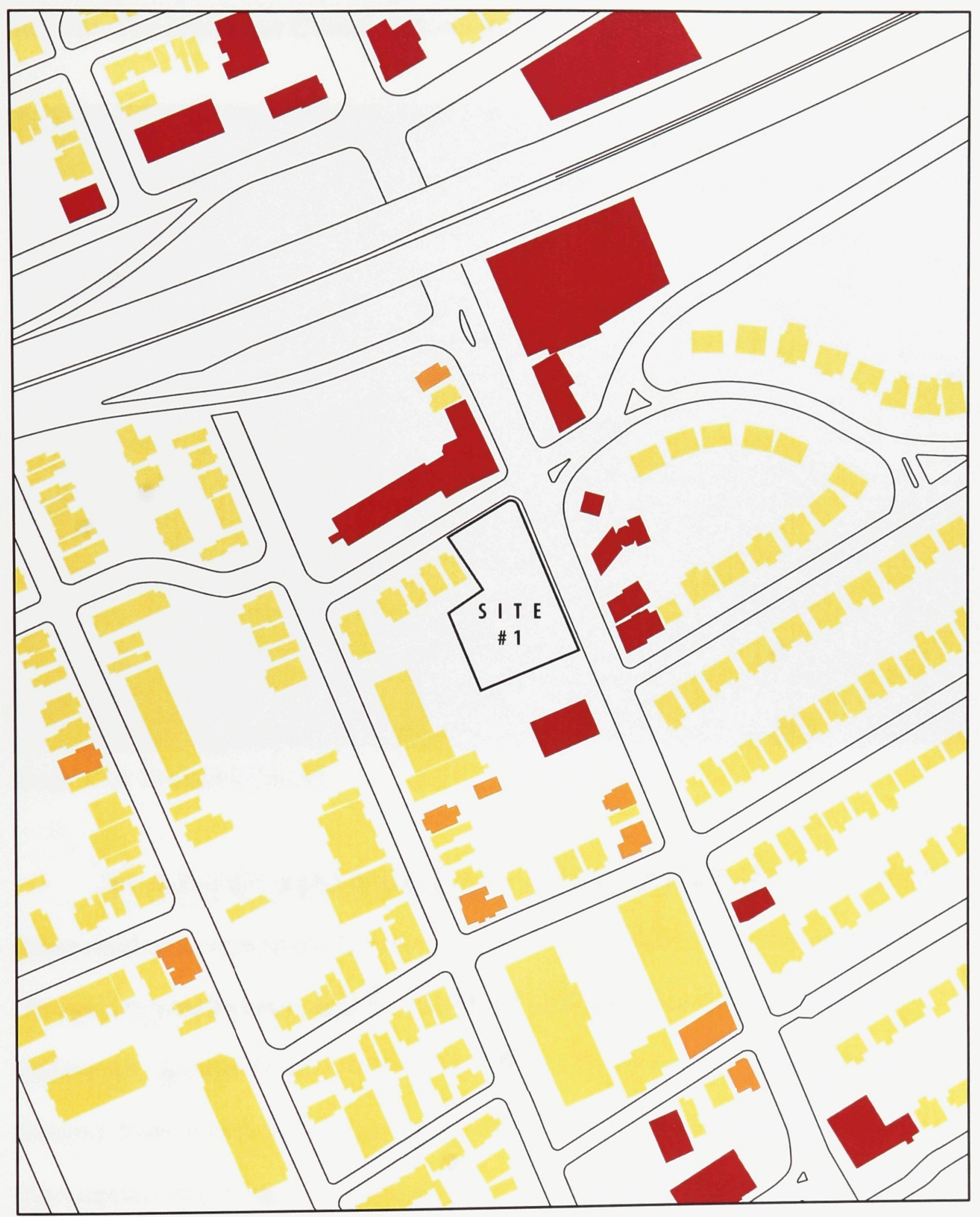

SITE \# 1 USAGES LEGEND:

scale: $1: 2750$

RESIDENTIAL

houses, mid and

high-rise

apartment blags.
MIXED -USE

(all blags. with

commercial AND

residential uses.)
COMMERCIAL

retail, warehouse,

restaurant and

office blags.
INSTITUTIONAL

educational, health-

care and religious

blags.

Image 3.1.5 Building program type diagram for site \#1. 


\section{Site \#2: The Northeast Corner of Somerset Street and Cambridge Street.}

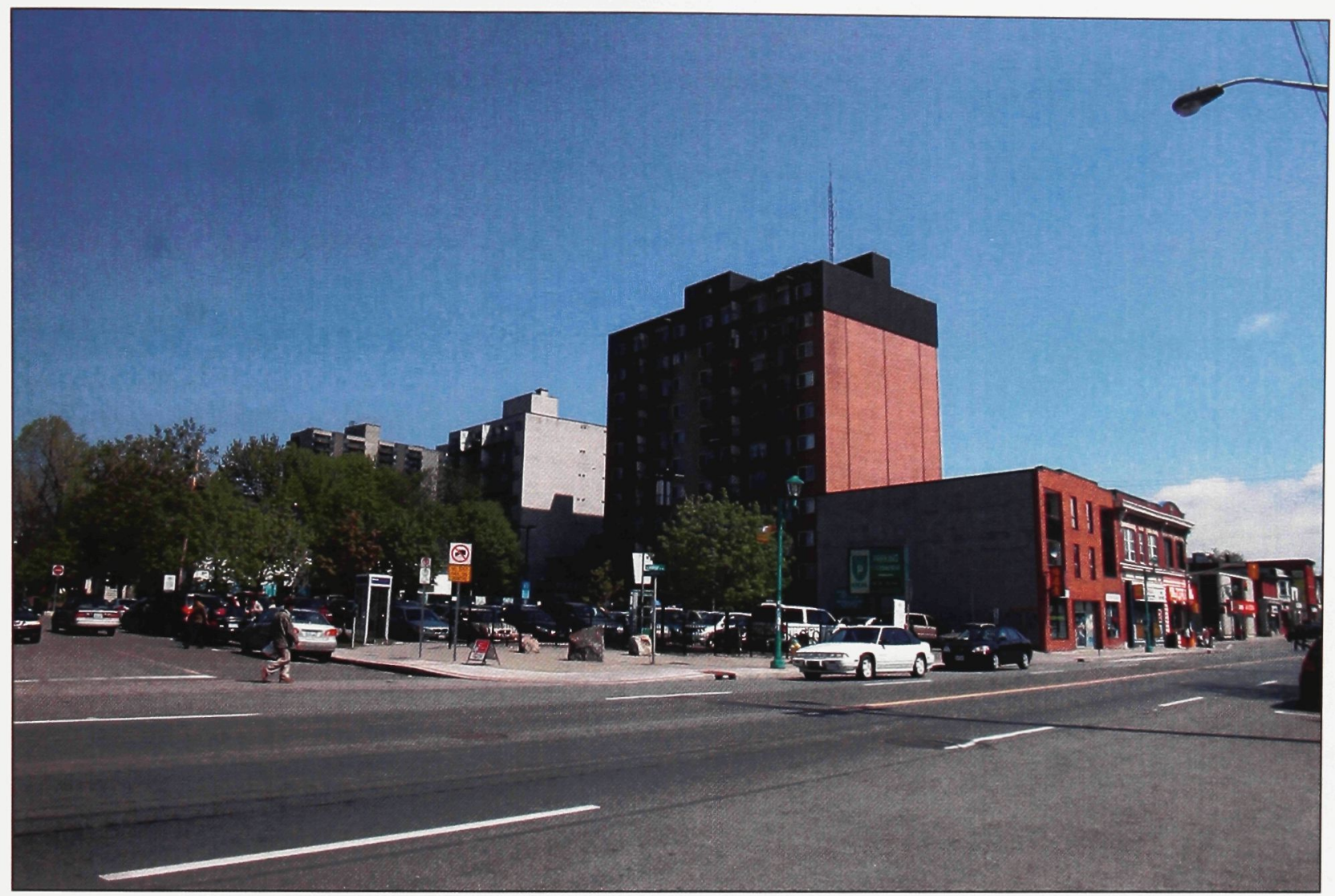

Image 3.1.6 Photograph of site \#2.

The second site under consideration for this project is in 'Chinatown,' a highlydense residential and small-scale commercial neighbourhood that is southwest of Ottawa's central business district. The site is currently a municipally owned payparking lot. Similar to site \#1, this property also sits on a major traffic corridor. Somerset Street, which runs east and west, is a part of the Somerset/Richmond Road thoroughfare that traverses central and western Ottawa. At this point on Somerset Street, Bronson Avenue is only one block to the east, making it close to a major north/south arterial road. The immediate context includes commercial buildings of low-rise on the east, across the street to the west, and also across the street to the south. Immediately to the north, two-storey houses line both sides of Cambridge 
Street which allows only southward traffic north of the site. Similar to site \#1, the larger context is inclusive of dense residential housing stock. Some institutional buildings (religious facilities, community buildings, and healthcare facilities) can also be found in the area.

This site seemed appropriate for a few reasons: first, in the quest for a 'sufficiently urban' site, the highly-dense and heterogeneous makeup of this particular pocket of the city was positive. Also, when considering current real-estate values of the residential buildings in the area, this seemingly became an affordable place to live in comparison with other parts of central Ottawa. As such, there was hope that the actual value of this site would be low enough for it to be feasible from a development point-of-view. Although the site is much smaller than some of the others, $(1,625$ square meters $)$ it has street frontage on two full sides. This would make the offering of commercial retail space on the ground floor facing both Somerset and Cambridge Streets a possibility.

Site \#2 proved to be an unrealistic choice. The first reason is that it is not in fact a cheap piece of property; the second reason has to do with its zoning requirements. Even though it is assessed at $\$ 174,000$ by the City of Ottawa, the most recent mortgage value (1991) was $\$ 1,600,000$. Oddly, the purchaser was the Corporation of the City of Ottawa. This site's extrapolated value today is over $\$ 2,000,000$. This would make this the most costly site per square foot, and any development other than high-rise, high-yield condominiums would not be economically feasible. Also, when examining the zoning associated with this parcel, it was determined that it is actually subdivided into two different zones. The first 
half of the site, closest to Somerset Street, is zoned for commercial uses, while the rear of the site, abutting Cambridge Street, is zoned for residential. At the surface, this would seem to support this project's goal of a multi-use building; however, these zoning requirements only complicated the idea. Each of the two zonings do not allow mixed-use buildings, which meant that each of the zones were subject to the required setbacks those zonings entail. There would be a pair of setbacks running right through the middle of the site, essentially creating two building envelopes. What began as a site of usable size became almost unusable when the required setbacks were considered because they ruled out the possibility of a single building. As it turns out, the only common allowable usage each of the zonings shared was 'parking lot,' - the site's current use. Even in the heart of Chinatown, where mixed building usages are quite common, this site is a prime example of zoning that disallows just that. 


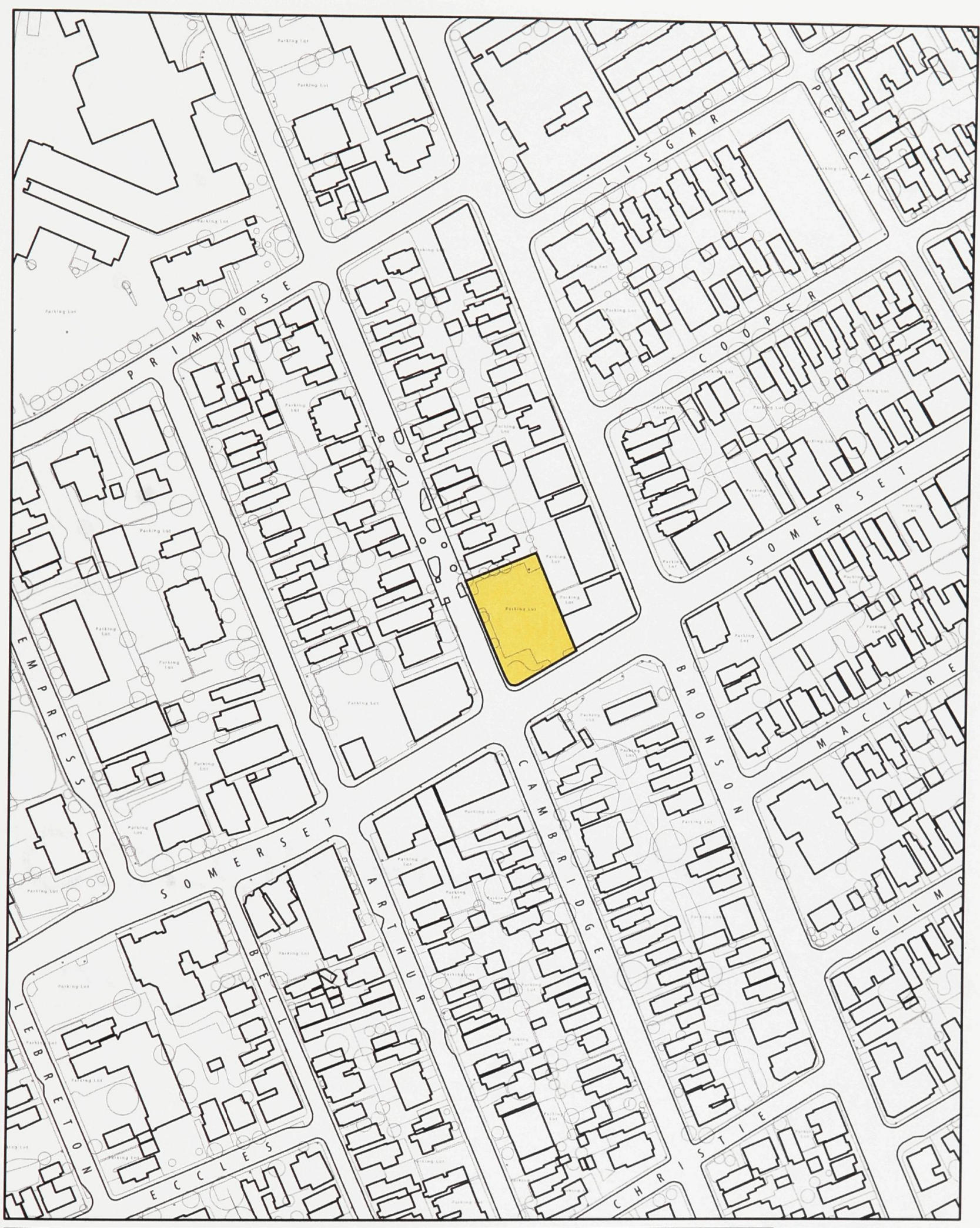

SITE \# 2 Northeast corner of cambridge st. and somerset st. 


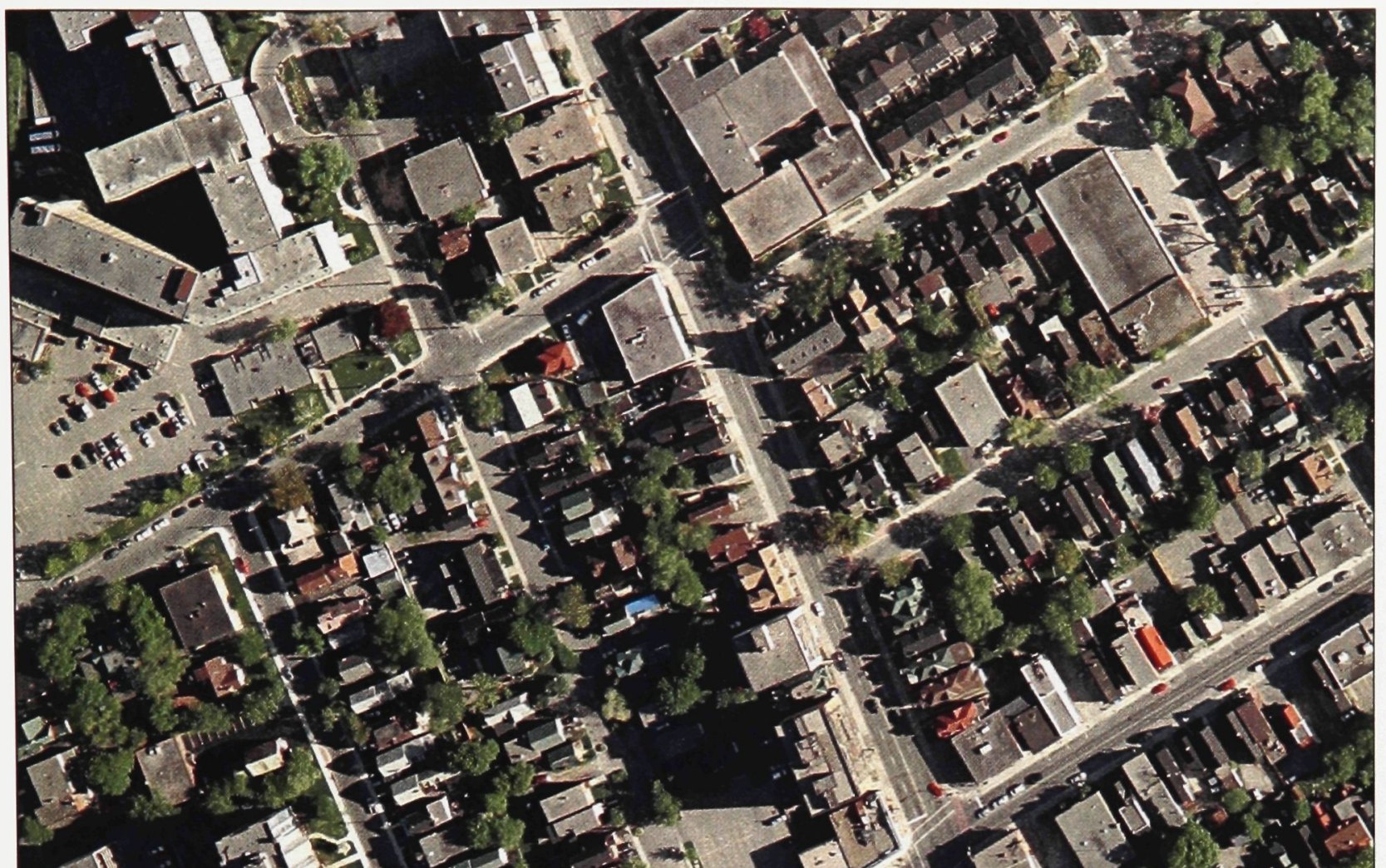

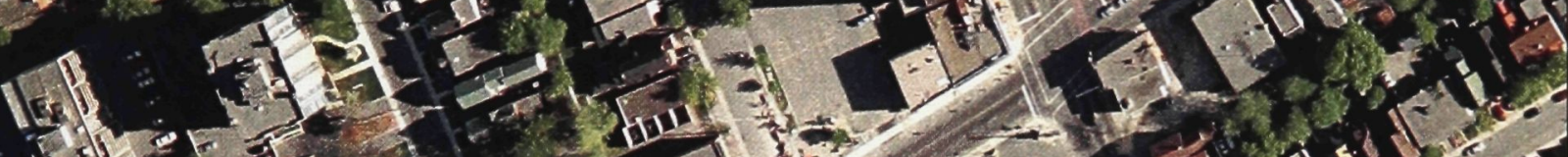

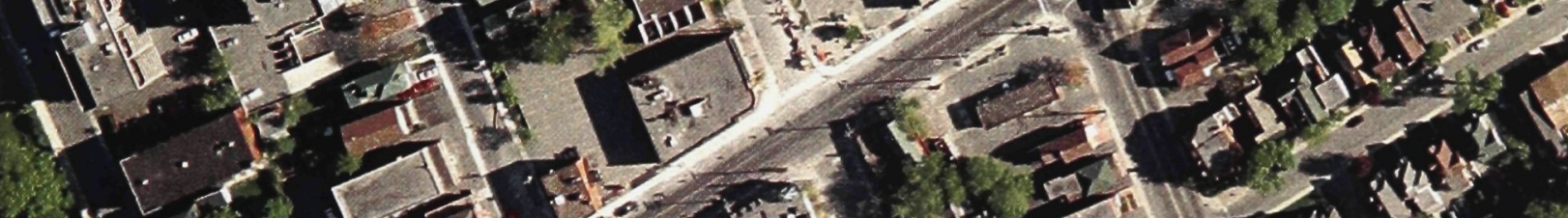

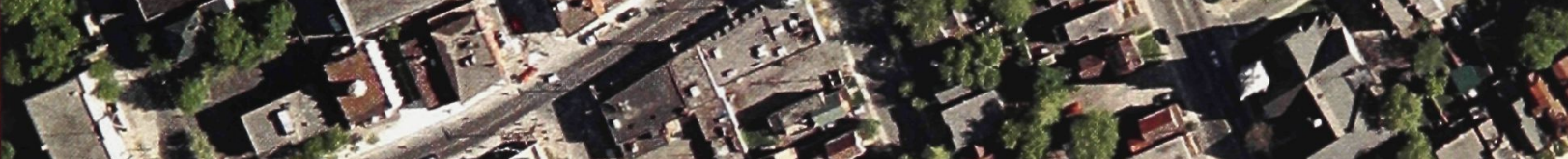

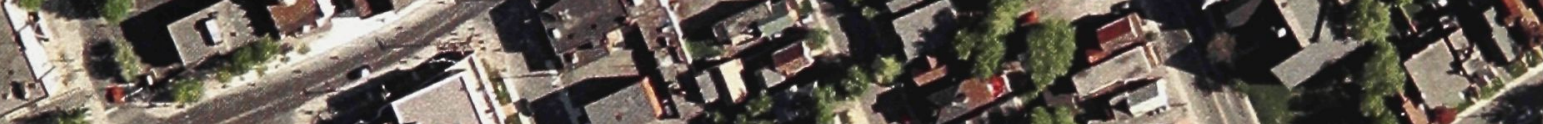

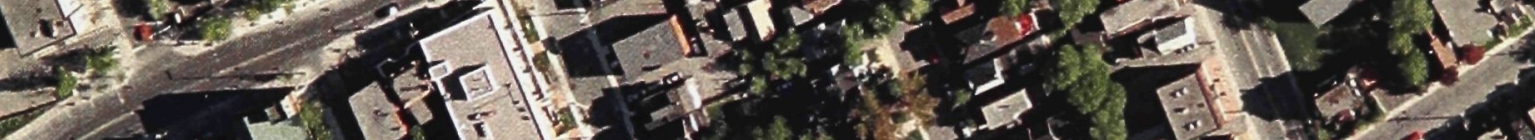

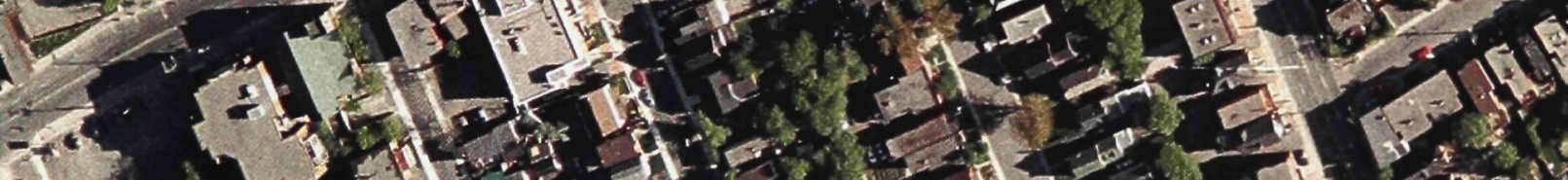

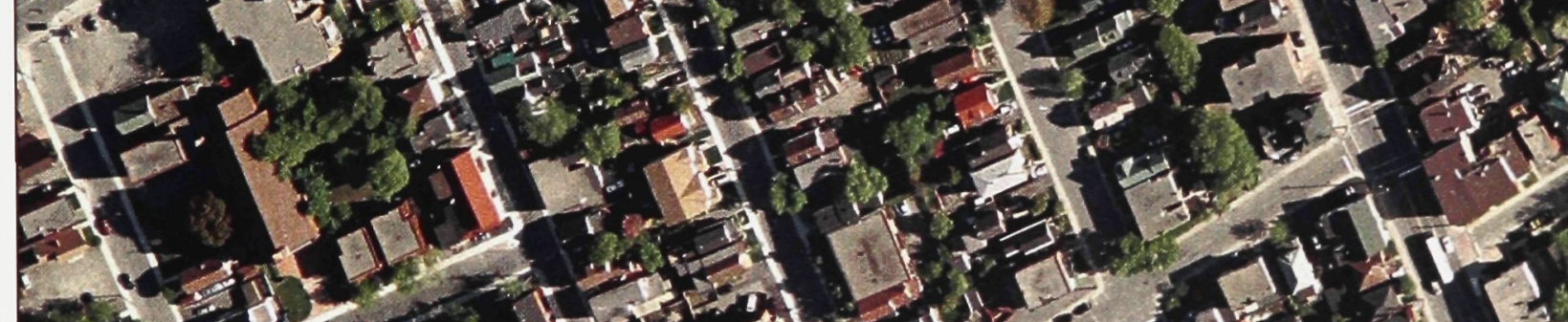

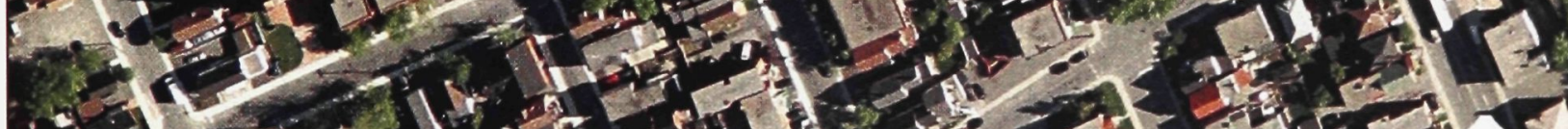

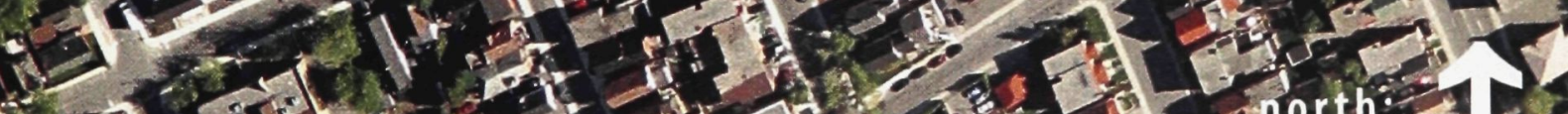

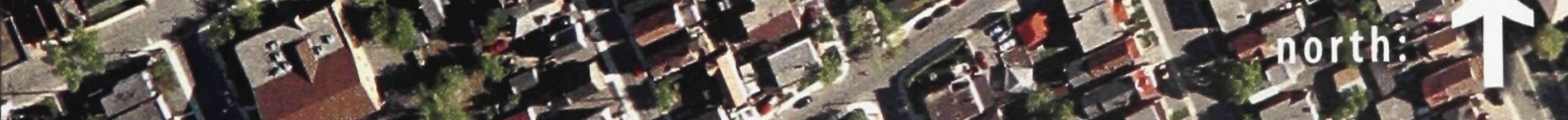

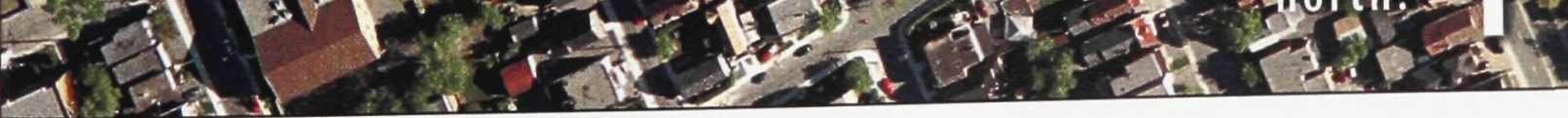

Image 3.1.8 Aerial photograph of site \#2. 


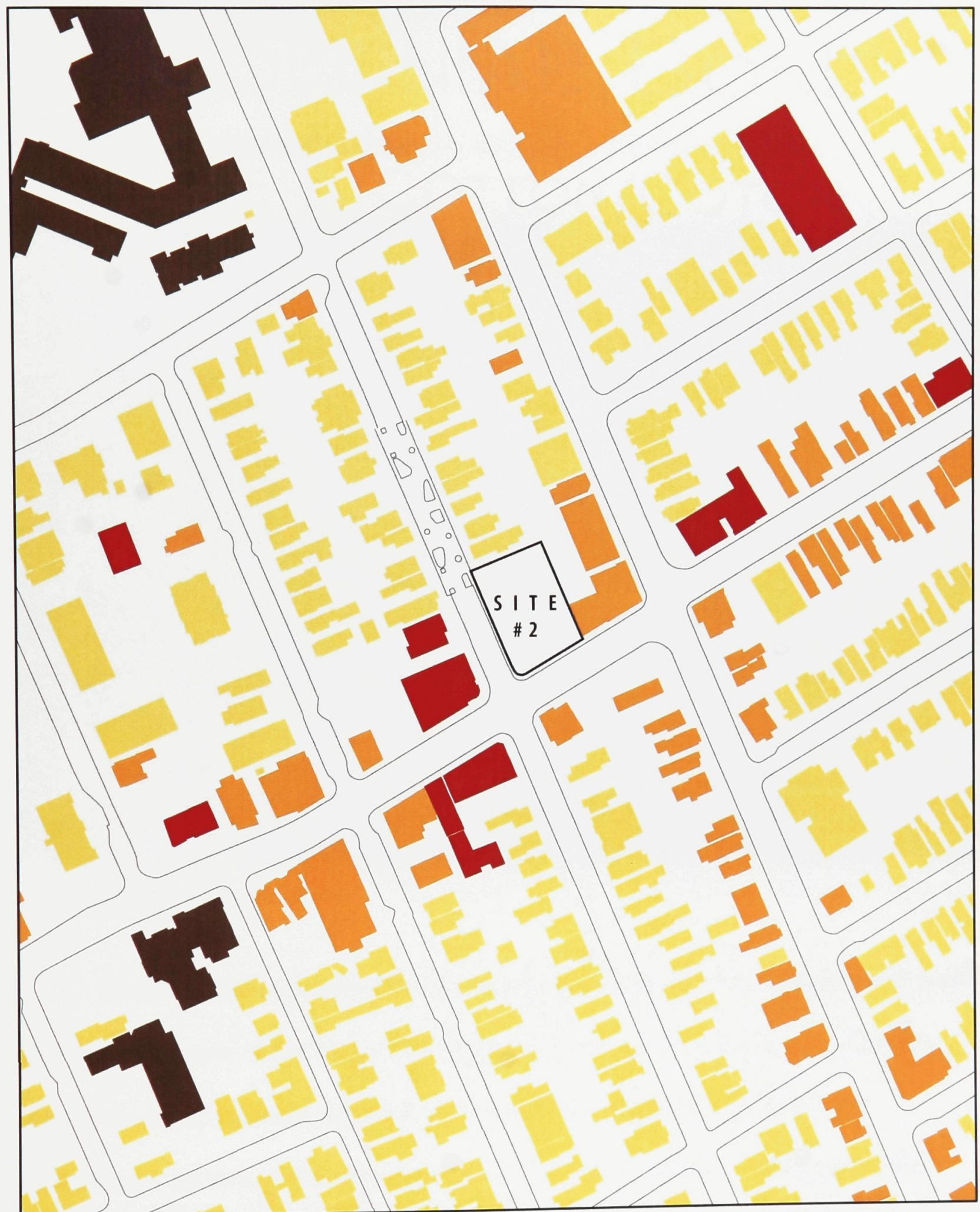

\begin{tabular}{|c|c|c|c|c|}
\hline SITE \# 2 & LEGEND: B U & ING USAGES & & \\
\hline scale: $1: 2750$ & $\begin{array}{l}\text { RESIDENTIAL } \\
\text { houses, mid and } \\
\text { high-rise } \\
\text { apartment bldgs }\end{array}$ & $\begin{array}{l}\text { MIXED-USE } \\
\text { (all bIdgs. With } \\
\text { commercial AND } \\
\text { residential uses) }\end{array}$ & $\begin{array}{l}\text { COMMERCIAL } \\
\text { retail, warehouse, } \\
\text { restaurant and } \\
\text { office bldgs }\end{array}$ & $\begin{array}{l}\text { INSTITUTIONAL } \\
\text { educational, health } \\
\text { care and religious } \\
\text { bldgs }\end{array}$ \\
\hline
\end{tabular}

Image 3.1.9 Building program type diagram for site \#2. 
Site \#3: The Northwest Corner of Somerset Street and Metcalfe Street.

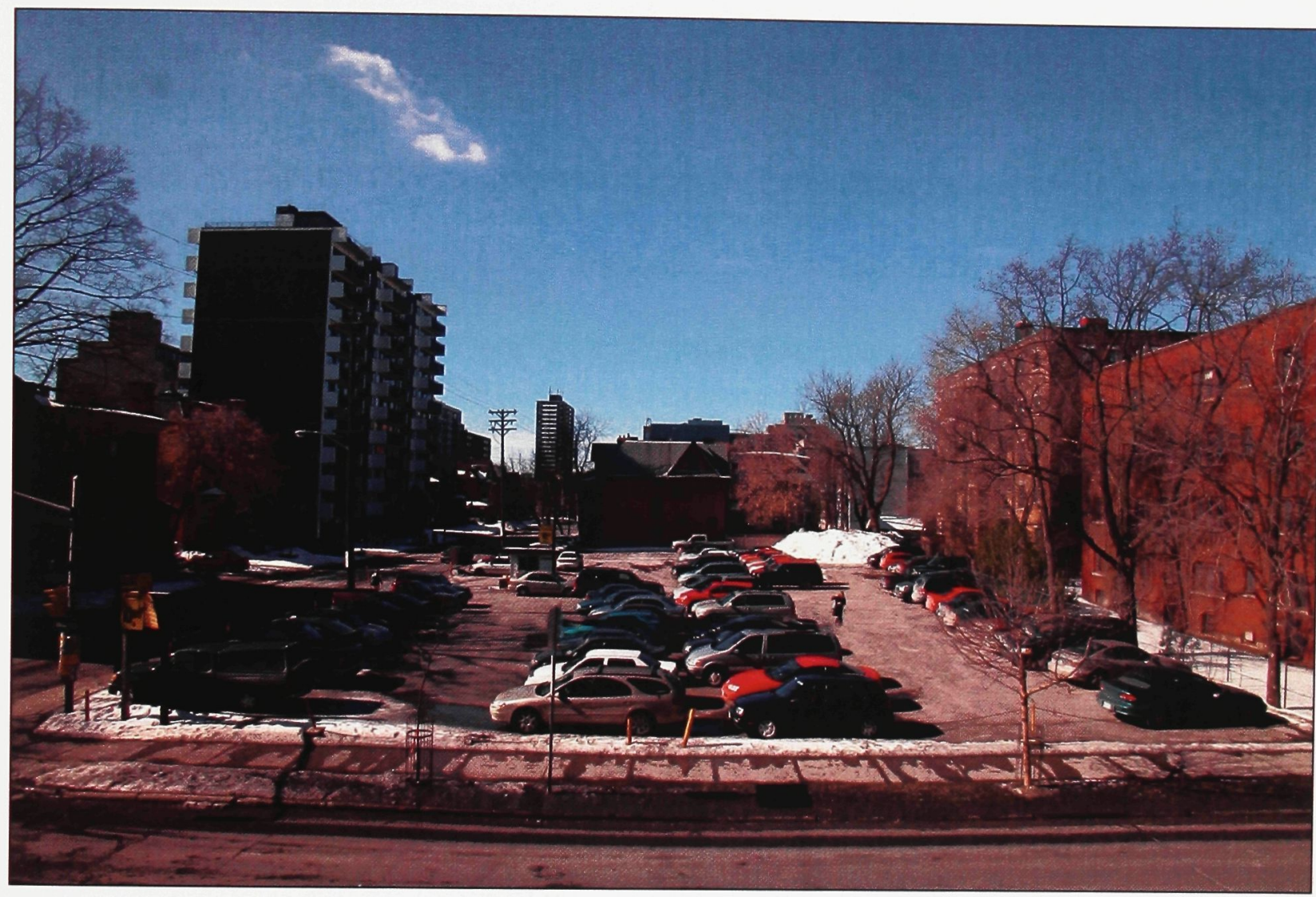

Image 3.1.10 Photograph of site \#3.

The third site considered for this thesis sits on the northwest corner of Metcalfe and Somerset Streets in the heart of Centretown Ottawa. The main appeal of this site was primarily its location, although its considerable size was also important.

Centretown is an area of the city that sits to the south of Ottawa's central business district and north of the residential area known as the Glebe. A number of major east/west arterial roads pass nearby including the Queensway (highway 417) and Somerset Street. It is bordered on the east by the Rideau Canal and on the west by Bronson Avenue. Centretown is a large area of downtown Ottawa and many of the 
north/south roadways that run through it are considered major, such as Bank, Metcalfe and Elgin Streets. In this particular area, the primary building usage is residential, although many commercial uses are present. The intersection of Metcalfe and Somerset lies at a half-way point in the transition from the high-rise buildings of the central business district, to the low-rise buildings of the rest of Centretown. The immediate vicinity includes some two-storey houses and apartments to the west of the site and two apartment buildings of four and five storeys adjacent to its north edge. Across the street to the east stands a twelve-storey apartment and office building with commercial space along the entire ground floor. To the south, one twelve-storey apartment building and several two-storey houses are being used as offices, homes, and a restaurant. According to the Land Registry Office at the City of Ottawa courthouse, this site currently has a mortgaged value of $\$ 950,000$. This value is dated in 1999 , which brings the extrapolated current value of this property to approximately $\$ 1,100,000$. This value is deceptive because the transaction values have fluctuated over the last few transactions and the property is now leined. Based on the value of homes and condominium units in the area, this part of Centretown is more expensive than other areas of the city. This neighbourhood, along with the Glebe, and the area on the eastern side of the Rideau Canal are commonly referred to as the 'Golden Triangle' by real estate agents for its lucrative nature, and this stigma puts pressure upon the development of open sites in this part of the city.

At this site on Somerset Street, there was a recent development proposal to build an eighteen-storey condominium building. The proposal was rejected by the City of Ottawa because it violated the height restrictions, and the project seems to 
have been stalled. ${ }^{12}$ This proposal does however point to the economic reality of development on downtown sites like this one; only a high-yield development will produce enough profit for the owner/developer. Although a four storey, low-rise apartment building is what the municipal zoning requires for new development on this site, a much higher-yield building project is required to make a reasonable development profit. The site is zoned 'R5D' which is described as a Low-Rise Apartment Zone, and only a handful of commercial uses are permitted under strict conditions.

The situation described above meant that this site had constraints that made it impractical for this project. It qualified as being sufficiently urban in that its location is highly connected to transit and major traffic corridors. There are buildings of all major usages in the area, as shown in Image 3.1.14, and they are of low, medium, and high-rise profile. This site is in the heart of a major residential neighbourhood, but it's also in close proximity to the Ottawa's institutional and governmental area at Parliament Hill, as well as other tourist destinations like the ByWard Market.

However, the economic pressures of development at this location, despite its current mortgage value, make it economically impossible to build anything other than a high-rise building. Furthermore, the zoning restrictions disallow multi-use buildings and buildings higher than four storeys. Even if this thesis project were to ignore these restrictions, the economic pressures of development on this site are at odds with the goals of this project because a high-rise type of building makes it difficult to express any notion of suburban living. In the immediate context around the site, although commercial uses are present in the neighbourhood, there are not many buildings of mixed-use and the current city zoning outlaws it altogether on this site. 


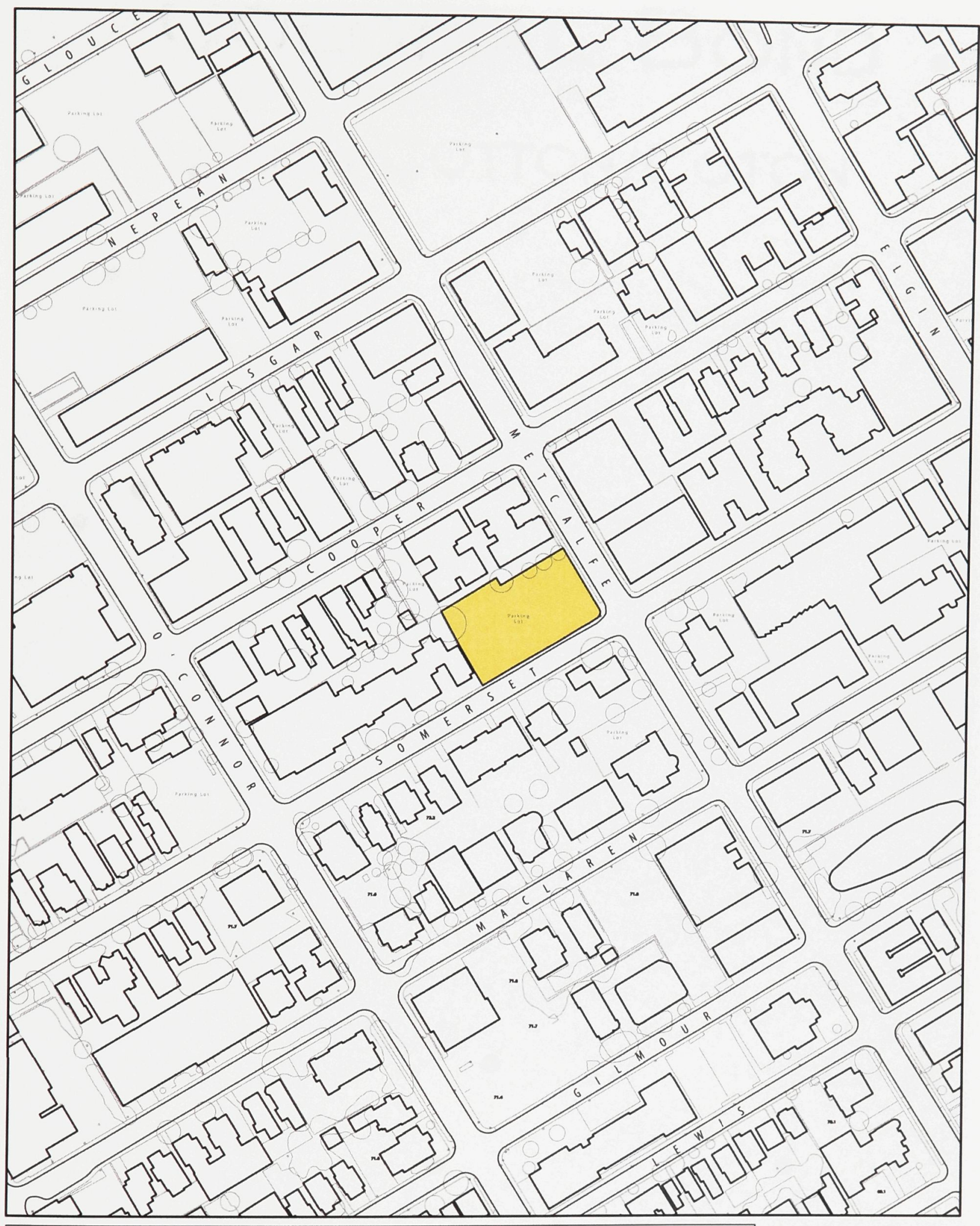

SITE \# 3 Northeast corner of Metcalfe st. and somerset st.

scale: $1: 2750$

north:

Image 3.1.12 Site plan of site \#3. 


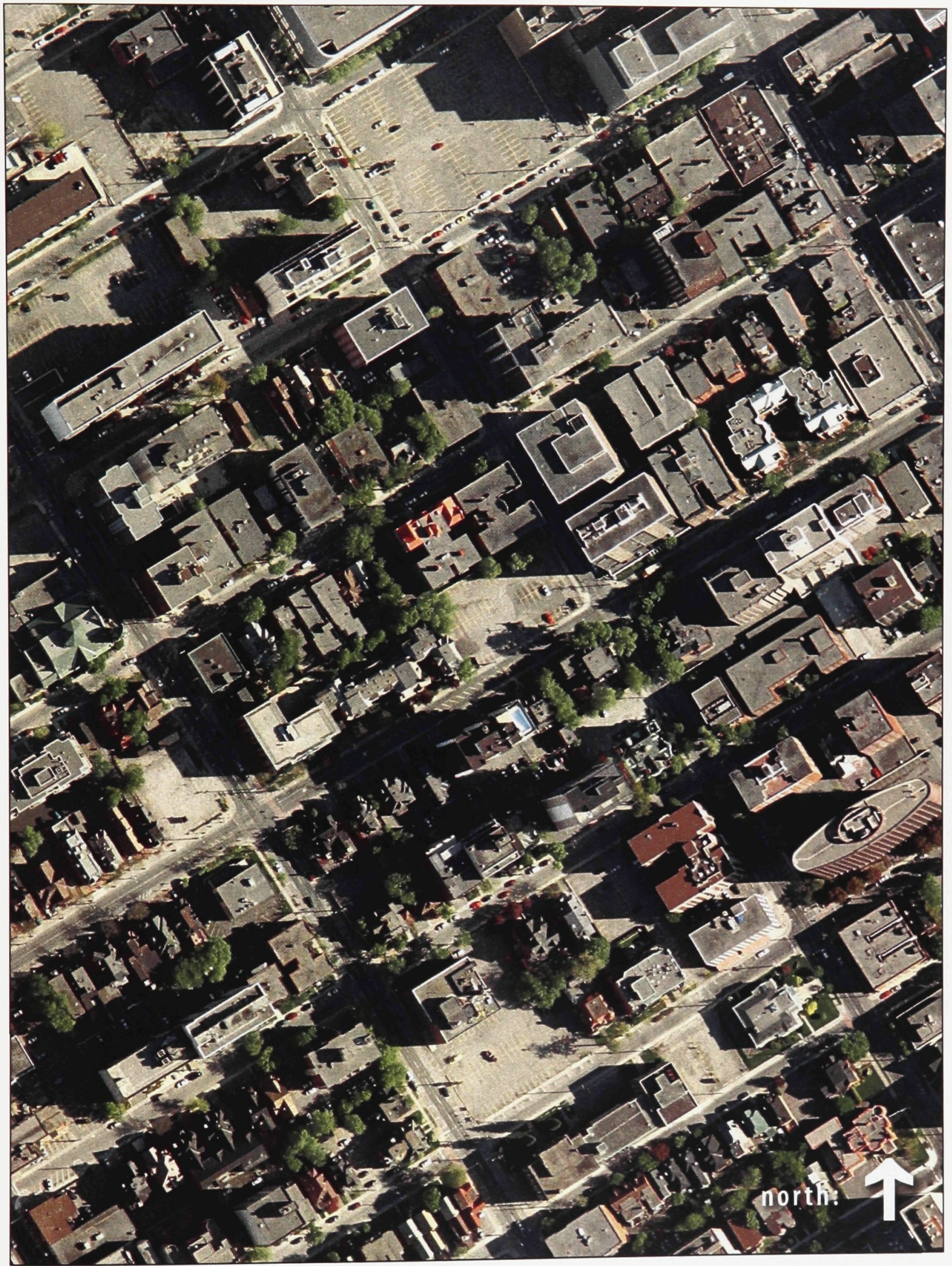

Image 3.1.13 Aerial photograph of site \#3. 


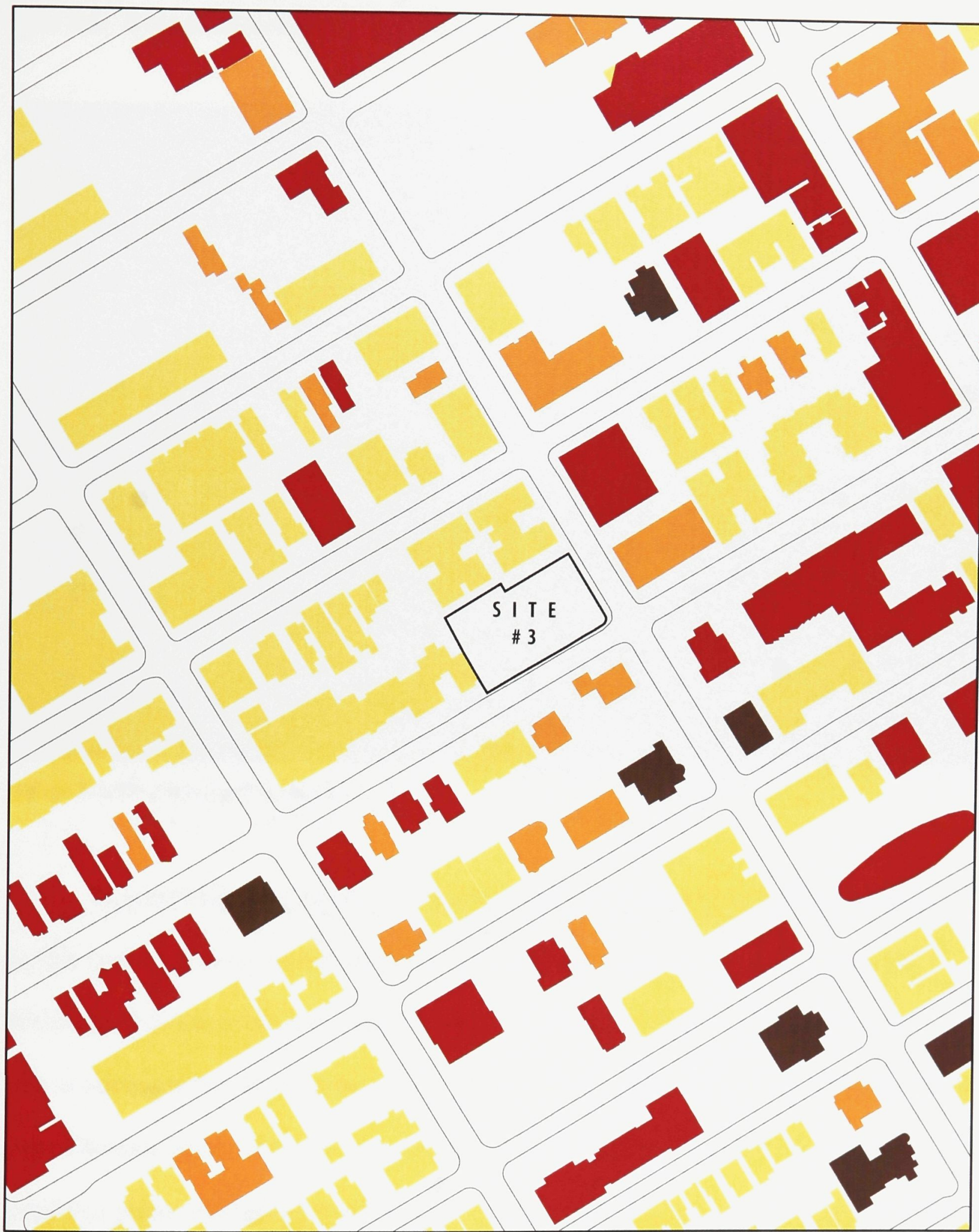

\section{SITE \# 3}

scale: 1:2750

north:

\section{LEGEND: BUILDING USAGES}

RESIDENTIAL

houses, mid and

high-rise

apartment bldgs

\section{MIXED-USE}

(all bldgs. with

commercial AND

residential uses)
COMMERCIAL

retail, warehouse, educational, health-

restaurant and

office bldgs
INSTITUTIONAL

care and religious bldgs

Image 3.1.14 Building program type diagram for site \#3. 


\section{Site \#4: Rideau Street between Cobourg Street and Charlotte Street}



Image 3.1.15 Photograph of site \#4.

In searching for a vacant site whose immediate context would be conducive to this type of project, numerous sites were rejected because they were too small. Although this site is not the largest of the four shown here, its 2,553 square meter size is adequate for development. Site \#4 is located at the eastern end of Rideau Street near Charlotte Street. Behind the retail uses that line either side of Rideau Street up until this point, residential buildings of all types fill the neighbourhoods to the north and south. Immediately adjacent to the site on the east, is a five-storey office building. To the west, two old houses are now being used as restaurants. The larger context includes a large public park (McDonald Gardens Park) to the north, the Rideau 
River to the northeast, as well as various institutional buildings throughout. However, the primary usage in the area is residential.

Like the others sites already discussed, the assessed value of site was less than its mortgaged value. It was assessed by the City of Ottawa in 2004 at $\$ 603,000$ even though it changed hands in August of 2003 for $\$ 1,075,000 .{ }^{13}$ This mortgage value, by extrapolation, assuming a $2 \%$ increase in value per year, would give an approximate value today of $\$ 1,120,000$. This is roughly the same value as site \#3, and this site is about 370 square meters larger, making it the most cost-efficient of all four sites.

Rideau Street is a major east-west traffic corridor, and it connects the downtown central business district to the neighbourhoods of Vanier and Rockcliffe as it passes over Cummings Bridge. Rideau Street is also the eastern extension of the Wellington Street promenade, which is Ottawa's major institutional strip, home to Parliament Hill, numerous embassies, galleries, and other federal buildings. This site also qualifies as 'sufficiently urban' because of its frontage on Rideau Street as a part of one of Ottawa's major commercial corridors. Many major routes of OC Transpo's bus lines use Rideau Street as well. 


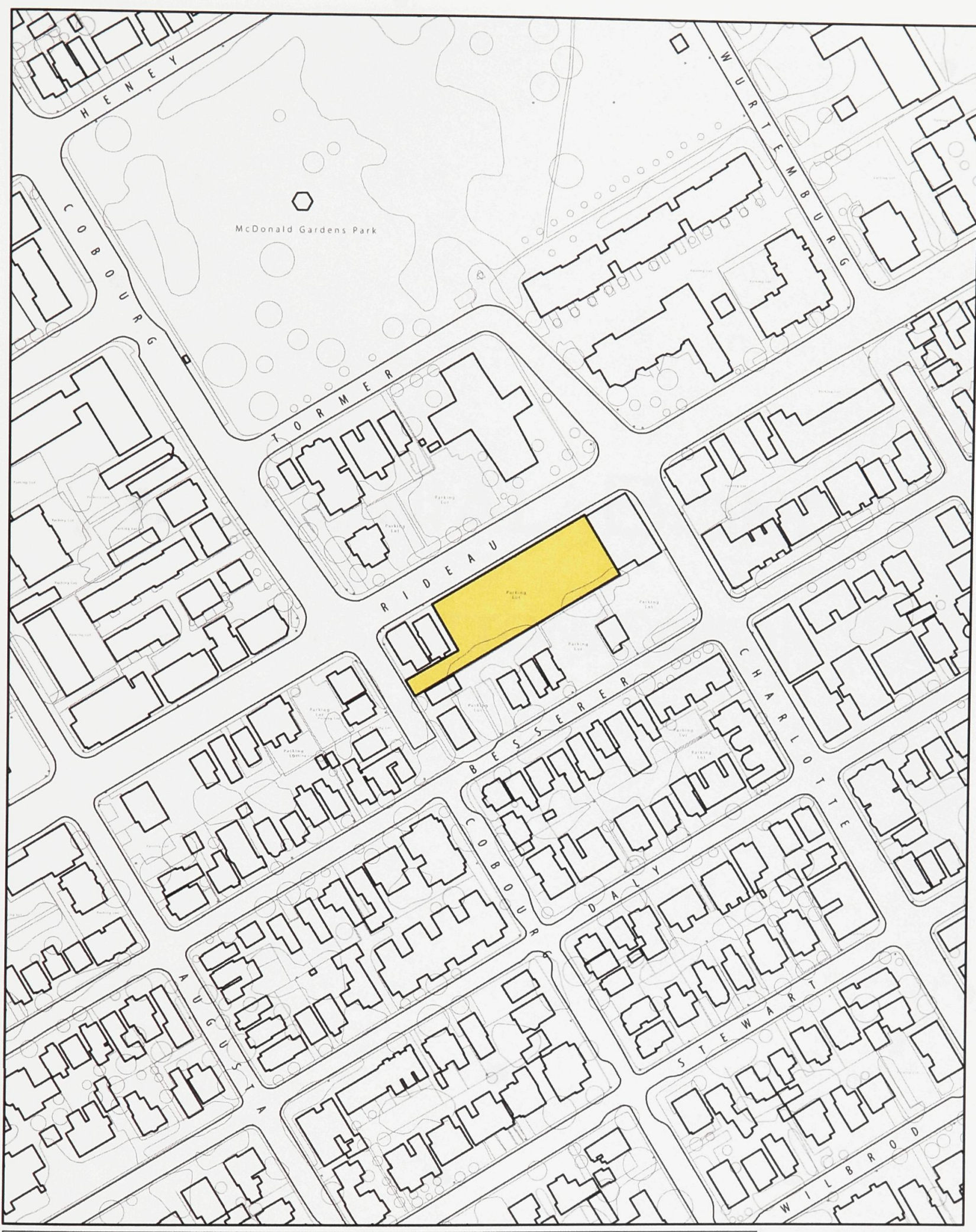

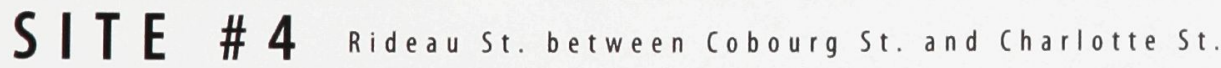

scale: 1:2750

north:

Image 3.1.16 Site plan of site \#4. 


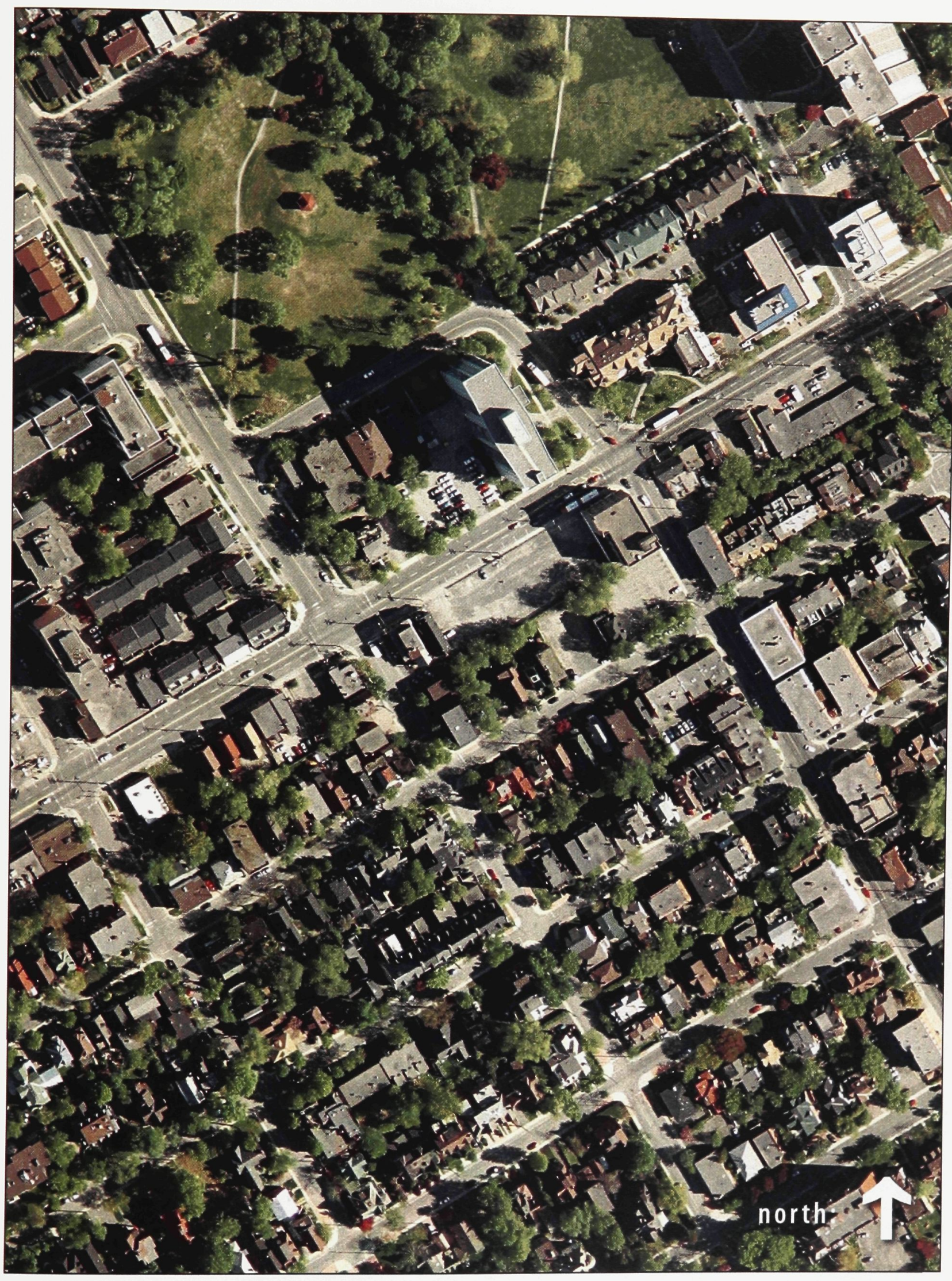

Image 3.1.17 Aerial photograph of site \#4. 


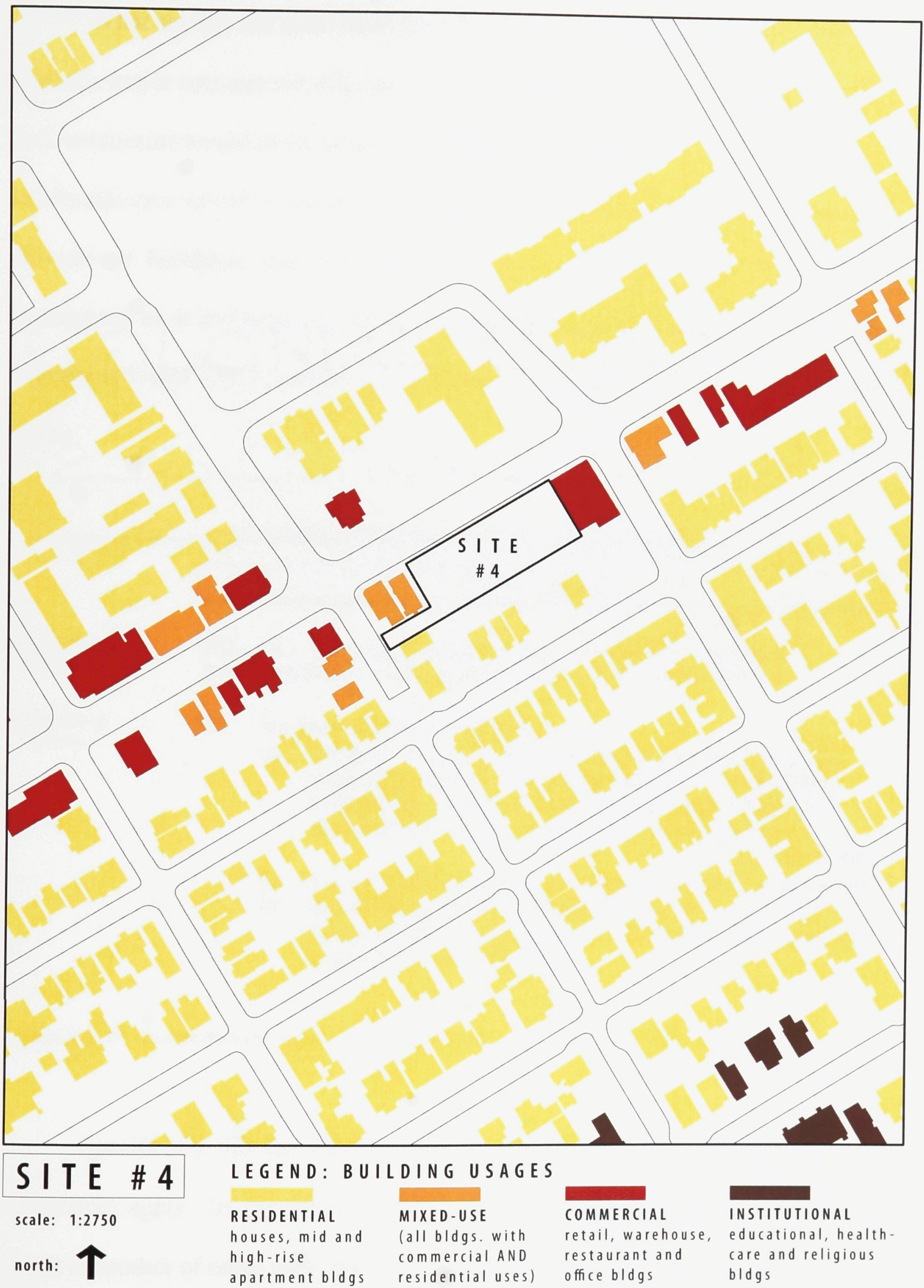

Image 3.1.18 Building program type diagram for site \#4. 
What set this site apart from the others was its zoning designation. Being a part of a major commercial strip meant that while various commercial uses (retail and restaurant) would likely be permitted under the zoning; it was unlikely that residential uses would be feasible. However, the zoning by-law is very encouraging of multi-use buildings, and even has a stipulation for 'amenity space' that must accompany each dwelling unit should residential space be a part of the development. The site is zoned ' $\mathrm{CN}-\mathrm{T}$ ', and an excerpt from the description of a $\mathrm{CN}$ zone is provided below:

CN - NEIGHBOURHOOD LINEAR COMMERCIAL ZONE AND SUBZONES

CN ZONE
$\begin{aligned} & \text { CN zone } \\ & \text { created }\end{aligned}$
$\begin{aligned} & \text { Purpose of } \\ & \text { the zone } \\ & \text { hereby established as the Neighbourhood Linear Commercial Zone. }\end{aligned}$
(2) The purpose of the CN zone is to,
(a) encourage a mix of commercial uses in a visually continuous
small-scale, street-level building form in areas designated as
[By-Law 5-2000]
(b) $\begin{aligned} & \text { Character Area of the central area in the Official Plan; } \\ & \text { (c) impose site regulations and development standards that will } \\ & \text { ensure that the commercial uses do not impinge on adjacent uses, } \\ & \text { or upon local residential uses. }\end{aligned}$

Image 3.1.19 Excerpt from the City of Ottawa's Zoning By-Law, PART VII 'Commercial Zones.'

Specifically, this site is designated as a $C N-7$ sub-zone where certain additional restrictions apply. In any $C N$ zone, various commercial uses are listed as permissible, as are number of other uses, given that they occur above the ground floor and that the ground floor be entirely occupied by one of the permitted commercial uses. 
Furthermore, in a $C N-7$ sub-zone, where a development exceeds 1858 square meters in gross floor area, at least $50 \%$ of the excess must be used as residential space. The Zoning By-Law goes on to stipulate how 'amenity area' must be provided for each dwelling unit:

Amenity space required

Outdoor space required

No obstruction allowed
315. In the CN7 subzone, amenity area must be provided for each dwelling unit at the rate of 18.5 square metres per dwelling unit.

316. One half of the amenity area required by section 315 , must be provided as outdoor amenity area.

317. The outdoor amenity space required by section 316 , must not be covered by any man-made object, and must be open to the sky.

Image 3.1.20 Excerpt from the City of Ottawa's Zoning By-Law, PART VII 'Commercial Zones.'

This is obviously one of the few zoning designations where multiple uses are encouraged, and the continuity of the neighbourhood character (commercial) is protected. Furthermore, the added requirements described in the $\mathrm{CN}-7$ sub-zone seem to describe a medium-density type of urban development where amenity space and exterior spaces for dwellings are actually promoted, not prohibited. The zoning of this site as a 'Neighbourhood Linear Commercial Zone' also makes the site more useable because side setbacks are greatly reduced, thus the allowable building footprint is considerably larger. 


\begin{tabular}{|c|c|c|c|c|c|}
\hline $\begin{array}{c}\text { SITE COMPARISON } \\
\text { CHART }\end{array}$ & $\begin{array}{l}\text { AREA } \\
\text { (sq. m.) }\end{array}$ & $\begin{array}{l}\text { ASSESSED } \\
\text { VALUE* }^{\star} \\
\text { (as of 2004) }\end{array}$ & $\begin{array}{l}\text { MORTGAGED } \\
\text { VALUE } \\
\text { (as of most recent } \\
\text { transaction) }\end{array}$ & $\begin{array}{l}\text { PRESENT } \\
\text { VALUE*** }\end{array}$ & $\begin{array}{c}\text { COST } \\
\text { per sq. m. } \\
\text { (present value / } \\
\text { area) }\end{array}$ \\
\hline \multicolumn{6}{|l|}{ SITE \# 1} \\
\hline $\begin{array}{l}\text { Plymouth St. \& Bronson Ave. } \\
\text { zONING NOTES: } \\
\text { "CG" General Commercial Zone } \\
\text { - Various commercial uses are permittec } \\
\text { small scale. } \\
\text { - Some residential uses are permitted, ar } \\
\text { exist for multi-use buildings. }\end{array}$ & $\begin{array}{l}2,657 \\
\text { elatively } \\
\text { ortunities }\end{array}$ & $\$ 264,000$ & $\begin{array}{l}\text { (unknown - no current } \\
\text { mortgages are held.) } \\
\\
\text { value extrapolated by } \\
\text { comparison: } \\
\$ 1,650,000\end{array}$ & $\$ 1,650,000$ & $\$ 621$ \\
\hline \multicolumn{6}{|l|}{ SITE \# 2} \\
\hline $\begin{array}{l}\text { Somerset St. \& Cambridge St. } \\
\text { zONING NOTES: } \\
\text { "CN / R4D" Dual-zoned as: Neighbo } \\
\text { Commercial Zone and Residential Mul } \\
\text { - The site is split down the centre, with t } \\
\text { zone at the Somerset St. edge. } \\
\text { - Zoning setbacks make much of the site }\end{array}$ & $\begin{array}{l}1,625 \\
\\
\text { Linear } \\
\text { Init Zone } \\
\text { nmercial } \\
\text { ble... }\end{array}$ & $\$ 174,000$ & $\begin{array}{c}\$ 1,600,000 \\
\text { date: } 1991\end{array}$ & $\$ 2,069,771$ & $\$ 1,274$ \\
\hline
\end{tabular}

\section{SITE \# 3}

Somerset St. \& Metcalfe St.

2,177

$\$ 771,000$

$\$ 950,000$

$\$ 1,158,046$

$\$ 532$

\section{ZONING NOTES:}

"R5D[82] H(10.7) HE" Residential with a Heritage Protection Restriction

- Due to the age and character of an adjacent building, new construction on this site is limited to 4 storeys.

\begin{tabular}{|l|l|l|l|l|}
\hline $\begin{array}{l}\text { SITE \# 4 2,553 } \\
\text { Rideau St. near Cobourg St. }\end{array}$ & $\$ 603,000$ & $\begin{array}{c}\$ 1,075,000 \\
\text { date: 2003 }\end{array}$ & $\$ 1,118,430$ & $\$ 438$ \\
$\begin{array}{l}\text { ZONING NOTES: } \\
\text { "CN-7" Neighbourhood Linear Commercial Zone } \\
\text { - Side sebacks are reduced, to allow for ground level } \\
\text { commercial space. Multi-use building is encouraged. } \\
\text { - Amenity space must be provided for residential uses, } \\
\text { which may only occur above the ground level. }\end{array}$ & & & & \\
\hline
\end{tabular}

* All "Assessed Values" are public information obtained from the City of Ottawa. Municipal assessment roles are prepared every year for taxation purposes. These values are not considered representative for lots without built structures.

** All "Mortgage Value" information was obtained from the Ottawa Land Registry Office.

*** The "Present Value" is calculated by adding a $2 \%$ annual increase in value to the most recent transfer value. The rate of $2 \%$ is an accepted long-term average for real-estate inflation.

Image 3.1.21 Site Comparison Chart. 
The choice of site \#4 at the east end of Rideau Street for use in this project allows the greatest opportunity to test the design intentions of this project. First, the site is appropriately sized and zoned to allow for multiple dwelling units in both the highly-dense, urban condominium tower arrangement or in some form of the lowerdensity suburban 'single-family homes' typology. Its current price of the site is relatively low, and the possibility of a medium density development does exist. This particular parking lot on Rideau Street is also appropriate for this project because it sits in a part of the city that qualifies as 'sufficiently urban:' it is part of a wellconnected transportation corridor, and the surrounding neighbourhood is multi-use, fairly dense, self-sustaining, and well-established. This urban context is a suitable testing ground for the ideals of suburban housing this project seeks to locate within the city: private homes, affordability, and open green space.

\subsection{Design Project Introduction}

The east end of Rideau Street is a transition area between two much more vibrant commercial zones. The first such zone is the west end of Rideau Street/ Wellington Street where the built density is much higher, and attractions like the Rideau Centre Shopping Mall, and the Byward Market can be found. The second occurs further east, along Montreal Road over the Cummings Bridge and is home to a lot of restaurant and retail space. The chosen site for this design project, just two blocks west of Cummings Bridge, fronts directly onto the busy urban street, but sits within the larger context of a quiet residential area. This site is at the same time within the 
urban core of central Ottawa, and also close to the edge of another district known as Vanier. The division between these districts is the Rideau River.

The site is currently undeveloped. Until recently, the space was used as a privately-owned pay parking lot. As seen below, buildings with retail and office uses abut the site on either side, while the street frontage totals seventy-eight meters in length. While the zoning envelope in this area against Rideau Street is set at ten storeys in height, few of the buildings in the surrounding context are that tall. The office building to the east is only five storeys high, and the housing stock to the west and in-behind are generally two to three storeys in height. Across the street, however, some high-rise residential buildings stand between twelve and seventeen storeys.

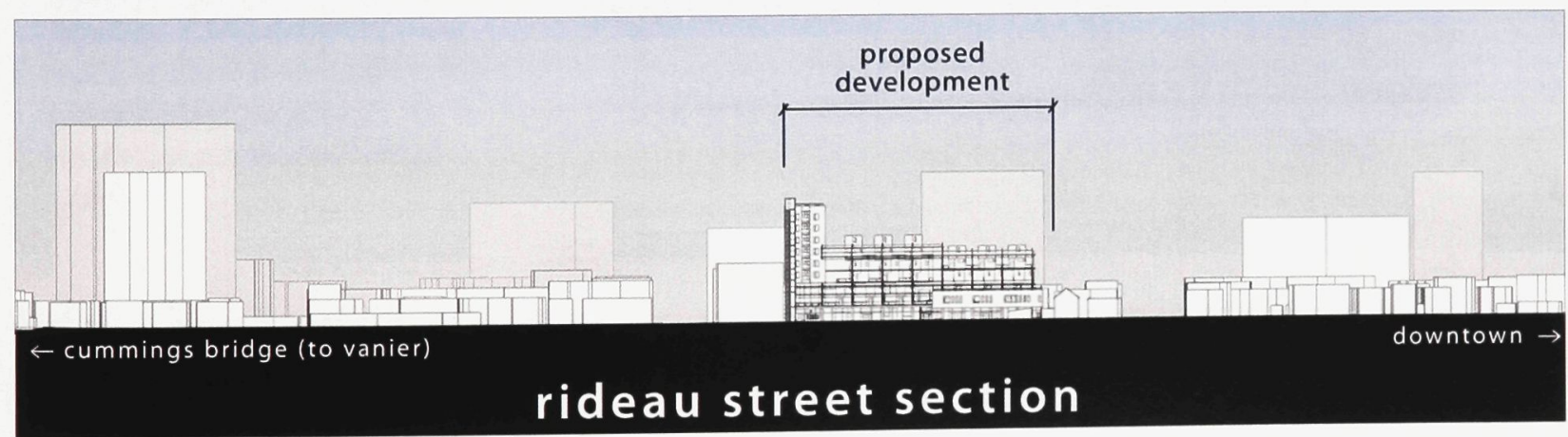

Image 3.2.1 Section drawing through Rideau Street looking south. The proposed development is shown within the surrounding context which ranges from 2 to 17 storeys in height. 
As stated in Section 3, this site was chosen for its fulfillment of said criteria. It met qualitative requirements as far as being well-connected with the rest of the city; it is also in an area of the city where many people can live and work. It satisfied quantitative requirements insofar as being large enough and zoned appropriately to sustain a multi-use building with extensive residential and amenity space. Other criteria, such as developer profit and cost-effectiveness, remained unproven although this site's cost was the cheapest per square meter of all the sites considered.

Image 3.2.2 Sketch of initial building scheme. Diagram is meant to convey a vertical layering of programmatic uses and the possible re-creation of a ground plane for private residences above commercial spaces.

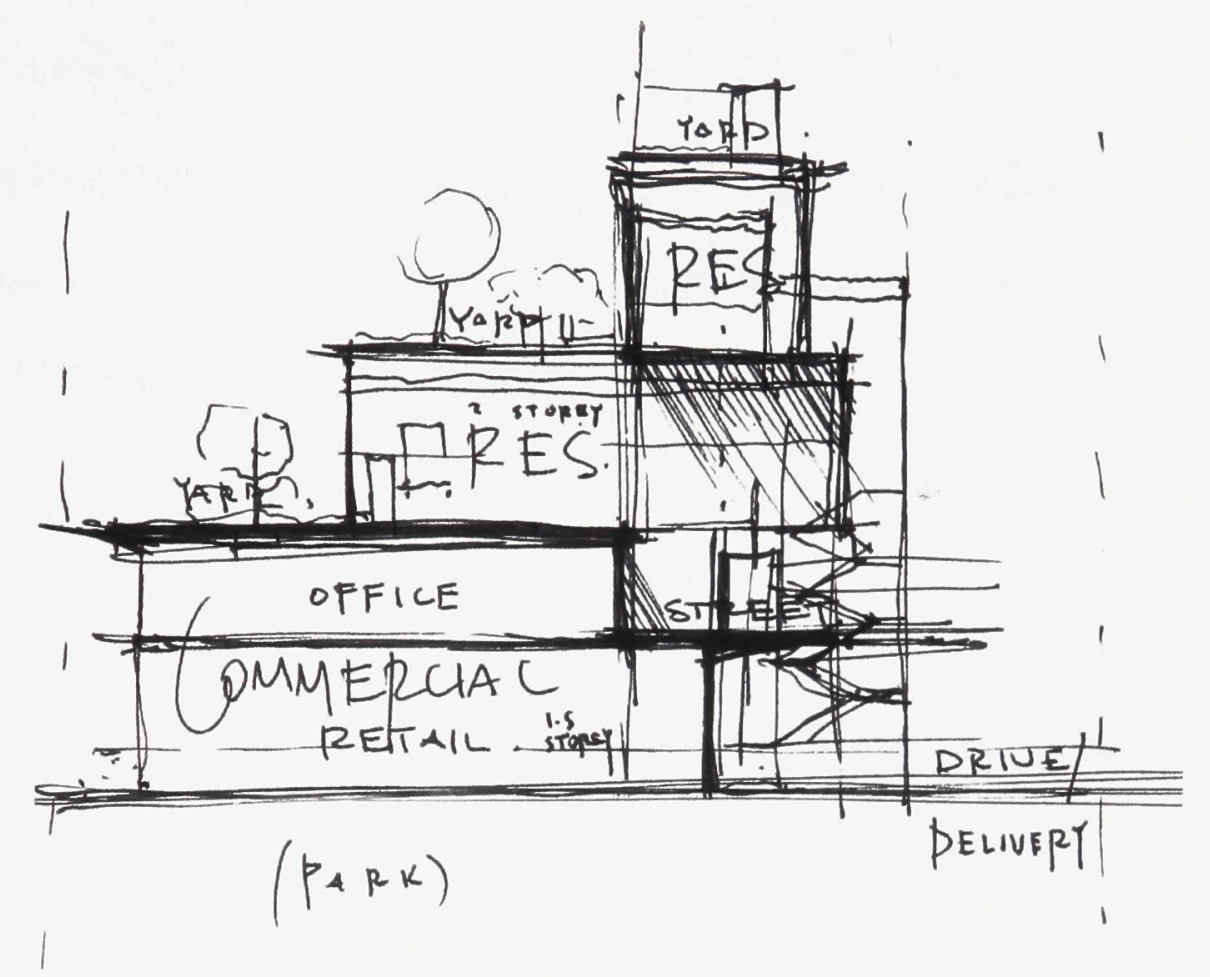

Initial design explorations addressed the formal arrangements of different programmatic usages on this site, while at the same time weighing the need to provide enough sellable or leasable space to satisfy the pressures of development in the urban core. The relationship of commercial space to the street was important, as 
was the provision of green space to the residential units. From the start, parking space for residents was supplied at the rate of one spot per residence. The assumption was that if the inhabitants of this building both work and live in the city, they would be able to get by with one car (or less,) by virtue of the building's location and access to mass transportation. Similarly, the idea of the suburban house is reconfigured. Here, the houses themselves could have a smaller footprint because the garage would be removed and replaced with a common underground garage. Portions of the often expansive space of the suburban lawn could be reconstituted and even shifted up onto higher levels of the built structure. The first sketches and massings done during this investigation sought to address questions about how sunlight would reach houses arranged in a stacked configuration, how the building might face the street and sidewalk, how on-site parking might work, and how the idea of a private house could be reconfigured yet preserved within the constraints of an urban site. 


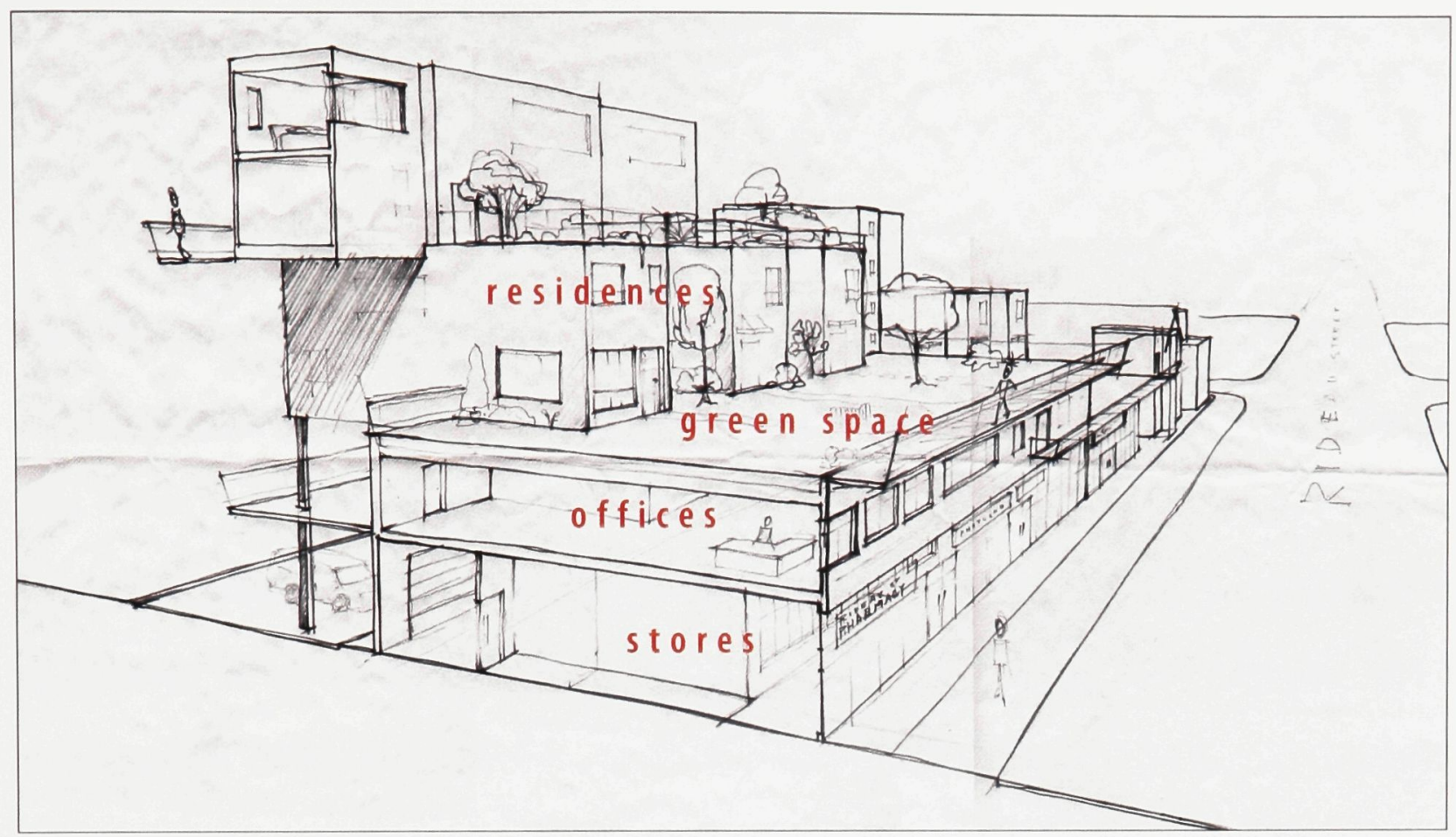

Image 3.2.3 Early design sketch. Section cut shows retail and office space below a re-created residential ground plane. In this arrangement of programmatic elements, common green spaces are oriented towards Rideau Street. Stacked private residences are accessed via vertical circulation along the south side of the building.

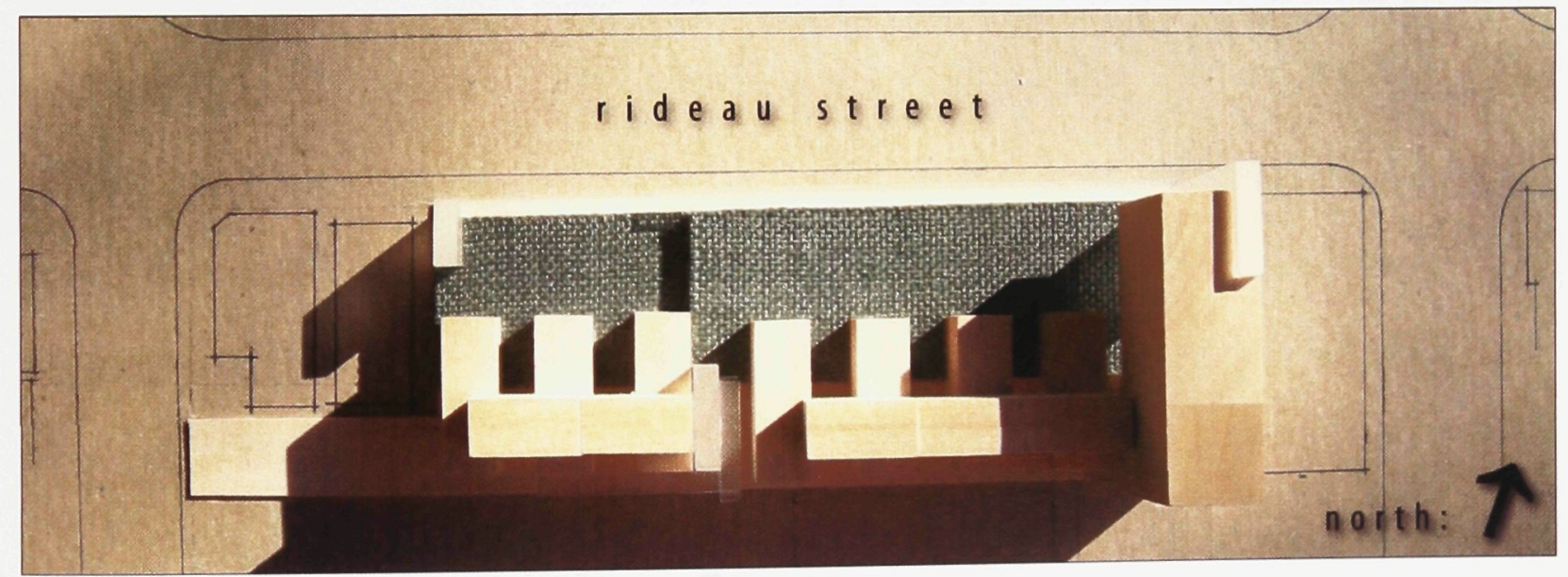

Image 3.2.4 Photograph of massing model. Private homes stacked at rear, green space facing the Rideau Street. 


\subsection{Project Documentation}

The final design produced in this thesis project is a culmination of design explorations which, albeit in different ways, addressed the dichotomy of city and suburb in the contemporary urban realm. This design, with its fittingly contradictory title Urban Suburbanism can best be described as a multi-use building. Programmatically, it offers commercial and residential uses in various configurations as a means of satisfying the notions of 'urban' and 'suburban' discussed earlier. The arrangement of these elements is supported structurally through a reinforced concrete superstructure coupled with a steel substructure. In general, public spaces are arranged to face the street, while private spaces and planted areas are oriented toward the rear of the building.

The elements of the building are arranged vertically in a layered manner, where their relation to each other and the path that the inhabitant would follow in and out of the building was of primary concern. This involved the creation of new ground plane above of the literal ground that separates office space and retail space facing the street from all of the residential space above. A parking garage intended for both residents and commercial patrons sits below ground, accessed off of Cobourg Street.

These layers of differing uses are accessed vertically through three elevator and stair cores - each meant for a different group of building inhabitants. The first is meant for the employees of the offices located on the second floor; this is the shortest of the three circulation cores. It joins with the parking garage at all levels, 


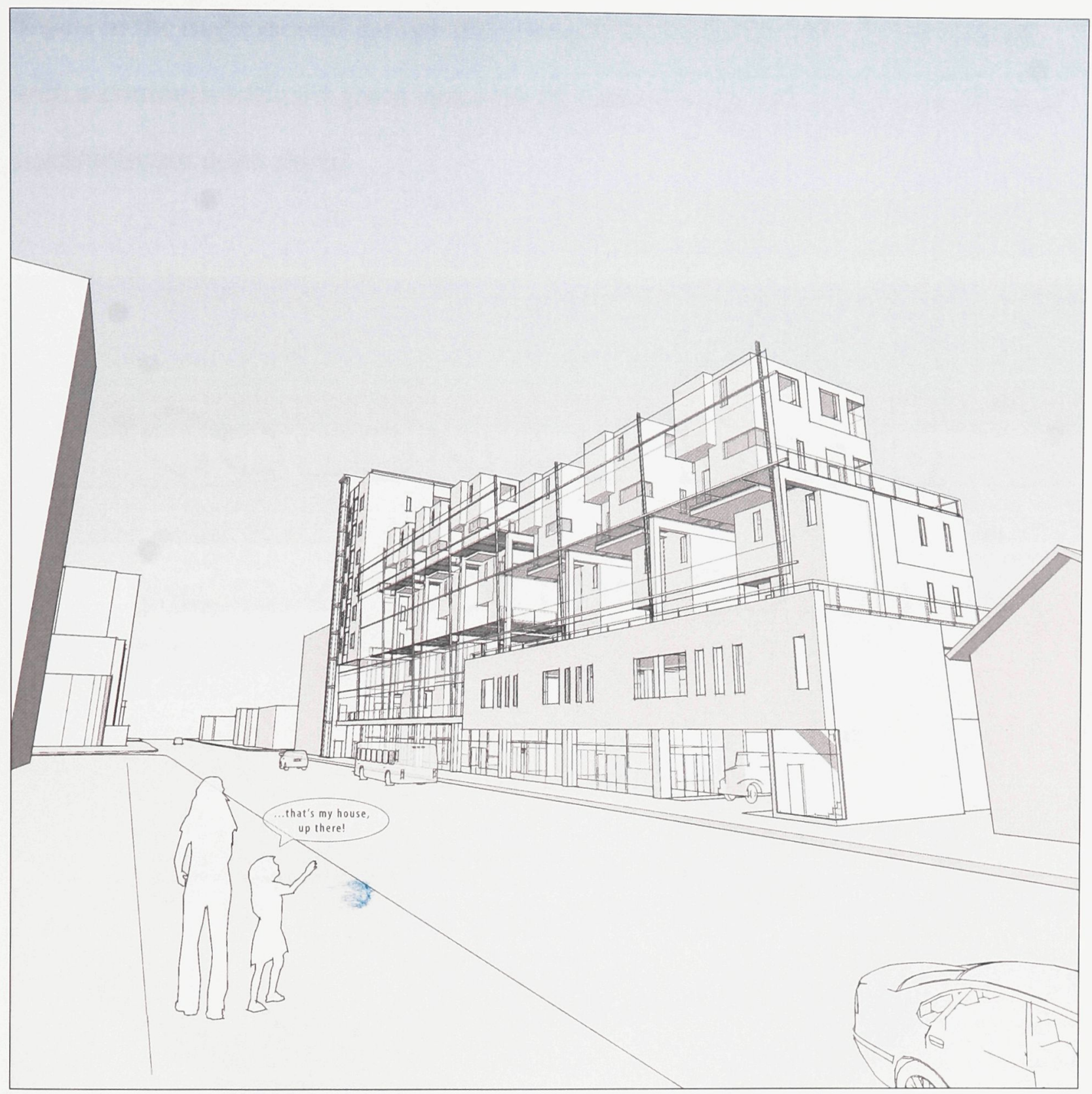

Image 3.3.1 Street-level view of the building design showing the immediate context along Rideau Street.

and with a delivery \& drop-off zone at the ground level. The second core, located near the centre of the site, is designed for the residents of the private residential units on the upper floors. It connects with the garage, with a common lobby on the ground level, and with the street-facing access-ways at the first level of each row of homes above. The third, and tallest of the vertical circulation systems, provides access for the residents of the condominium tower at the east end of the site. It 
begins in the underground garage and connects with another lobby at the ground, with a common enclosed green space on the second level, and with the six floors of condominium units above.

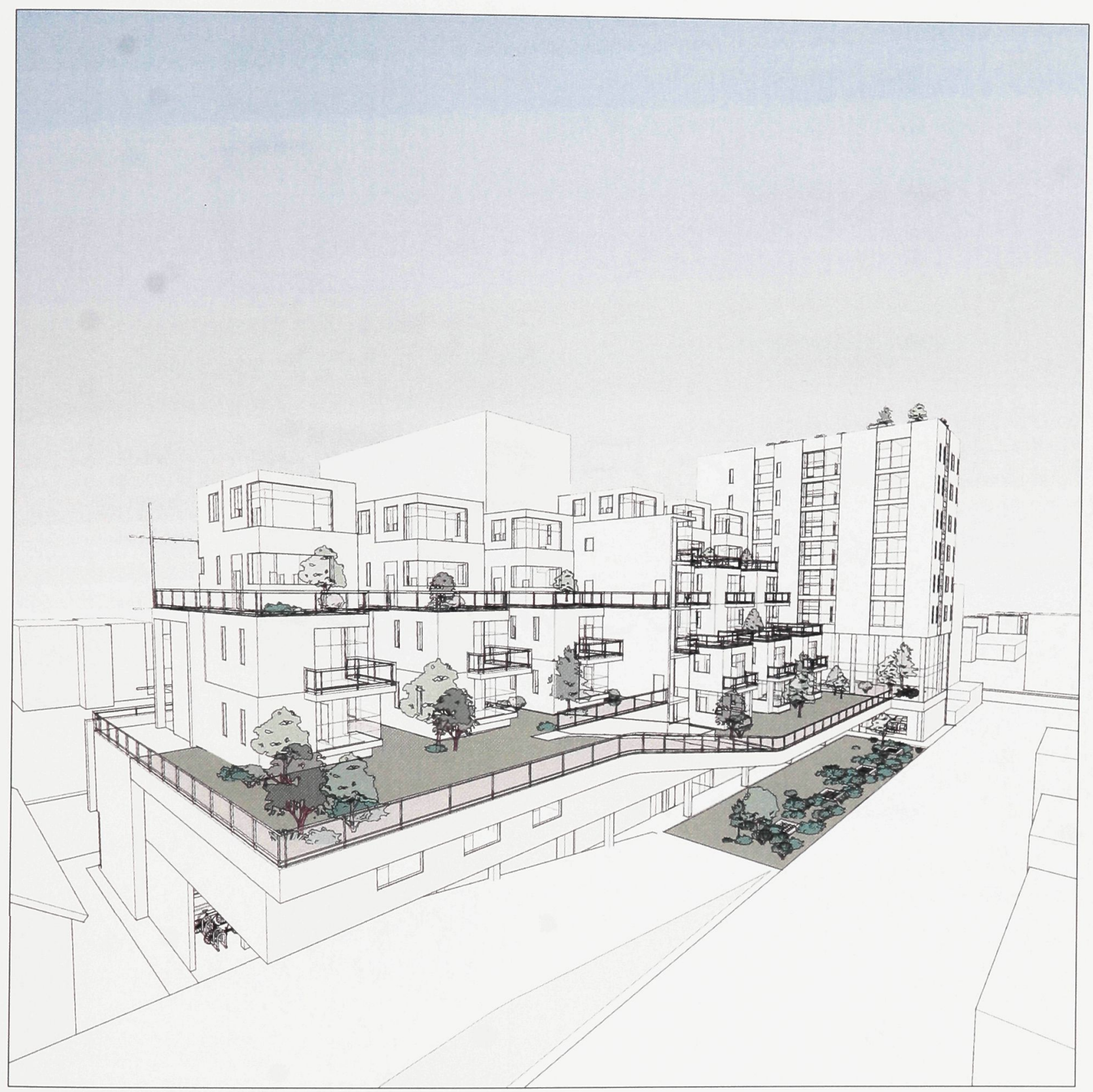

Image 3.3.2 View of the south-facing façade showing common landscaped areas and private gardens. 


\section{URBAN SUBURBANISM}

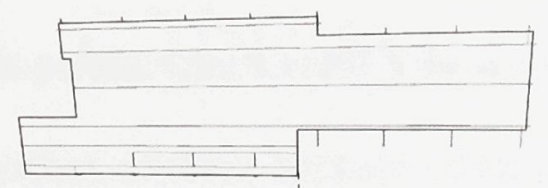

GLAZED FACADE

(wind borrier)

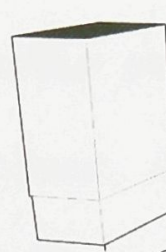

RESIDENTIAL SPACE

(condominium)

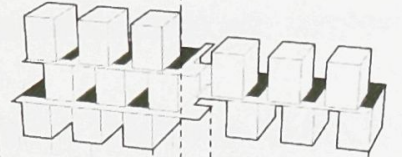

RESIDENTIAL SPACE

(detached home)

RE - CREATED

GROUND PLANE

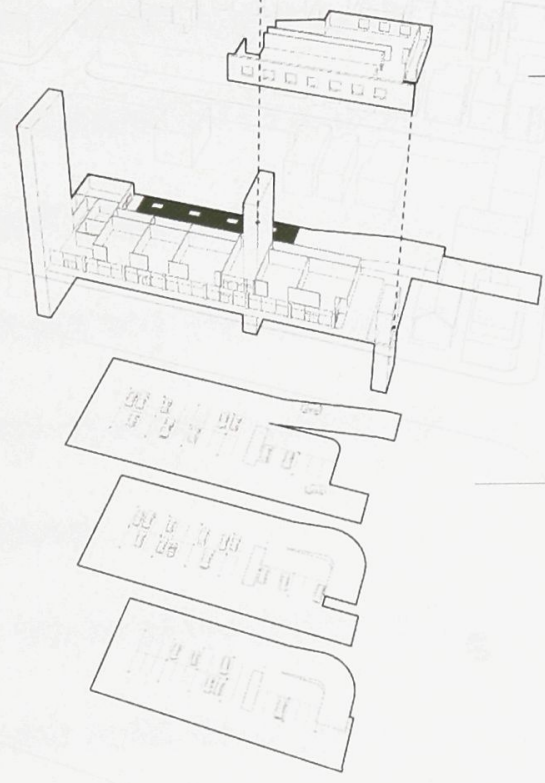

OFFICE SPACE

RETAII SPACE \&

RESIDENTIAL LOBBIES

PARKING GARAGE

Image 3.3.3 Exploded perspective drawing showing programmatic elements. 
Passage through this building design is best conveyed from the distinct vantage points of its three main user groups: the retail patron, the office worker and the resident. The extent to which these pathways overlap varies according to where they are in the building. All users share the parking garage. At the ground floor, retail spaces are public spaces and join with semi-private residential lobbies.

Entrance into either of these lobbies often involves passage through the indoor retail promenade, another public space, which connects directly with the sidewalk at the edge of Rideau Street. All residential units have private entrances, but are accessed in different ways. The condominium tower (at the east end of the site) offers residents access to their units off a hallway that connects with the elevator and stairwell, as is typical in an urban high-rise. Each condominium has an apartment number, but the whole tower shares a street address, 580 Rideau Street. Conversely, each private residential unit is accessed off of a semi-private access-way (exterior) that connects with an elevator and scissor stair. At each level, three houses share these steel access-ways which act as a sort of suburban sidewalk. Each house, although accessed in this semi-private manner, has it own street address, mailbox, front door, and private yard space.

The places where these paths might collide are in the shops or cafés that are located in the ground level retail space. Similarly, residents of the condominium tower and the private homes might cross paths and engage each other in any of the common green spaces at the rear of the building on the re-created ground plane. Both residential lobbies connect directly with the retail promenade, and the condominium lobby is actually open to the enclosed green space above where residents can sit in the shade or swim in the pool. 

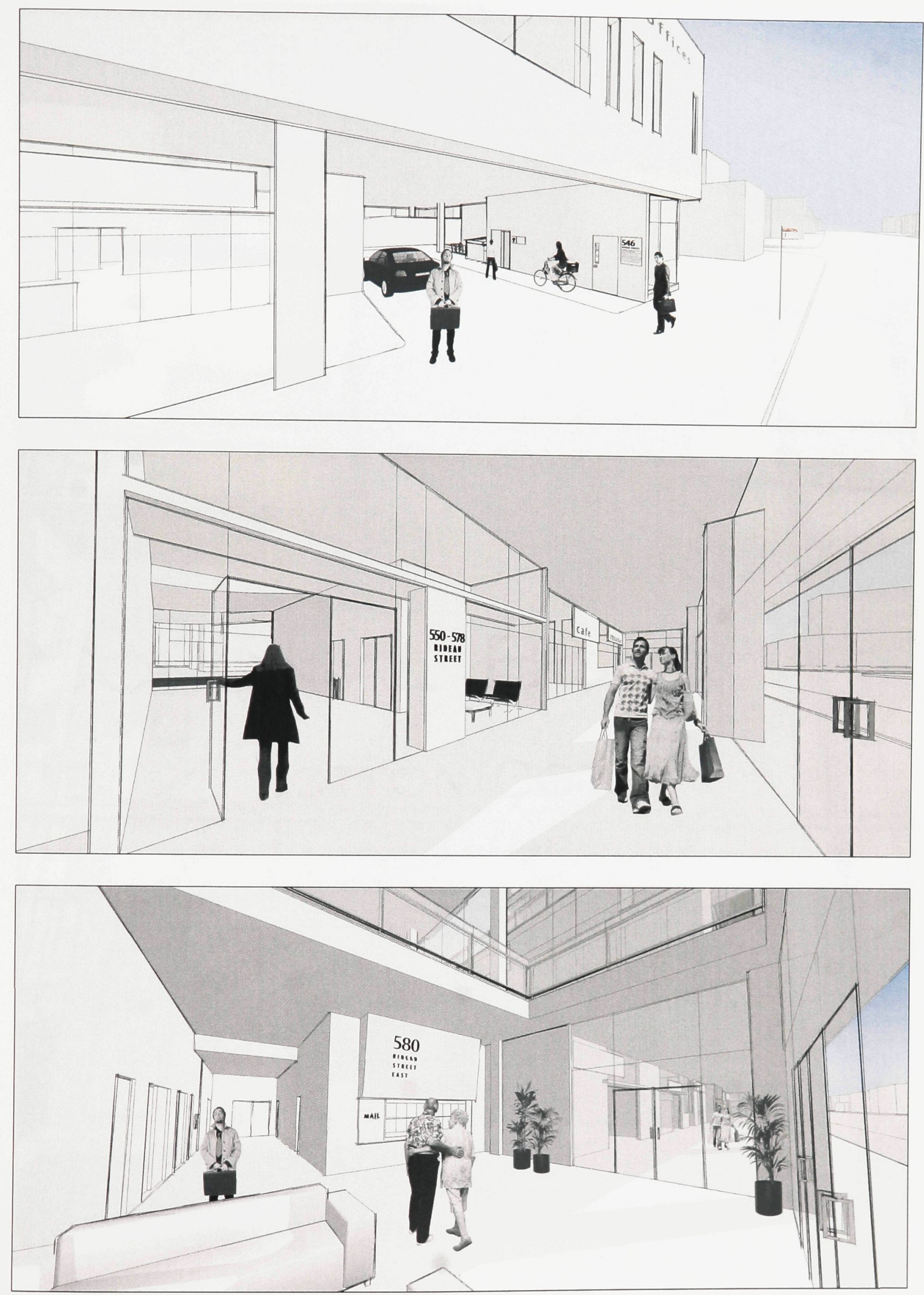

Image 3.3.4 Ground level entry conditions for 3 building elements: Offices space, Private Home Residential, and Condominium Residential. 


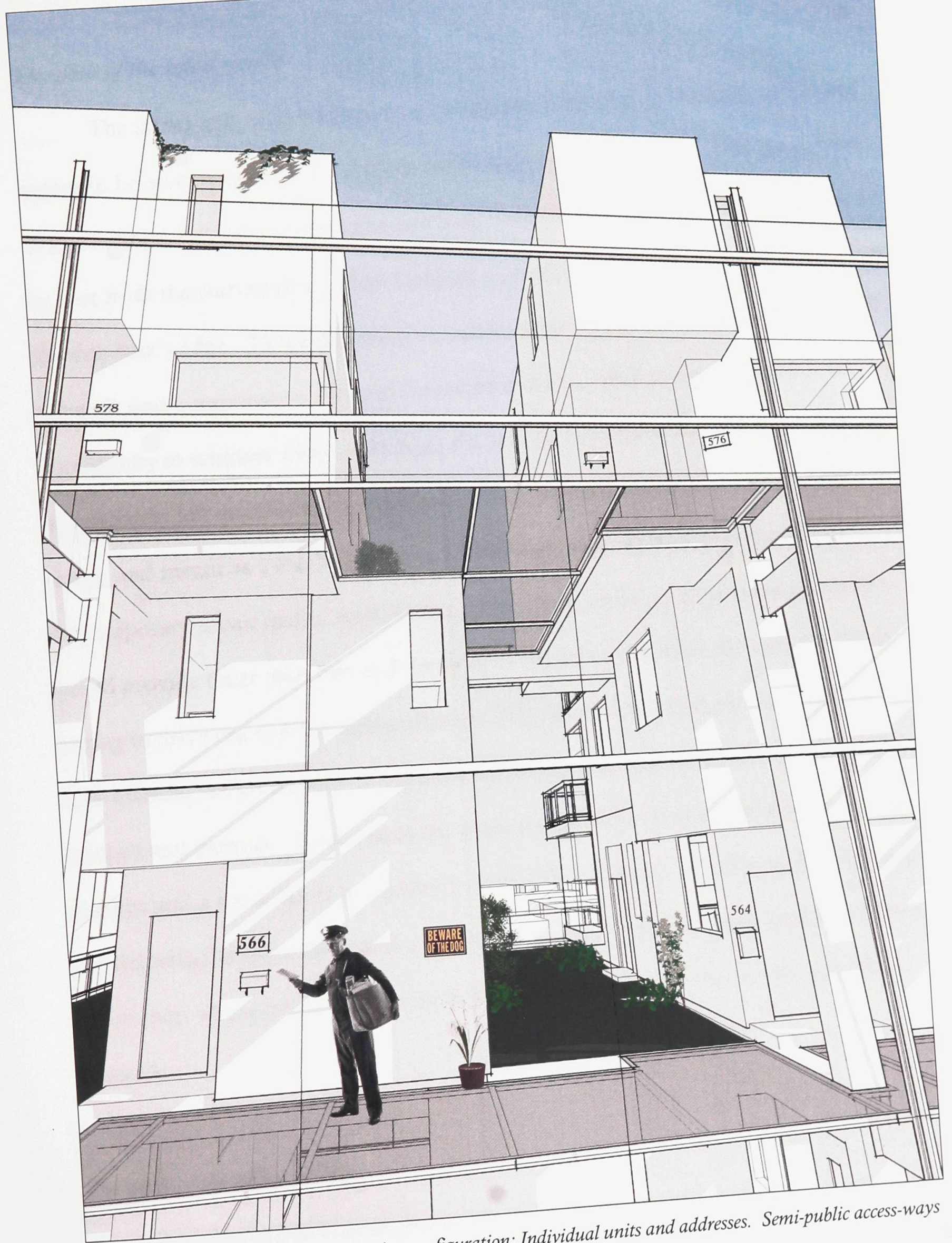

Image 3.3.5 Private residential housing
along the north façade facing Rideau St. 


\section{The path of the retail patron}

The stores and cafés included on the ground floor of this building design are meant to be an extension of the Rideau Street commercial corridor. For the patron of these shops, having arrived at the sidewalk in front of the building either by bus or by foot from the surrounding urban context, a continuous, glazed building front lines the sidewalk's edge. Through the doors, inside what is essentially an enclosed sidewalk and a response to the cold Canadian climate, retail patrons are given an opportunity to window shop. Although the specific tenants of these retail spaces are intentionally left undefined, they are envisioned as small-scale retail and grocery stores, and meant as a local alternative to the large scale retail outlets that fill the contemporary urban realm; small coffee shops, drug stores, or fresh produce outlets would provide those who live and/or work in the area with what they need without having to drive out of the neighbourhood. Still, should the retail patron arrive via their own car, an entire level of the parking garage is dedicated for use by the retail workers and patrons. Once inside the retail promenade, shoppers pass by store front displays and a set of doors to a lobby provided for residents. Further along, walking parallel with the sidewalk outside, the shopper passes a movie rental store and then a coffee shop whose tables and chairs spill out into this climate controlled, sun-filled sidewalk.

\section{The path of the office worker}

Arriving at 546 Rideau Street for work, after either parking their bicycle or stepping down off the bus, the typical office employee would enter the elevator or 
stairwell which leads up one level, directly to their place of work. Should he or she have arrived via their car, parking spots are available near this elevator in the garage below. The office space at 546 Rideau Street looks out onto the street from the second level providing a view of the bustling urban street below from the desks of many workers. In fact, these offices make up the only non-glazed, solid portion of this building design's façade, which is meant as a continuation of the urban streetfront so prevalent at other parts of the Rideau Street corridor. For these workers, lunch breaks can be spent in the shops below or in the public landscaped areas above.

\section{The path of the resident}

There are two distinct pathways for the residents of this multi-use building: one for the residents of the condominium tower, and another for those who live in the stacked private homes.

The path of the condominium dweller is enriched here through its contact with the other programmatic elements of the building. In this building design, the path from the sidewalk (or the parking garage below) to one's door involves passage through a lobby that is connected directly to other public and social aspects of the building. Within this lobby space, a seating area is provided for those waiting to meet someone. The lobby itself is open to the enclosed green space and pool area above, making it a three-storey space. It connects with the retail promenade, and with a common laundry room that opens onto the green space at the rear of the site. This is also the place where residents can collect their mail or check the community bulletin board. The second level enclosed green space is an indoor extension of the 
raised ground plane on the back side of the building. This enclosure, another reaction to our climate, is sealed by a party wall on one side and by glazing on the other three sides allowing for a landscaped area and swimming pool that can be used year-round. It is an enclosed common green space, open to use by all residents: the condominium dwellers and the private home dwellers. These common areas help provide the neighbourly contact and sense of community that is often lacking when the path from the street to the private doorway is completely discreet. Off of the sidewalk, through a set of glass doors, the condo resident might exchange "hellos" with a neighbour as they check their mail. Noticing the diminishing afternoon sun and the sound of laughter from the open space above, the condominium dweller heads briefly into the stairwell and out again onto the second level enclosed green space. Here, he or she sits and reads their mail on a park bench while kids from the other residential units splash around in the in the pool behind. The elevator completes the path to a hallway that leads to our condominium dweller's front door and, finally, inside.

For the dweller of one of the 'private' homes, the daily ritual of coming and going is based on the path of the suburbanite. In a typical suburban development, the path from one's breakfast table to the car, and subsequently to the office is a daily routine known as 'the commute.' In this project, through an arrangement referred to as urban suburbanism, the path is changed. The garage has been removed and relegated below ground. Work might only be a few blocks away or a short trip via public transit. Certain features generally deemed desirable about suburbia have been preserved: the idea of a private home and the desire for contact with open green 
space are still present but in altered forms. It's the spatial arrangement of these elements that is different, and the suburban path from breakfast nook to office workspace is inevitably reconfigured. Beginning from the completely private space of the home itself, the resident ventures off to work after finishing their morning routine. The south-facing, eat-in kitchen looks out onto a green space that is composed of not only a private garden space, but the greenery rising from numerous other gardens below. Stepping off of the front porch onto a pathway of steel grating, closing the front door behind, the resident sees a row of homes on one side and the inside of a glass façade on the other. Beyond the glass is the city of Ottawa and Rideau Street immediately below. He or she is on a sidewalk of sorts, four levels above the street. Through the grating above, their neighbour can be seen leaving their home for the day. Two school-kids meander along the access-way below as they make their way down to the school bus. As he or she walks along, the elevator core and stairwell are around the corner, only two doors down. They get glimpses into the yard spaces of their neighbours, but not into the homes themselves. Almost no windows face these walkways - just front doors, mailboxes and their accompanying addresses. Waiting for the elevator, the resident is out of the winter winds because of the glass façade that separates these pathways from the street at all levels. Looking toward the rear of the building, he or she can see the rear gardens as they step down to the common green space below where another neighbor is walking her dog. The elevator stops at the ground level where, through a semi-private lobby, the resident passes into the retail promenade and quickly out through another set of doors to the sidewalk before hopping onto a city bus. 
Returning home, this time from the vantage point of a motorist, to a house at the top level of this building will involve passage through the underground parking garage. Off of Cobourg Street, the ramp down to the garage descends below the rear of the site. As the garage door rises, the resident drives under and down the ramp slowly, because kids who live above are often playing ball hockey at the bottom. The top level of the parking garage is popular for such activities because of the skylights that help vent the air and allow sunlight in. From the resident's reserved parking spot on the second level, he or she passes by their locked storage room after getting out of the car. The elevator stops at the ground level lobby so he or she can detour into the retail promenade and pick up the bag of milk their spouse reminded them to pick up on the way home. From the checkout of the store, the resident can see out onto the sidewalk where some neighbours are getting off the bus and heading for their homes. The elevator takes them all to their various levels, the elevator cab itself opening onto opposite sides at each stop. At the top, the resident passes the post person dropping mail into the mailbox of your next-door neighbour at 574 Rideau Street. Stepping up onto the front porch, the resident notices an elderly neighbour tending to his garden. He or she says a quick hello, gathers the mail, turns the key, and steps inside. 


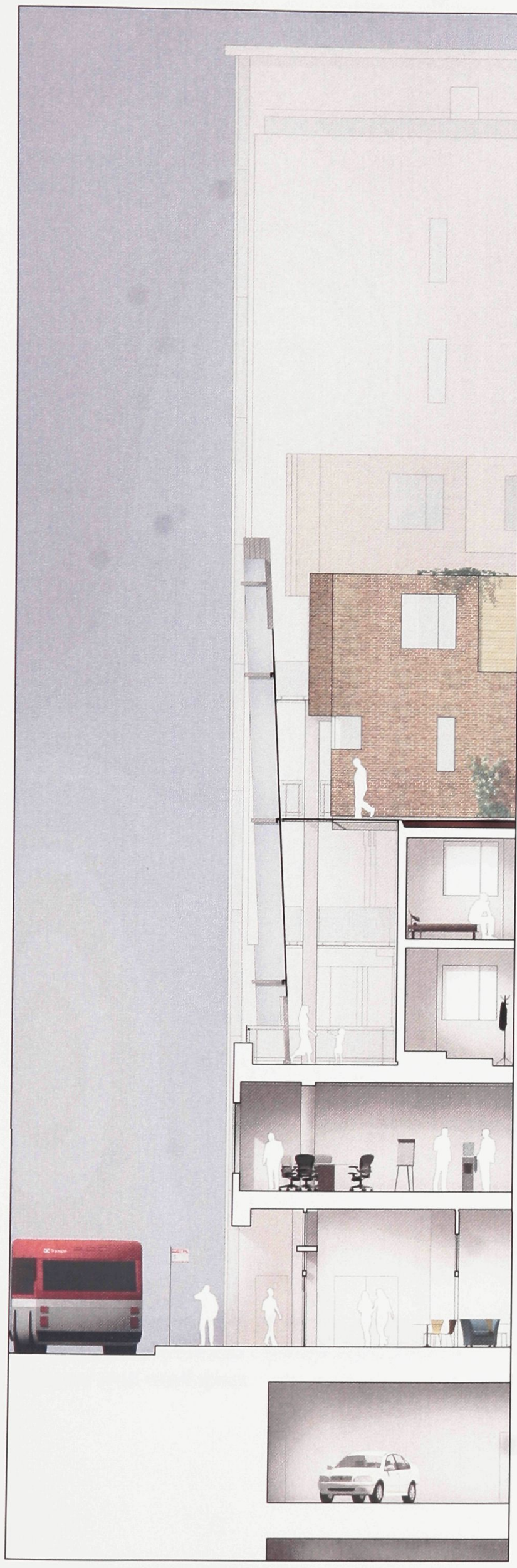

Image 3.3.6 Partial section through front facade. The streetfront includes an indoor retail promenade under the second floor office space. Private residential units, accessed off of street-facing walkways are protected by a continuous barrier of glazing. 
Image 3.3.7 Partial section through rear of building. Private residential yard space and common green space sit above the ground level retail space.

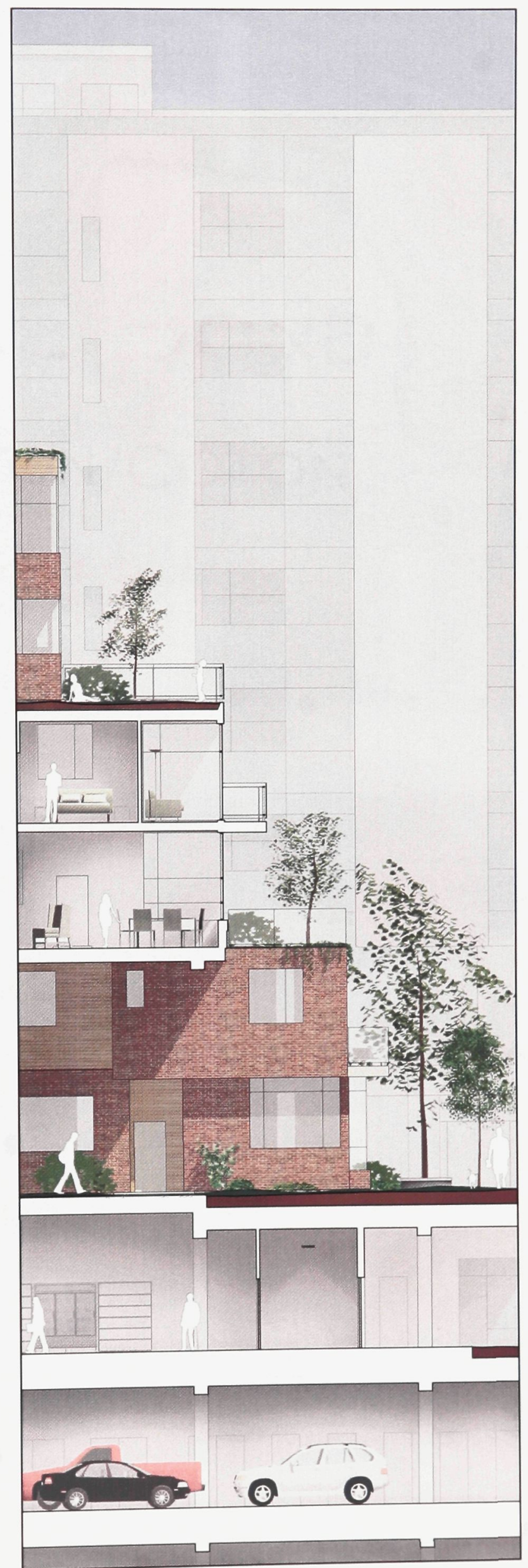




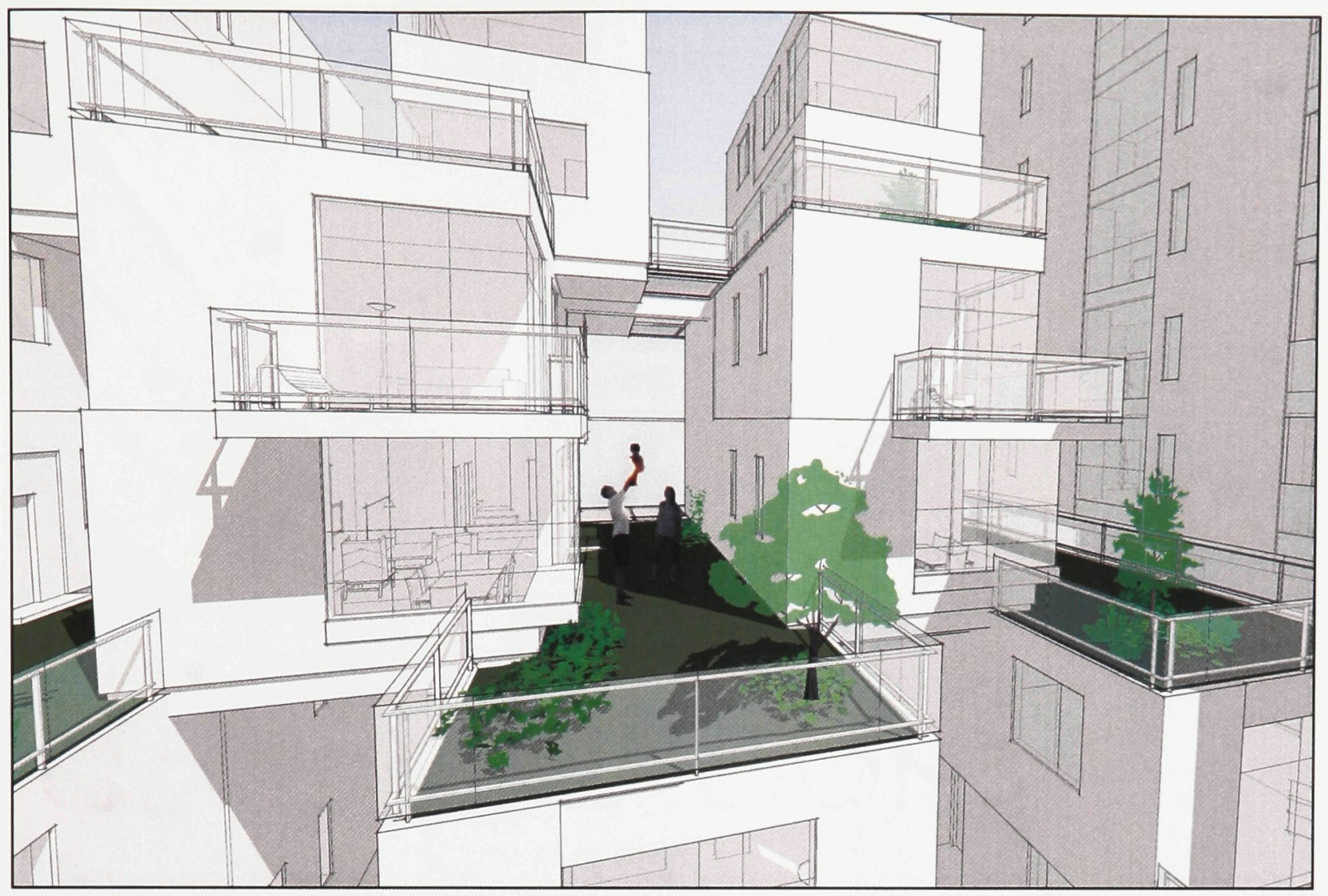

Image 3.3.8 Perspective view of private garden space in between private residential units.

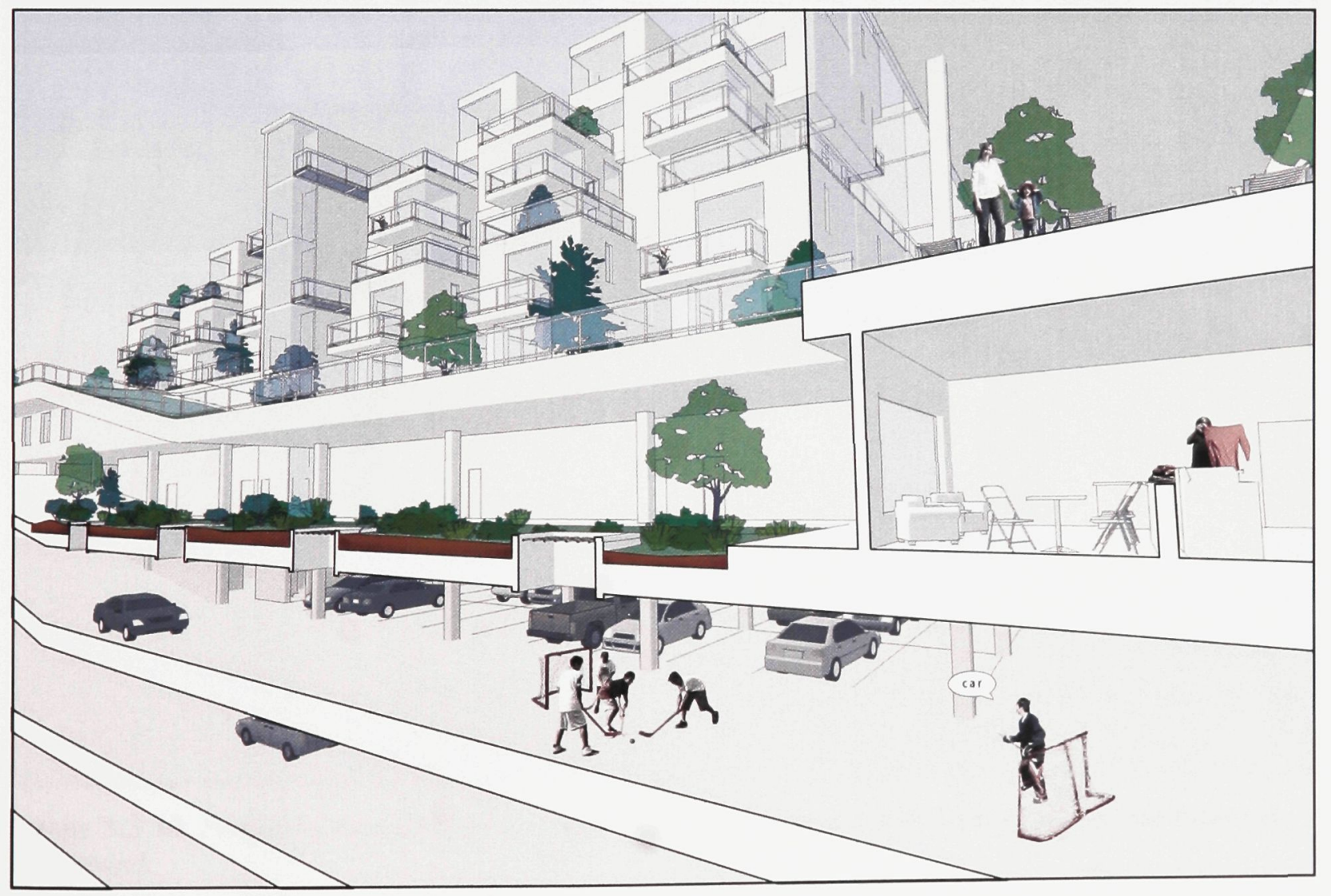

Image 3.3.9 Sectional view of parking garage, laundry, and landscaped areas at ground level. 


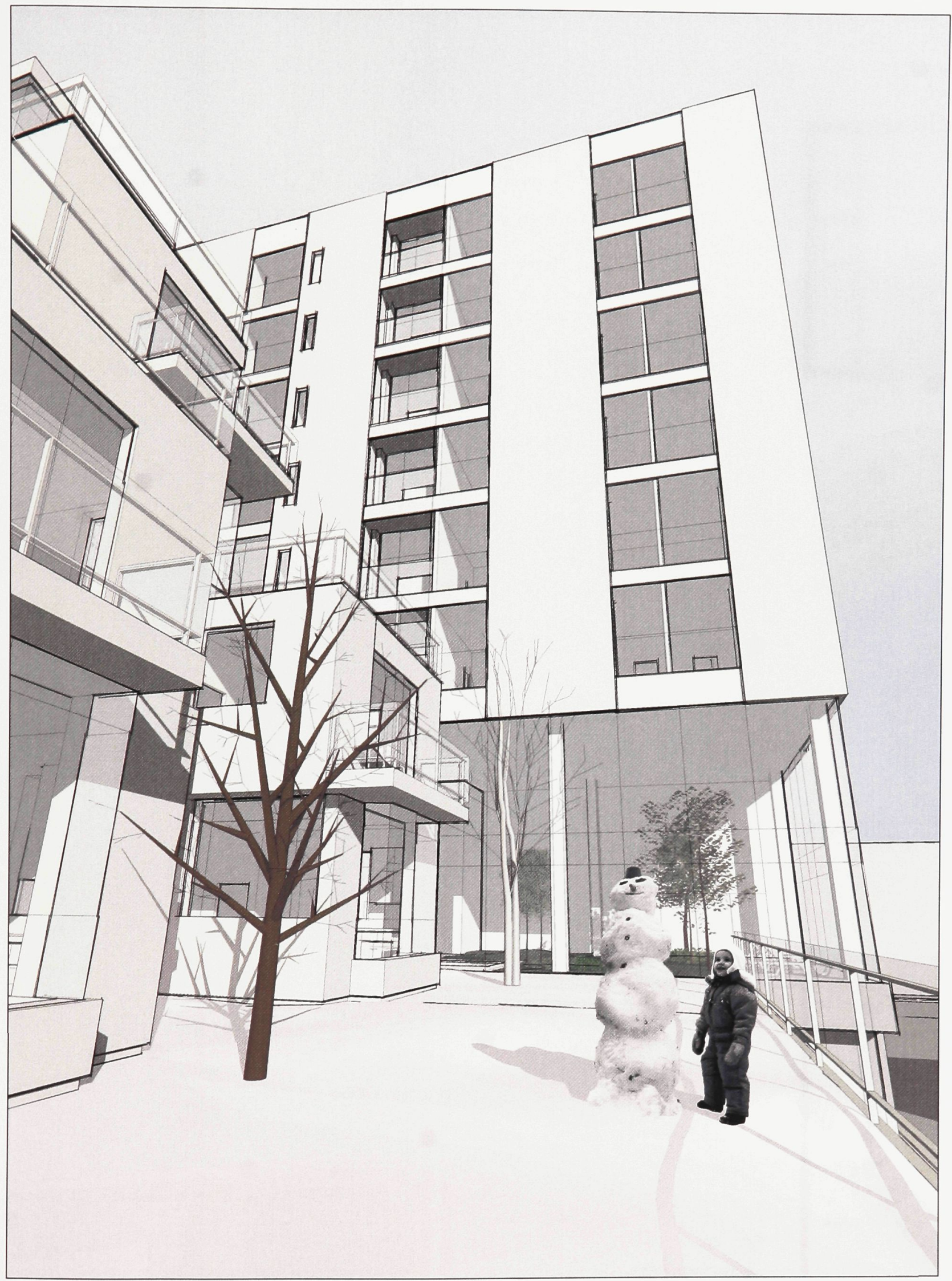

Image 3.3.10 Perspective view of rear green space in winter. Condominium tower and enclosed green space in background. 


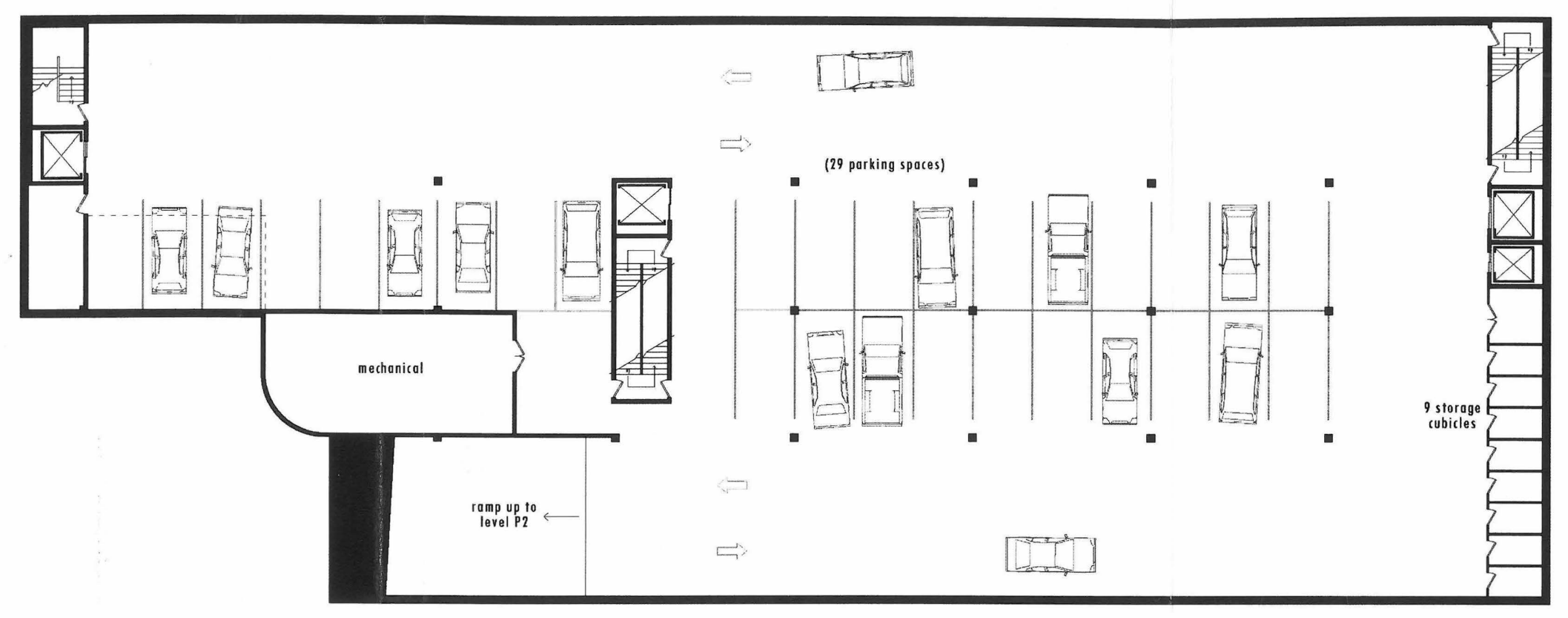

level P3

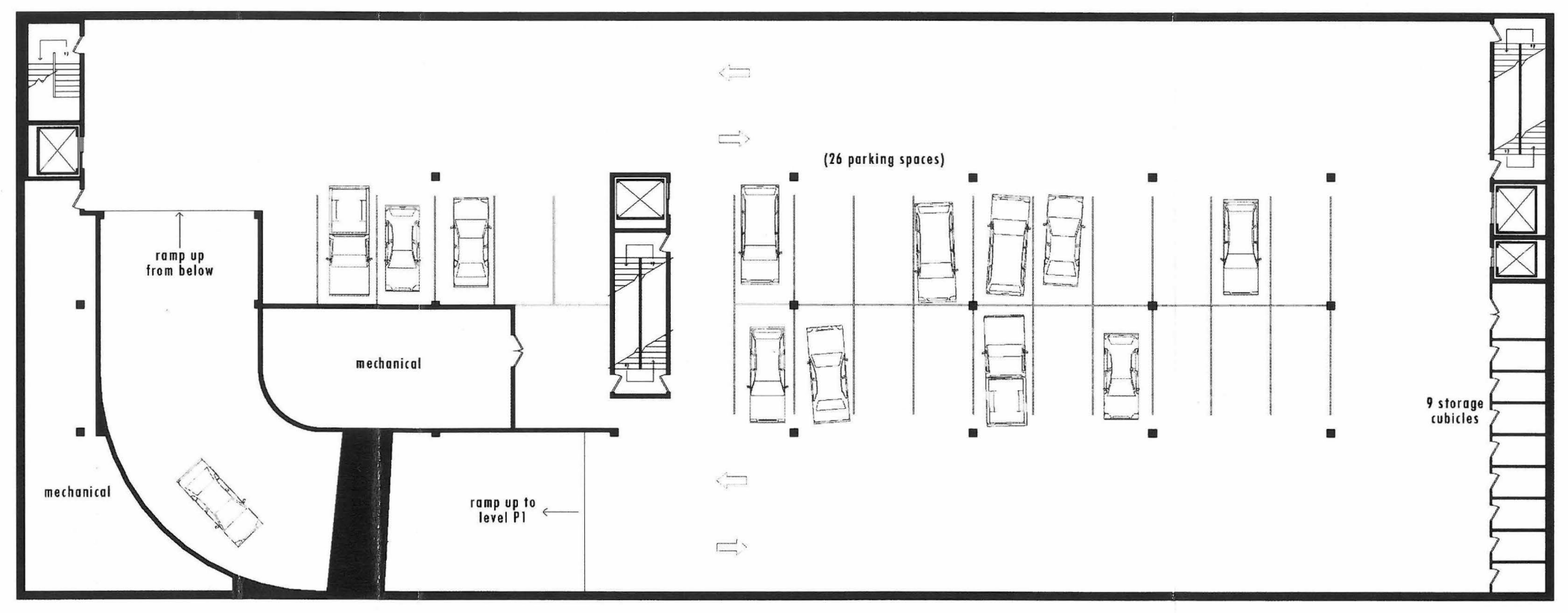

level $P 2$ 


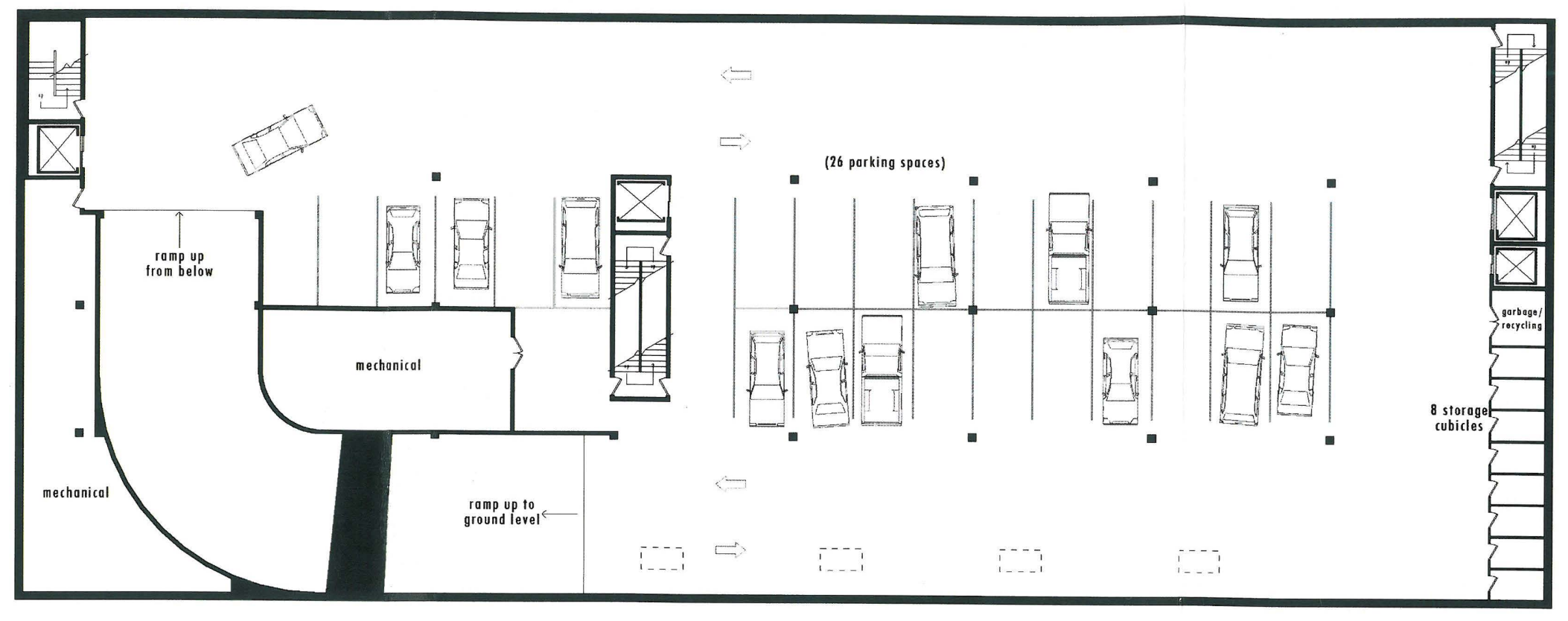

level PI

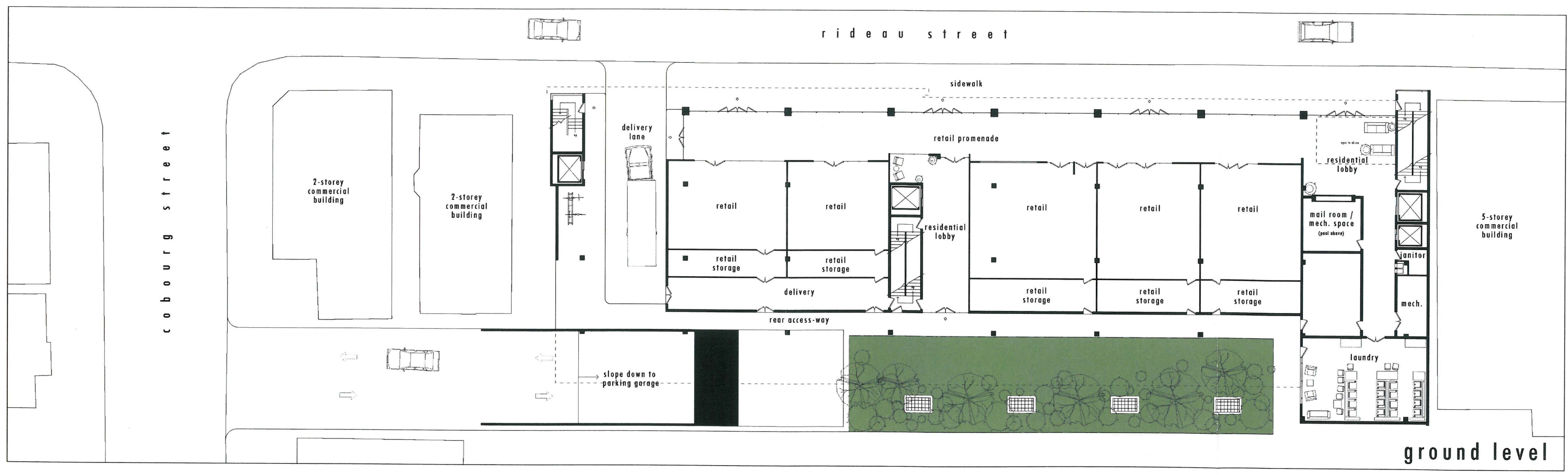



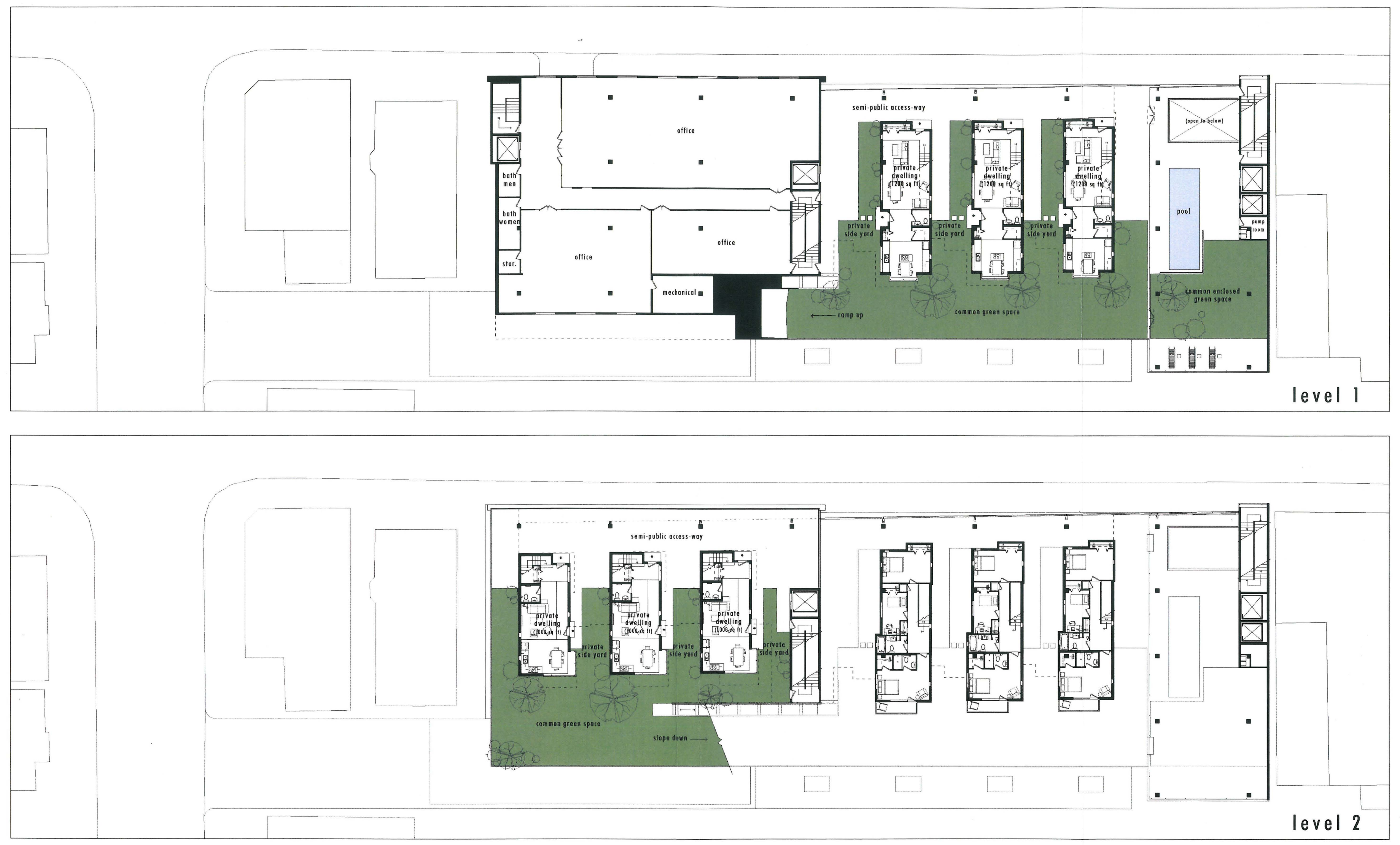

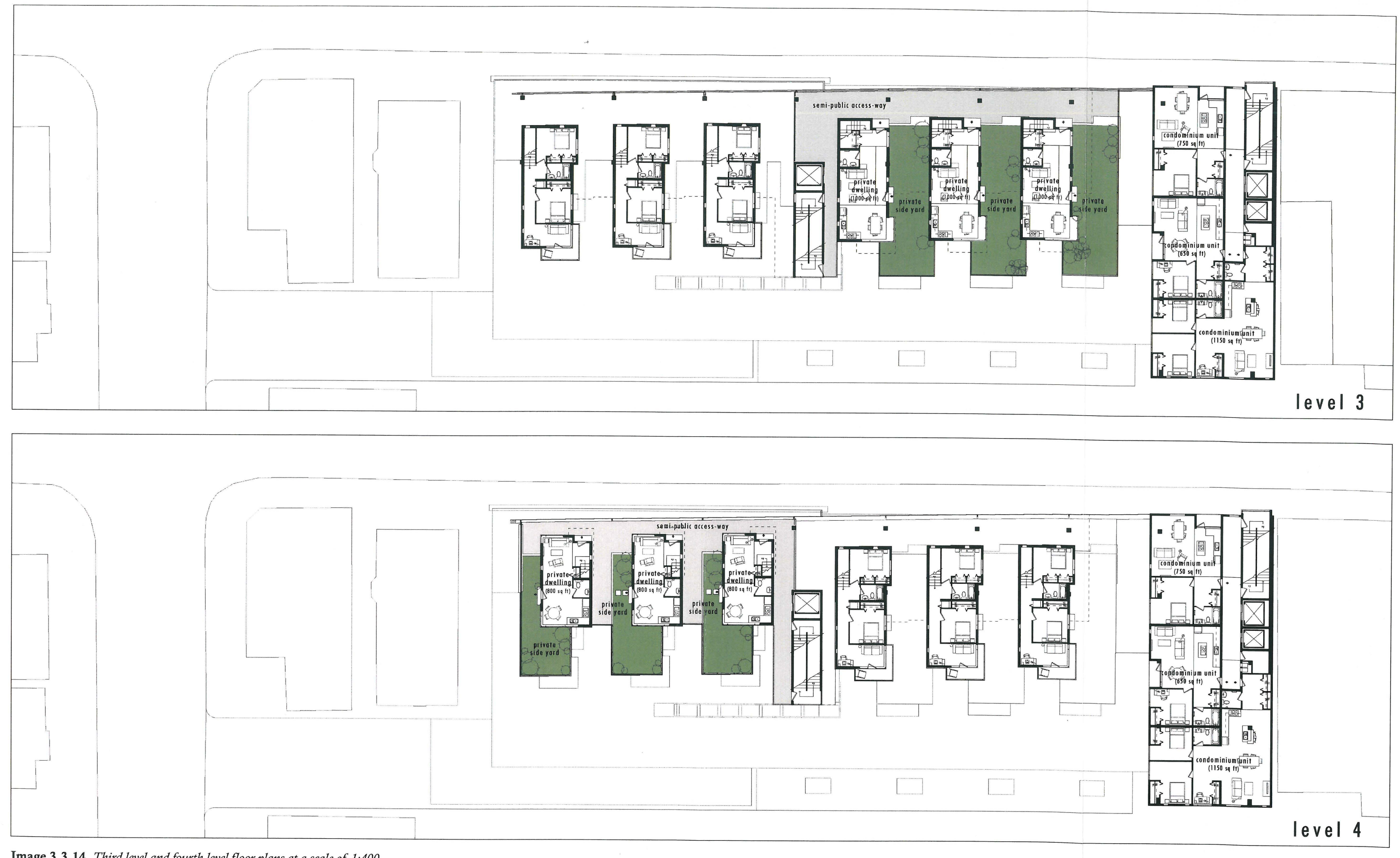

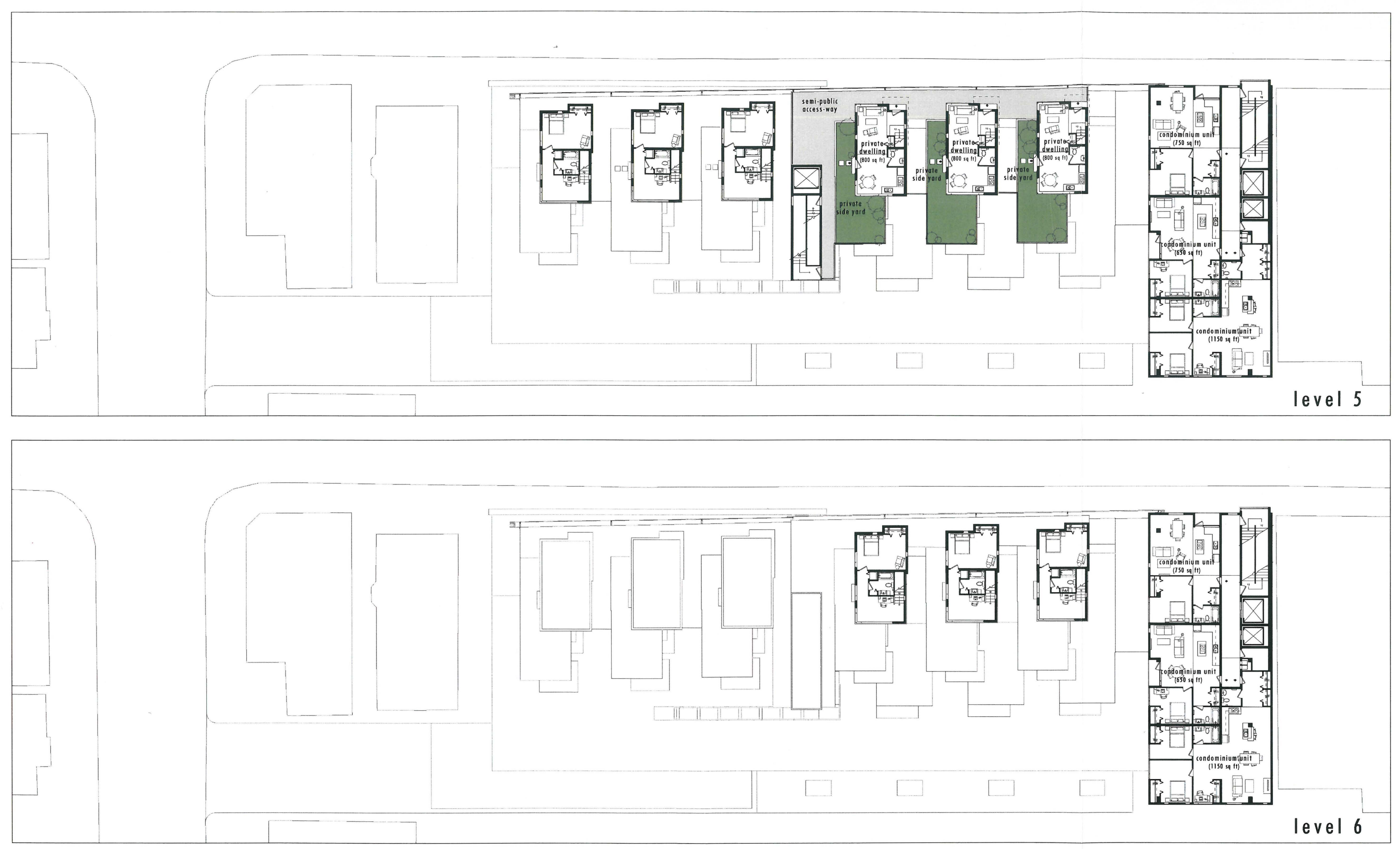

Image 3.3.15 Fifth level and sixth level floor plans at a scale of 1:400. 

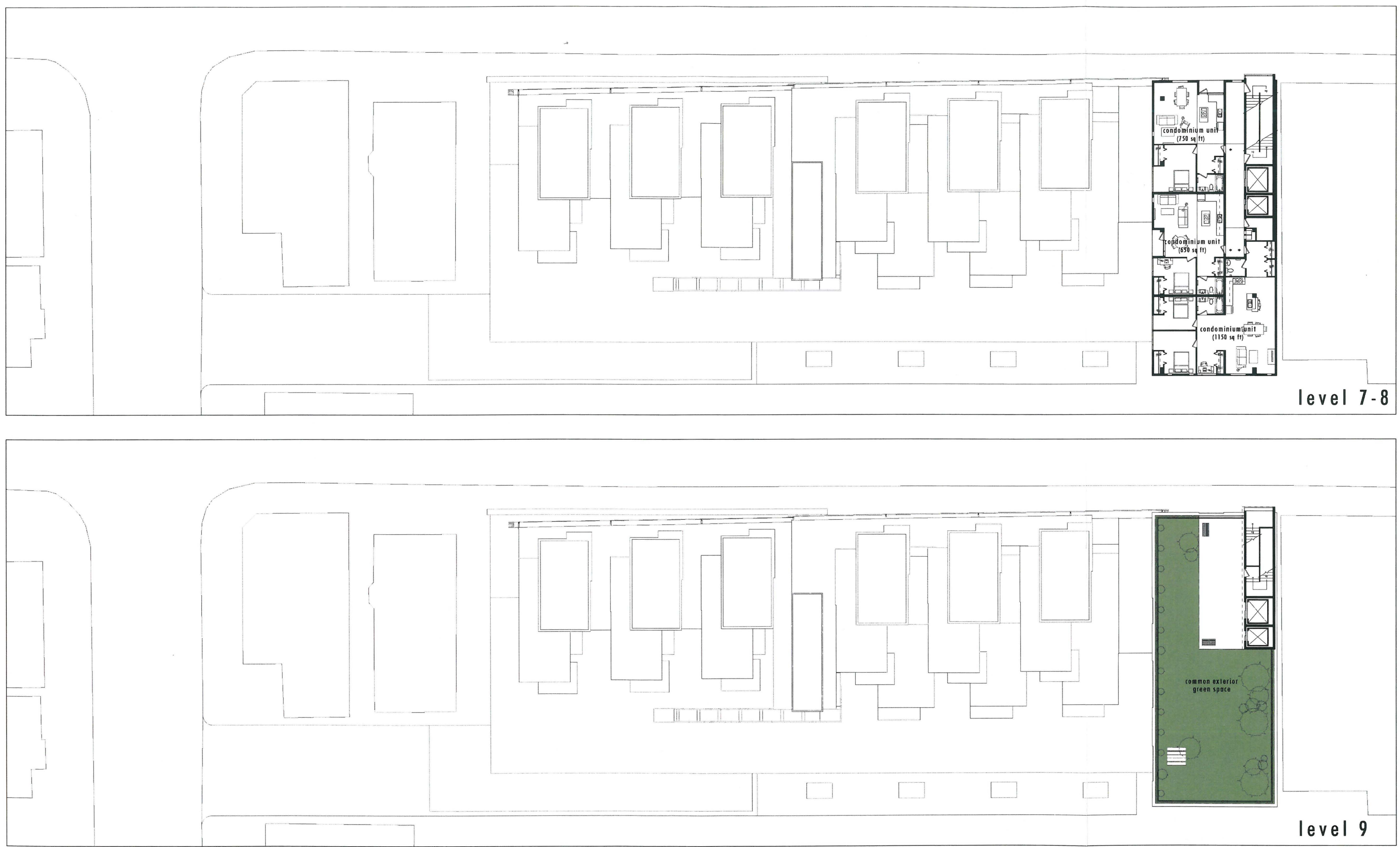


\section{Domestic space and Urban Suburbanism}

The detailed design of the residential space is the most important aspect of this building design. Although this project operates on an urban design scale, it has from the outset been concerned primarily with the provision of suburban housing. As such, the 'private homes' described briefly above are a response to the central questions of this thesis project. How, in the context of an urban building in the downtown core, can suburban homes ever fit in? How are they composed? Are they technically still 'private homes'? How small or large are they? For whom are they available? Would a suburbanite even want to live there?

Research conducted in the suburbs of Ottawa in 2004 and 2005 for this thesis was focused on the large residential subdivisions being built where the primary products were single family, fully-detached homes. Floor plans and pricing schemes were collected from showrooms and salespeople were quizzed about the plans for the developments and the population demographics they were targeting. Responses were vague regarding the specific population groups these homes were created for. The overall trends in single-family homes showed a continued enlargement of the interior space of the home itself, although the lots on which they were built were no larger, and, in most cases, the lots were smaller. Most homes had four bedrooms. A few 'starter homes' had only three, and some larger homes had five. The average number of bathrooms was two and a half. Larger 'open concept' spaces were being provided on the ground floor. Other rooms such as a home office, media room, 'multi-purpose' room, and a dedicated laundry room had become commonplace as well. 
This ongoing trend in which the suburban house was growing larger and larger was curious in light of statistics collected at the time of the 2001 National Census. According to Statistics Canada, the Ottawa-Gatineau region has more than 400000 households. Of those, nearly half are in the 'single-detached' category. ${ }^{14}$ Furthermore, of the total number of households, more than one quarter of all of them were inhabited by just one person. Exactly how many of the single-detached homes were one-person households could not be determined, but it seemed to point towards an inverse relationship between the size of new homes and the average number of people in those households.

\section{Household size (2001 Census)}

\section{Ottawa-Gatineau}

Total households 415,940

1-person households 107,980

2-person households

3-person households

Total persons in households

Average number of persons in household

URL:

http://www40.statcan.ca/101/cst01/famil53f.htm

Image 3.3.17 Chart showing the distribution household sizes in the Ottawa-Gatineau region, 2001. 
Based on other census data, the number of inhabitants living in private households has decreased steadily since 1961. Nationally, the average number of people in a home is now only 2.6 - down from 3.9 . This project will not attempt to answer the question as to why developers are building four and five-bedroom homes when only three people will likely reside there. However, this information led into this project's development of a smaller suburban house type that is more responsive to these averages.

Type of dwelling and population by type of dwelling (1961-2001 Censuses)

$\begin{array}{llllll}\text { Year Population } & \begin{array}{l}\text { Occupied } \\ \text { private } \\ \text { dwellings }\end{array} & \begin{array}{l}\text { Private } \\ \text { households }\end{array} & \begin{array}{l}\text { Collective } \\ \text { dwellings }\end{array} & \begin{array}{l}\text { Population in } \\ \text { collective } \\ \text { dwellings }\end{array} & \begin{array}{l}\text { Average \# of } \\ \text { persons per } \\ \text { private } \\ \text { household }\end{array}\end{array}$

$\begin{array}{lllllll}1961 & 18,238,247 & 4,554,493 & 4,554,736 & 22,475 & 483,718 & 3.9 \\ 1966 & 20,014,880 & 5,180,473 & 5,180,473 & 18,236 & 463,266 & 3.7 \\ 1971 & 21,568,311 & 6,034,508 & 6,041,302 & 17,585 & 392,695 & 3.5 \\ 1976 & 22,992,604 & 7,166,095 & 7,166,095 & 16,445 & 384,530 & 3.1 \\ 1981 & 24,343,181 & 8,281,531 & 8,281,531 & 17,370 & 405,735 & 2.9 \\ 1986 & 25,309,331 & 8,991,672 & 8,991,672 & 19,800 & 434,370 & 2.8 \\ 1991 & 27,296,859 & 10,018,267 & 10,018,267 & 21,020 & 446,885 & 2.7 \\ 1996 & 28,846,760 & 10,820,050 & 10,820,050 & 22,615 & 449,001 & 2.6 \\ 2001 & 30,007,095 & 11,562,975 & 11,562,975 & 25,755 & 479,520 & 2.6\end{array}$

URL:

http: / $/$ www40.statcan.ca/cgi-bin/getcans/sorth.cgi?lan=eng\&dtype=fina\&filename $=$ famil $66 \cdot \mathrm{htm} \&$ sortact $=2 \&$ sortf $=7$

Image 3.3.18 Chart showing the decrease in Canadian household size since 1961. 
Although part of a larger building meant to express the urban characteristics of the site, some of the residential aspects of this design are meant to embody certain suburban ideas. The design of private residential space in this project was meant to satisfy two main aspects of suburban housing: the private home, and contact with green space.

\section{Re-creating the suburban lawn}

The suburban desire for close contact with green space is given here through the use of exterior residual space for private gardens and grass-covered areas. The outdoor areas found atop the built structure below are utilized for their capacity to support a planting medium for grasses, sedums, bushes, and shallow-rooting trees. At every level above the retail and office spaces, roofs become the private yard spaces and communal landscaped areas for the residents. Within the constraints of this project, this is the form that the typical suburban lawn takes as it is brought into the urban realm. The reinforced-concrete superstructure of the building provides structural support for soils as well as adequate irrigation and drainage. The gardens and lawn spaces make use of "intensive green roof technology," 15 a system of roofing where roofing membranes and a planting medium actually combine to increase the thermal value the roof assembly. More specifically, a structurally supporting surface (poured concrete) is fitted with the drainage and irrigation hardware required to sustain the plant life, and then a series of waterproofing and insulating layers are applied directly to it. On top of that, a growing medium up to half-of-a-meter deep 
acts as soil, creating the base for a garden able to support shrubbery, flowers, and shallow rooting trees.

This strategy for the provision of a 'green space' next to each private home is partially based on the methods used in typical suburban development. During the construction of residential neighbourhood under the 'subdivision' process, the land is cleared and graded. To facilitate ease of construction, all trees are generally removed, and any other vegetation is razed during the leveling of soil. After the houses are built, landscaping is brought back in the form of sod and shrubbery, and, in some cases, a few young trees or well-placed rocks. In this way, the 'natural' landscape that is provided in the suburbs is already contrived. The green spaces provided in this design project are admittedly artificial, having been technologically re-created in a similar fashion as a suburban lawn. But, unlike a suburban lawn, these spaces are not described as 'nature,' or envisioned as a replacement of any forest habitat destroyed during construction.

The design of the typical yard spaces of most any suburban subdivision, which are also a technologically-reproduced green space, would fall short in comparison with the green spaces provided in this design project. Here, the gardens align directly with the spaces of the house that are meant to look out onto them. They are not, as is often the case in the suburbs, a buffer zone between the roadway and the house or a residual exterior space between homes that happens to have been covered with sod. 


\section{Intensive Green Roof}

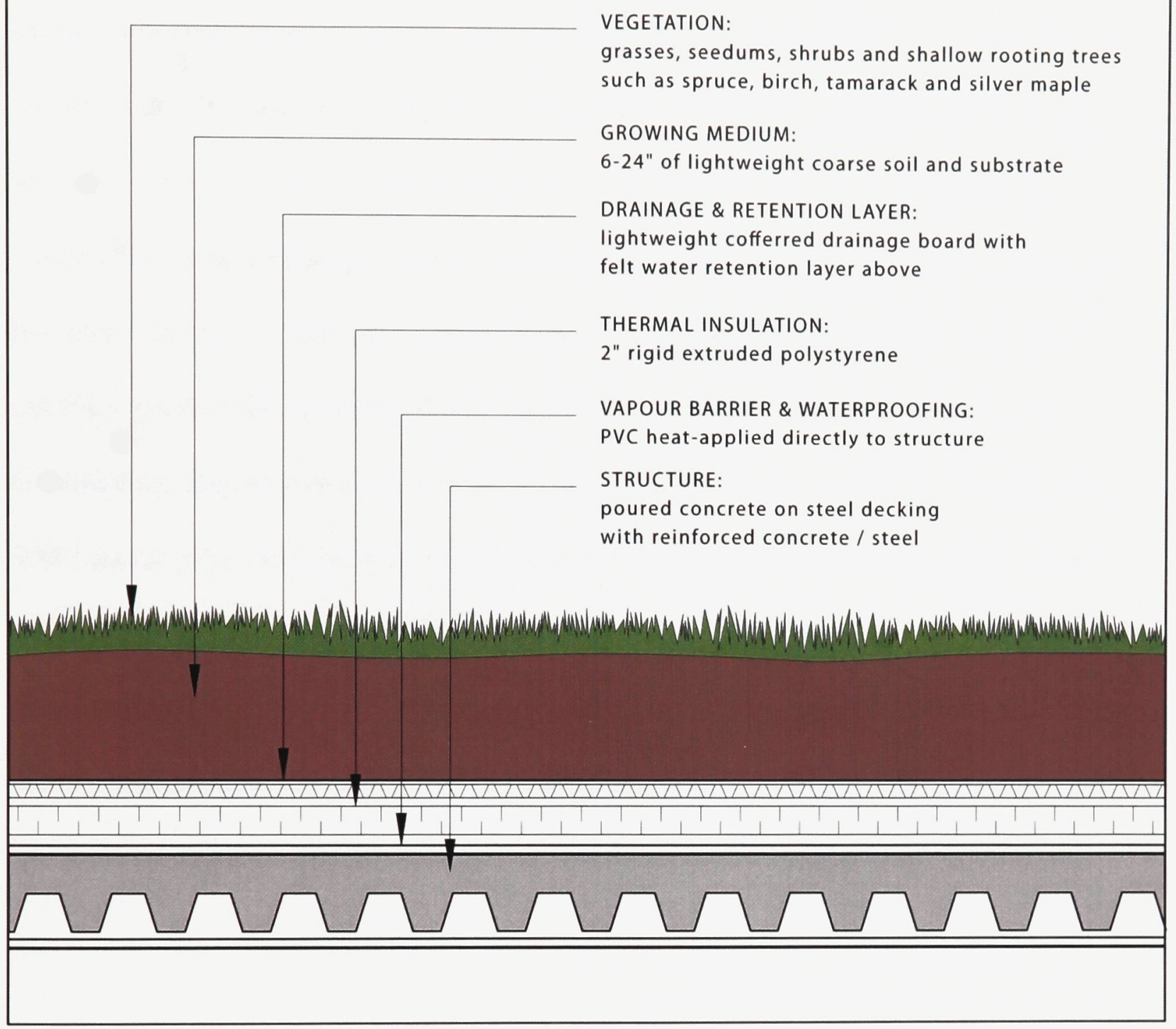

Image 3.3.19 Section detail of an intensive green roof assembly.

\section{Preserving the suburban house plan}

This project aims to achieve the suburban ideal of the private home by

providing rows of semi-detached homes that are separated by private gardens. When composed as part of a larger building, the recognition of any home as completely private proved to be the most difficult aspect to achieve. The formal arrangement of 
these homes where they do not share exterior walls but only the roof space of the home below is the closest this design came to the ideal of a fully-detached, singlefamily suburban home. The suburban house does exist in this building design, but it has been distilled and reconfigured. Most significantly, these homes are smaller, and wasteful interior space has been removed. In all three layouts, the ground floor living space is less spacious than a typical suburban home. The laundry room has become a laundry closet, and there are no longer any grand staircases, no vaulted ceilings, no double-height spaces, and, of course, no fourth or fifth bedrooms. Conversely, these homes are similar in many ways to their suburban counterparts. Yard space is in clear view from the interior as the house's openings are oriented toward the private garden and common green space at the rear of the building. Even the suburban 'bay window' is present, looking out from the eat-in kitchen. Living spaces and spaces meant for entertaining are located on the ground level, while the most private spaces (bedrooms and full bathrooms) are on the upper levels. 

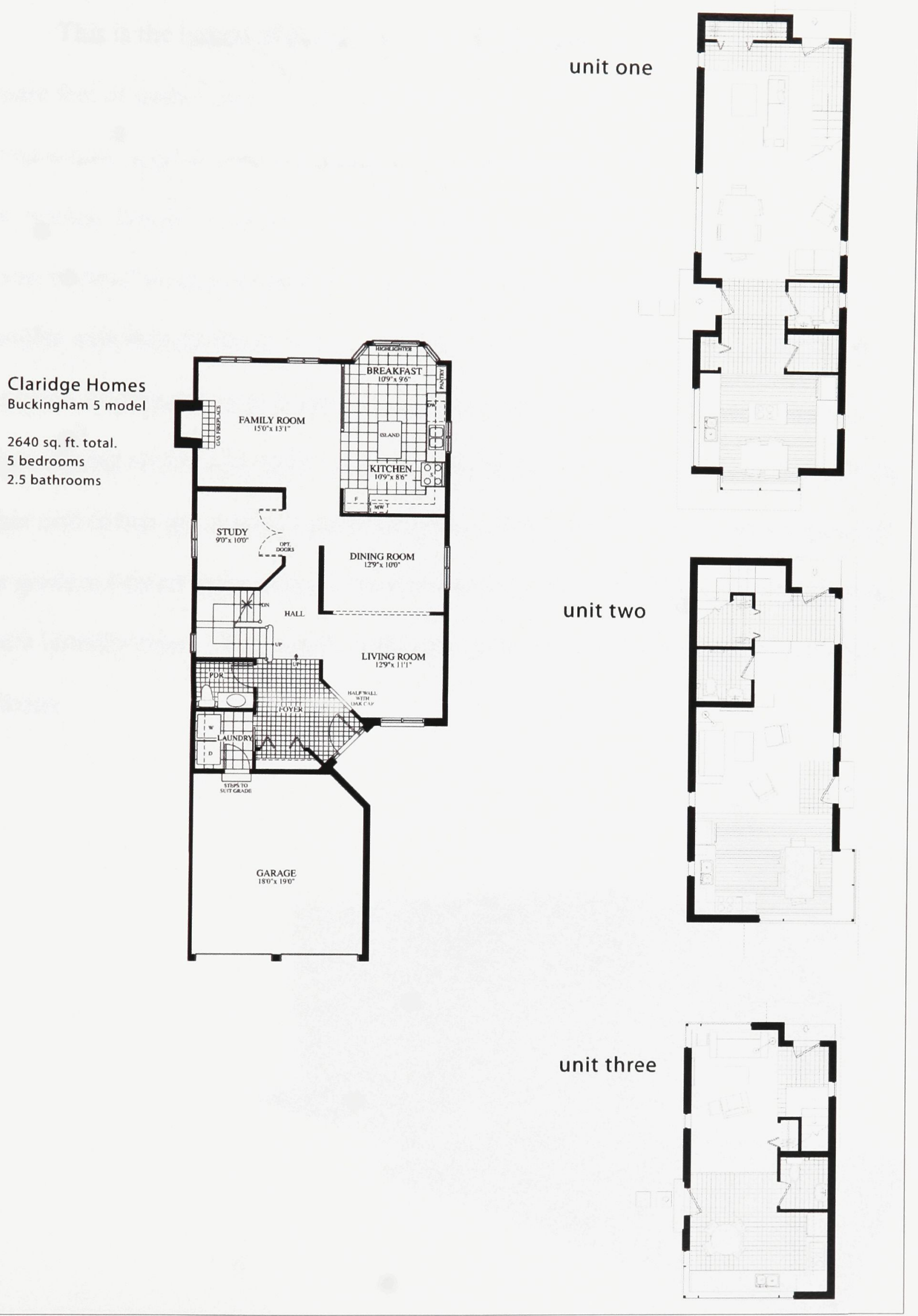

Image 3.3.20 Comparison image of the typical suburban floor plan and all three unit plans at the same scale. 


\section{Unit \#1}

This is the largest of the private homes provided. At approximately 1200 square feet of usable space, it is already drastically reduced from the typical suburban house which is greater than 2500 square feet on average. ${ }^{16}$ This house is designed for the 'nuclear family' arrangement of parents and 2.5 children or for other less 'conventional' arrangements that require more than one or two bedrooms, such as families with step-children, live-in relatives, or boarding tenants. From the front entrance, inhabitants step down into the living space which combines the living room, dining room, and study. A large kitchen, powder room, and pantry are at the other end of this space where generous glazing looks onto the grass and greenery of the gardens behind these units. Upstairs there are three bedrooms, a full bathroom, and a laundry closet. The master bedroom connects with its own ensuite bath and balcony.

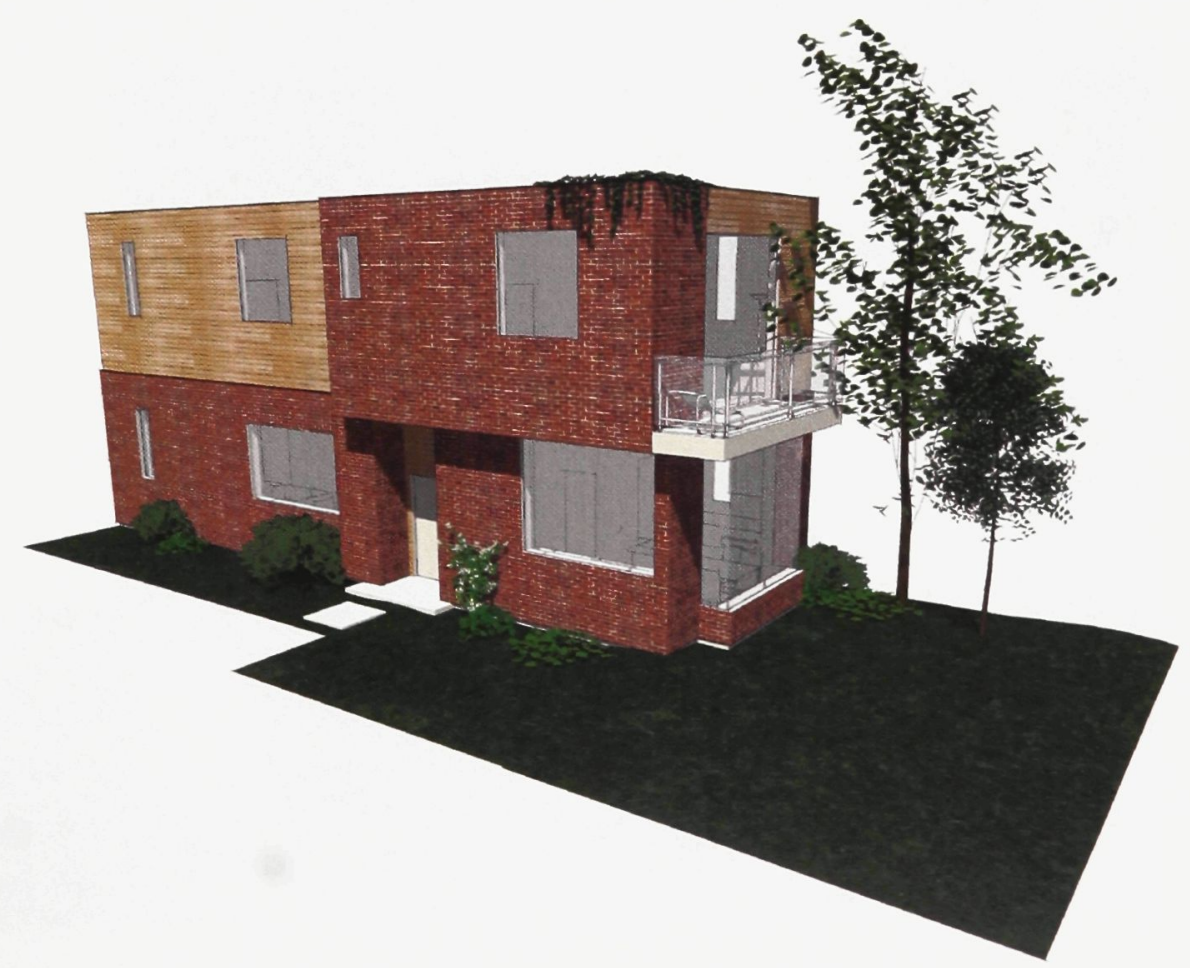

Image 3.3.21 Exterior view of private residential unit \#1 showing garden and exterior finishes. 


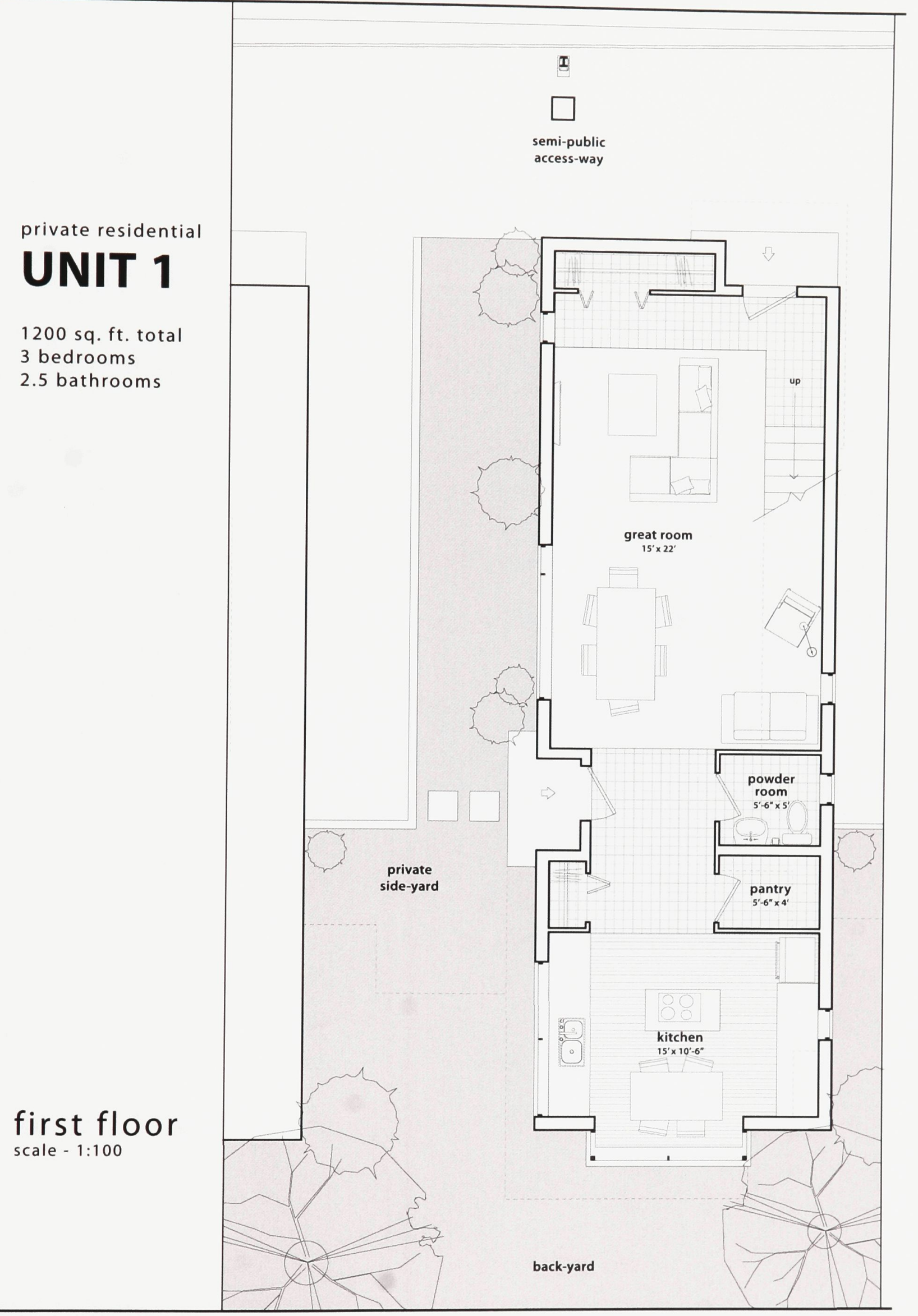

Image 3.3.22 First floor plan of private residential unit \#1. 
private residential

\section{UNIT 1}

1200 sq. ft. total

3 bedrooms

2.5 bathrooms second floor scale - 1:100

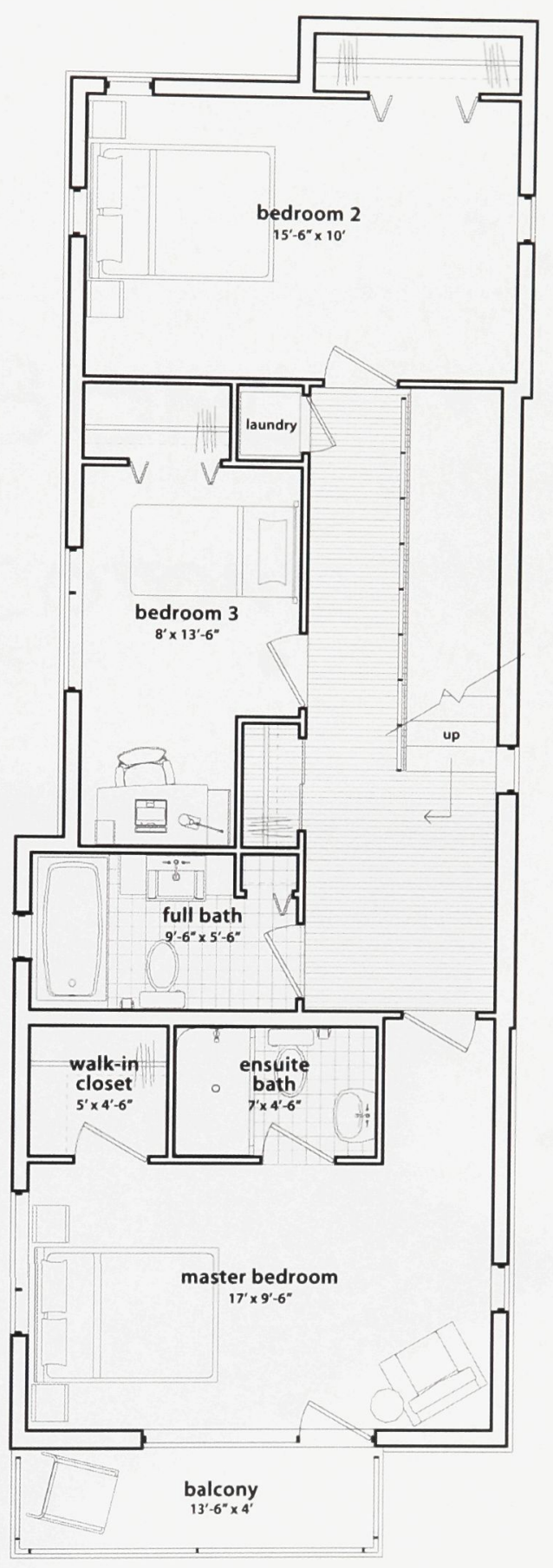

Image 3.3.23 Second floor plan of private residential unit \#1. 


\section{Unit \#2}

There are six such units in total, three of which sit on top of the larger 'unit \#1' houses below. Meant for a small family, or for any living arrangement that requires space for the national average of 2.6 inhabitants, this house provides two bedrooms and one-and-a-half bathrooms. Unit \#2 offers 1000 square feet of space within a five by twelve meter footprint. The majority of the glazing, again, faces south and to the east side where the side door and bay window connect with the private garden. Much like unit \#1, the inhabitant enters the front door one step up from the ground floor living spaces and eat-in kitchen. A staircase to the right leads over the closet and powder room to the second level, comprised of two bedrooms. A full bathroom and a den/office complete the upper level.

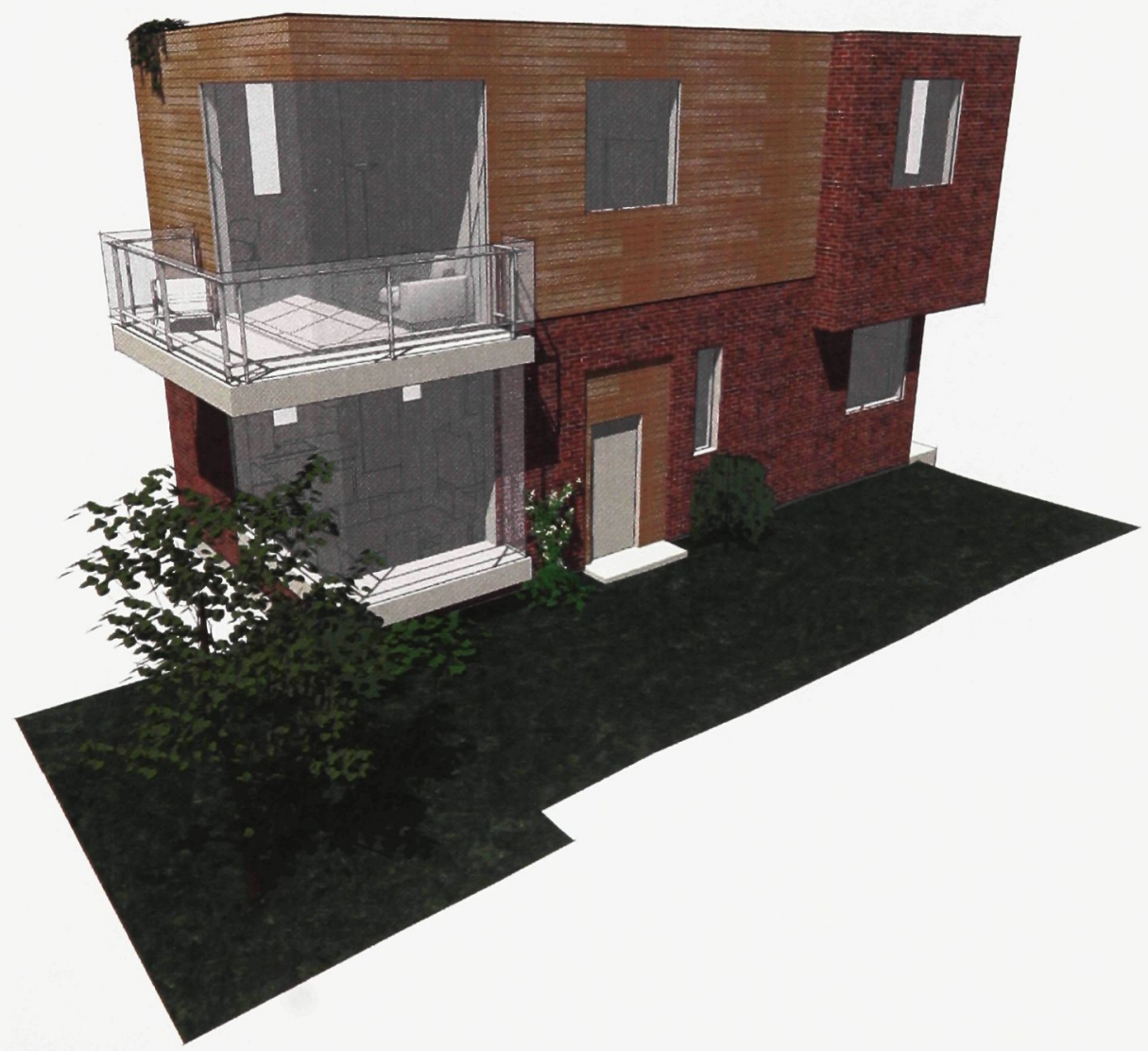

Image 3.3.24 Exterior view of private residential unit \#2 showing garden and exterior finishes. 


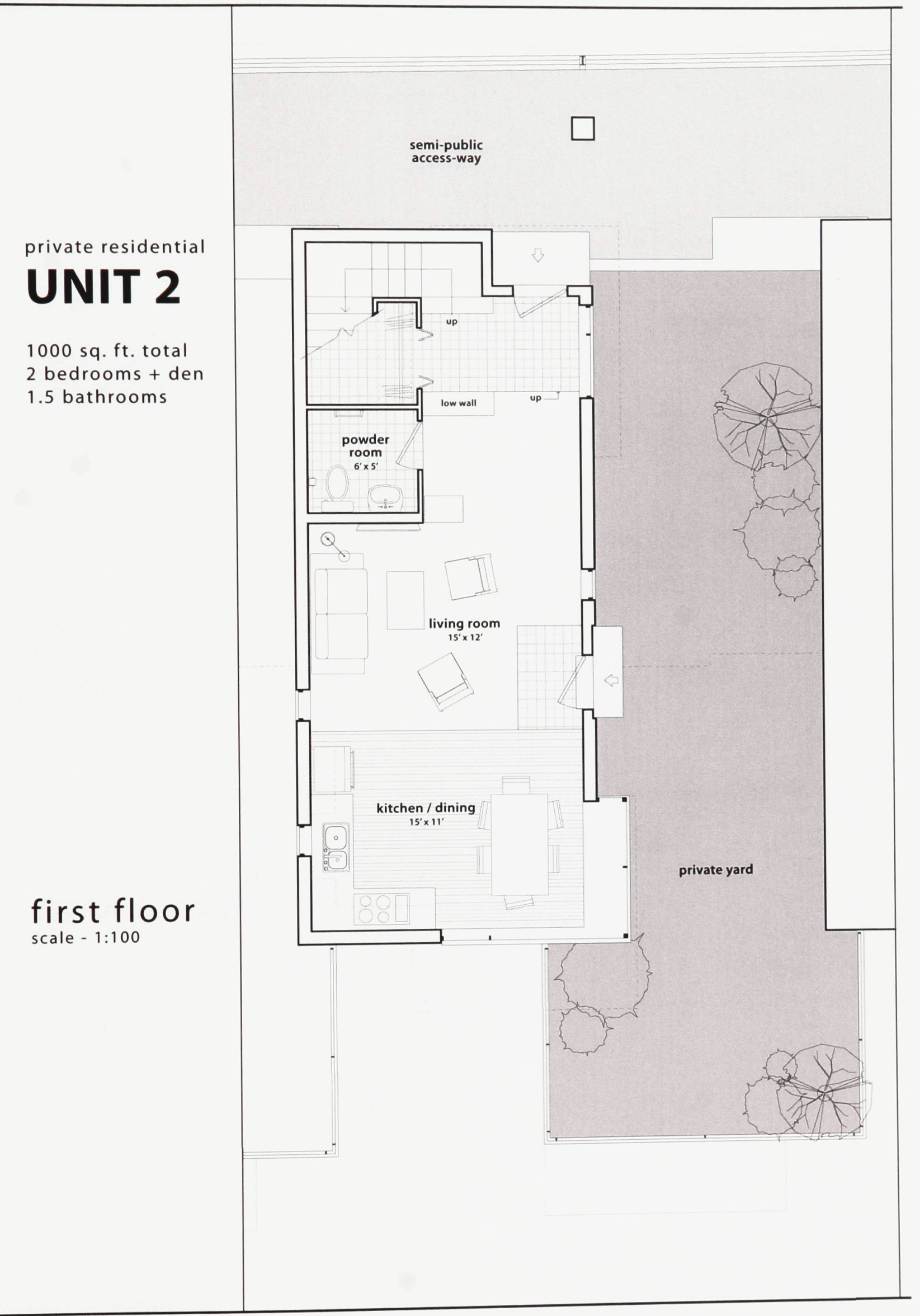

Image 3.3.25 First floor plan of private residential unit \#2. 
private residential

\section{UNIT 2}

1000 sq. ft. total

2 bedrooms + den

1.5 bathrooms

second floor scale - 1:100

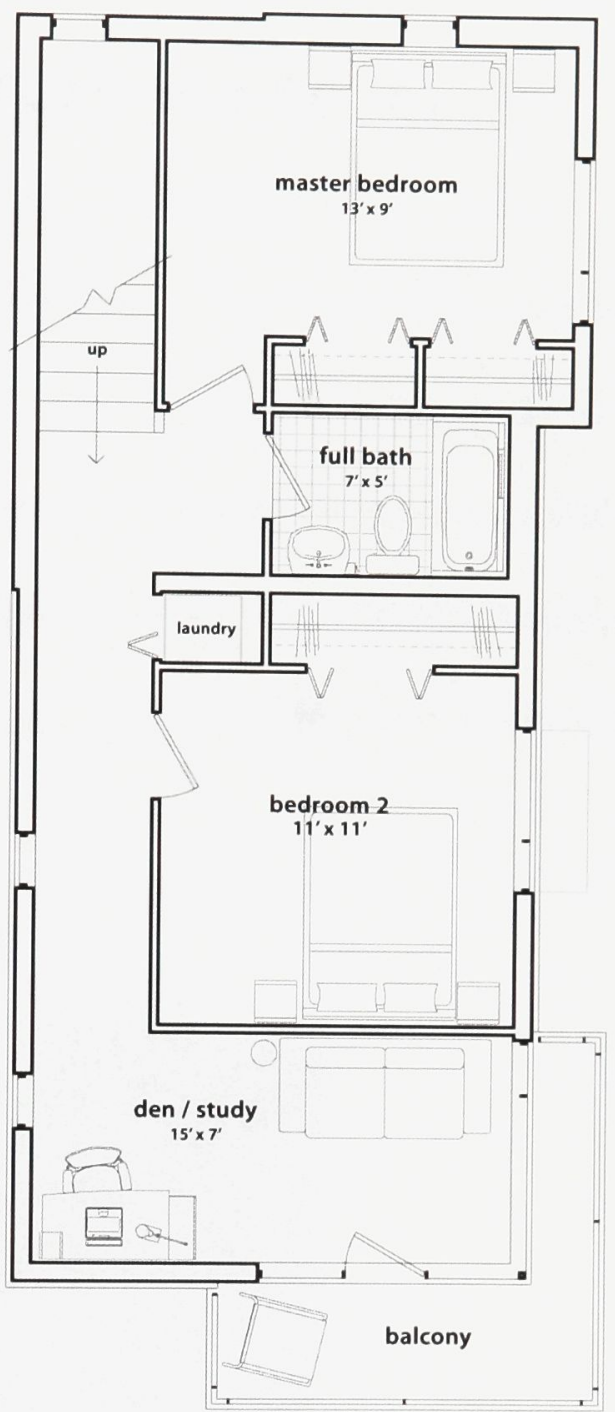

Image 3.3.26 Second floor plan of private residential unit \#2. 


\section{Unit \#3}

This house is designed as a reaction the reality whereby many suburban homes are being occupied by only one or two people. At 800 square feet, this unit offers the same amount of usable space as the Levittown house although its footprint is smaller (- just five by nine meters). Appropriate a single person, for a young couple, or a retired couple, this unit has one large bedroom, one and a half bathrooms, and a large study that could be used as a guest bedroom. Entering off the front porch, the inhabitant has the option to step down into the living room or travel up the stairs leading to the second level. A closet and a powder room are tucked under those stairs, opposite from the side door entry. The eat-in kitchen's windows look out over the greenery and trees rising from the gardens of the units below and westward to the private side-yard and garden.

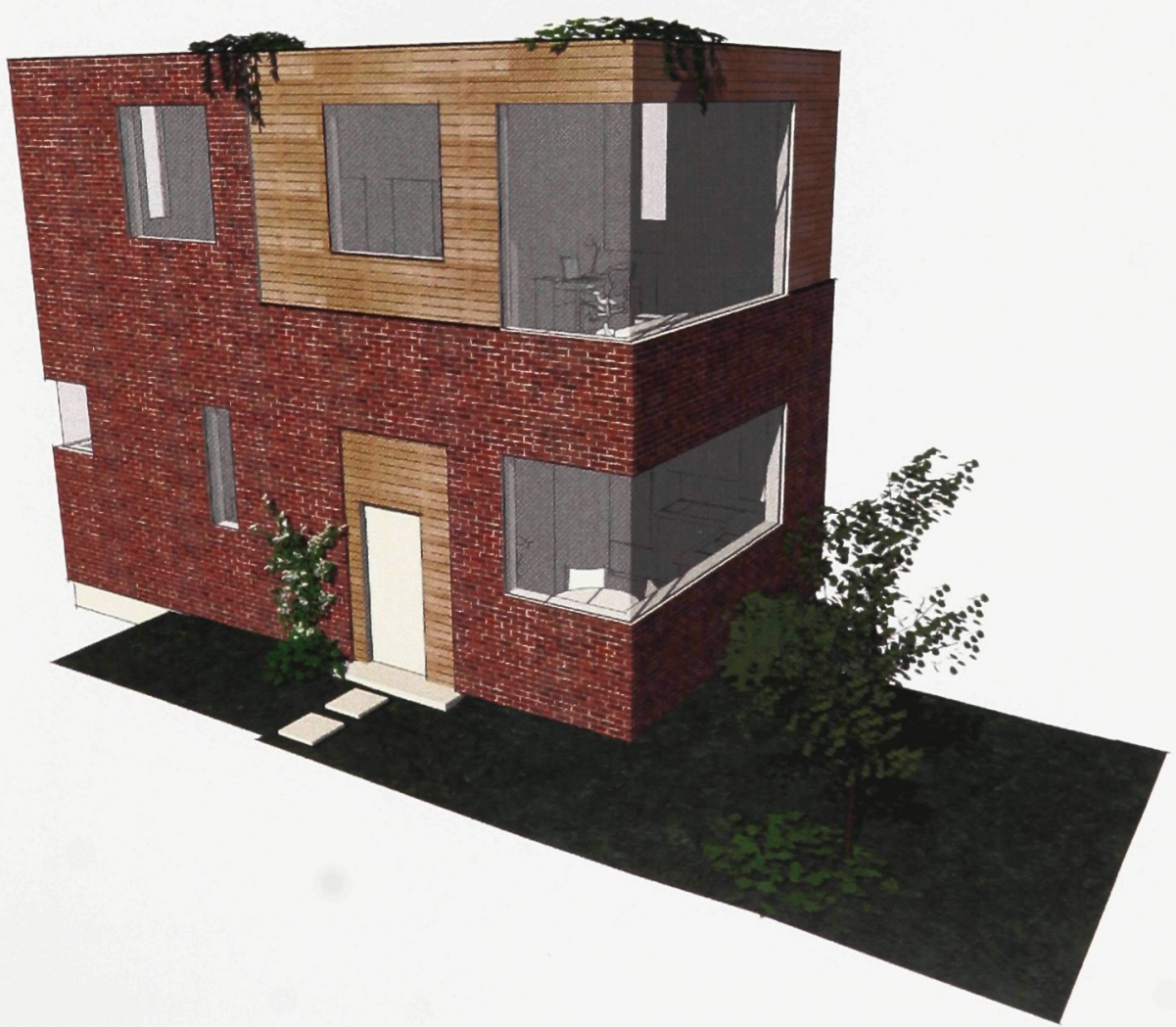

Image 3.3.27 Exterior view of private residential unit \#3 showing garden and exterior finishes. 


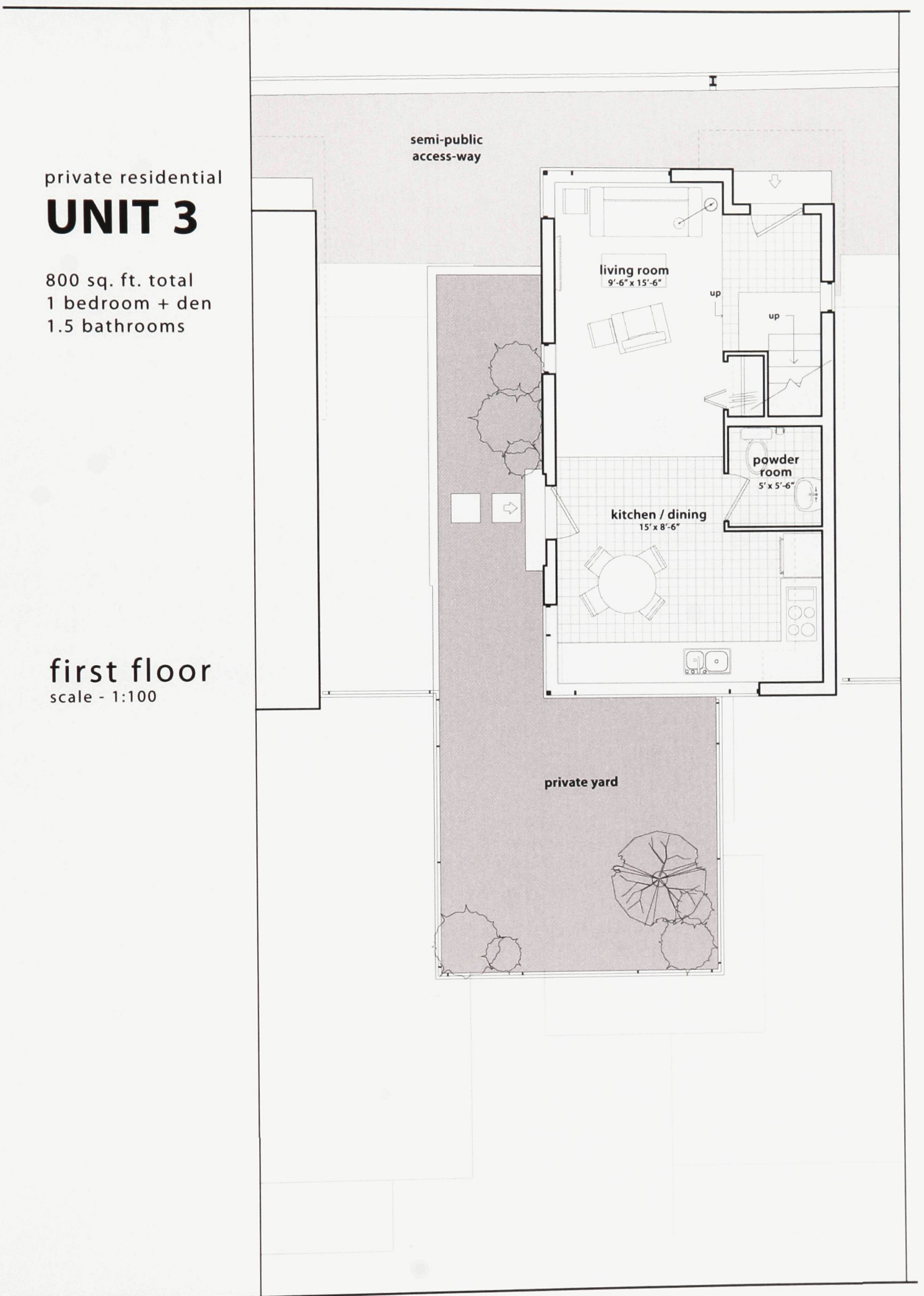

Image 3.3.28 First floor plan of private residential unit \#3. 
private residential

\section{UNIT 3}

800 sq. ft. total

1 bedroom + den

1.5 bathrooms

second floor scale - 1:100

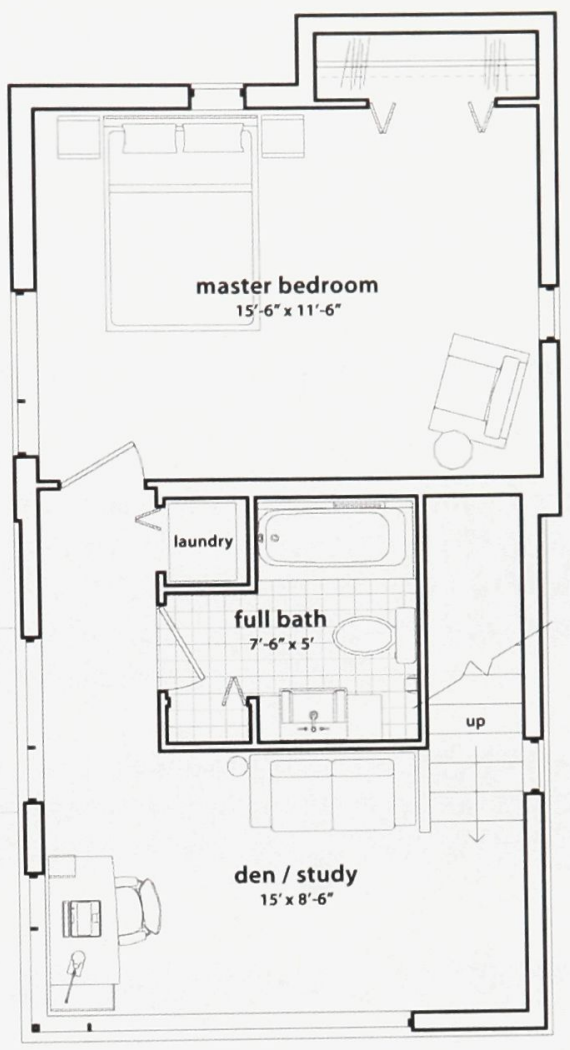

Image 3.3.29 Second floor plan of private residential unit \#3. 
${ }^{1}$ James Howard Kunstler, Home from Nowhere: Remaking Our Everyday World for the Twenty-First Century (New York: Simon and Schuster, 1996) 68-69.

${ }^{2}$ Jane Jacobs, Dark Age Ahead (New York: Random House, 2004) 145-147.

${ }^{3}$ Robert Fishman, Bourgeois Utopias: The Rise and Fall of Suburbia (New York: Basic, 1991) 38 . 2000) 250

${ }^{4}$ Edward W. Soja, Postmetropolis: Critical Studies of Cities and Regions (Oxford: Blackwell,

${ }^{5}$ For an image of the area being considered to be the central core, refer to image 3.1.1. Also, the city of Ottawa's central area and inner road network schedule shows an area that is bordered on the east by the Rideau River, on the North by the Ottawa River, on the west by a rail line near Preston Street, and on the south by the Queensway. The Ottawa 20/20 Plan is currently available online at: http://www.ottawa.ca/city_services/planningzoning/2020/op/index_en.shtml

${ }^{6}$ Refer to images 4.2 .5 and 4.2.6 in section 4 for a basic analysis of the cost effectiveness of the design presented in section 3 . Estimated building costs based on current construction values are used in conjunction with market values of retail, office and residential space to convey the economic feasibility of building design.

${ }^{7}$ Rhys Phillips, “An Eye for Neighbourhoods” Capital Style Magazine Fall 2003 Ed. $<$ http://www.capitalstyle.ca/fallo3/home_story.html>

${ }^{8}$ This value was given by the current owner of the site, Imperial Oil of Canada. Jackie Whitla, Property Administrator, Ontario Division. Imperial Oil of Canada. As per correspondence of July 11, 2006.

${ }^{9}$ Other properties whose City of Ottawa Assessment Roles do not compare with their own recent mortgage values were studied. Empty lots are not always able to be accurately assessed by City officials. See chart 3.1.21 for comparisons between assessed and mortgaged values.

${ }^{10}$ Information obtained from the Ottawa-Carleton Land Registry Office. 161 Elgin St., Ottawa $4^{\text {th }}$ Floor.

${ }^{11}$ All zoning information is freely available to the public and was obtained from City Hall, specifically the "Client Services Centre for Corporate Services and Public Information" on the first floor at 110 Laurier Avenue West, Ottawa.

${ }^{12}$ This development proposal was submitted on behalf of the owners of the site (Freedman Holdings Inc. and Claridge Homes) by Page + Steele Architects (Toronto). The eighteen-storey building would have included more than one-hundred and fifty residential units and three levels of underground parking. According Saide Sayah, the planner at the City of Ottawa's Planning and Development Department who was involved the review of the development's application, the project was rejected because it was simply too large in scale.

${ }^{13}$ Information obtained from the Ottawa-Carleton Land Registry Office. 161 Elgin St., Ottawa $4^{\text {th }}$ floor. 
14 "Selected Dwelling Characteristics," Statistics Canada, 25 Dec. 2005 <http://www40.statcan.ca/ 101/cst01/famil09a.htm?sdi=type\%20dwelling>

${ }^{15}$ Earth Pledge Foundation, Green Roofs: Ecological Design and Construction (Atglen, PA: Schiffer, 2005) 23. An "Intensive" green roof is different than an "Extensive" green roof because it is meant for human occupation and use. An extensive green roof assembly is simply a set of "planter boxes" laid side by side, on top of an existing roof; they are self sustaining, and grow only grasses and sedums. Intensive green roofs require more maintenance, but can support more vibrant panted environments. As such, they require more structural support and drainage systems.

${ }^{16}$ Research conducted by the author in 2004 throughout the suburban developments in the greater Ottawa area showed that the average suburban house was 2557 square feet in usable space. This amount is only reflective of the Ottawa-Gatineau region, at the time that the floor plan offerings were collected from developer's showrooms, and these amounts are the advertised footages, which often differ greatly from the actual sizes constructed. 


\subsection{CONCLUSIONS}

\subsection{Restatement of Argument}

This project is a reaction to the state of our contemporary urban realm. In the urban environment that defines many of North America's major metropolitan areas, the areas known traditionally as 'downtown' are suffering. Fewer and fewer people are living in working in the centers of large cities. ${ }^{1}$ Similarly, what were once known simply as 'suburbs' are disappearing because they have become urban centers of their own, complete with copious amounts of commercial and office space in addition to all the housing. ${ }^{2}$ This new type of supposedly urban development, referred to here as the 'contemporary urban realm' occurs at a much lower density than the traditional city. Filled with sprawling office campuses, huge swaths of retail's new big-box store format, and endless subdivisions, these places are in the middle-ground between the traditional suburb and the traditional city. The built density that defines the idea of the city is lost. The simple, clean, and removed nature of the suburbs is also lost.

If this trend in which our cities and suburbs continue to merge persists unaltered, the North American landscape will become a fully decentralized and, I believe place-less environment. The built density would require the use of a car to get just about anywhere. Even now, the North American dependency on the automobile has become a serious problem from an environmental and personal physical and mental health perspective. In light of this reality, this thesis project is an architectural response that proposes an alternative. 
The contemporary urban realm qualifies neither as city nor suburb. The present-day merging of these two divergent notions has resulted in a decentralized, medium-density built fabric where the positive aspects the truly urban and the truly suburban are lost.

Having stated that, the thesis question asks:

In recognition of the ongoing merging of city and suburb, is there an architecture that can more accurately hybridize the urban and suburban realms?

Some of the specific project goals described in this project's scope were put in place to ensure that the project remained socially and economically realistic -realistic from the point of view of a developer, or even the planning department at the City of Ottawa. To have worked outside of the constraints of economic feasibility would likely have produced a building design unreasonably expensive to construct. As such, no meaningful comparisons could ever have been made between this project and real developments -- urban or suburban. For this reason, parts of the design project had to be approached from a developer's point of view. In the same way, the design project was also influenced by municipal zoning requirements. As one of the major terms of reference in the argument, the urban quality of the chosen site had to be carefully considered. How could a design project claiming to "contribute to the surrounding urban context" not adhere to the basic zoning by-laws governing the site? As such, the stipulations that limited usages, setbacks, building heights, and amounts of amenity space were carefully observed. In the end, it was these constraints and the self-imposed requirements set out at the beginning that 
largely defined and shaped the building design presented in Section 3. For the sake of reference, those requirements were:

- Programmatically, the building had to provide 5000 square feet of leasable retail space and 5000 square feet of leasable office space. It had to offer a minimum of 30 dwelling units, where at least 15 of the total numbers of units are of the 'partially-detached' private home type. (At a minimum of 800 square feet each.) Also, there had to be automobile parking in the amount of one space per dwelling unit, and at least one full level (approx. 30 spaces) of underground parking reserved for use by patrons of the retail and office space.

- A basic financial analysis of the construction costs and projected sales income had to produce a $100 \%$ profit within the first 5 years of construction completion.

\subsection{Project Summary}

The degree to which the design project can be judged as having met its stated goals is only part of the criteria for its success. Should it only partially satisfy its quantitative and qualitative goals it would still stand as an one of the few urban design projects that contribute specifically to this topic in the context of the City of Ottawa. It is one of only a few projects that argue for a migration of the suburban traits into the city, as opposed to the much more common scenario which involves bringing aspects of the city out to the suburbs.

This project met its quantitative goals which aimed to yield affordable 'suburban' housing and a developer profit of $100 \%$ in the time prescribed. The self- 
imposed requirements of total square footages were met and exceeded. The parking requirements were satisfied, and the provision of a certain number of private homes was achieved. Even the financial analysis, although it is difficult to explicate definitively, shows that the building design can be profitable within the conventional developer time requirements stated. This issue will be explained in more detail later in this text. The programmatic elements of the building conform to the zoning bylaws, and the amenity space requirement of eighteen square meters per residential unit has actually been surpassed.

It is the qualitative goals that are more difficult to judge because they are subjective. Despite the difficult nature of this type of evaluation, the purpose of this section of the text is to discuss how the design project addressed the three central suburban ideas and their hybridization with the surrounding urban realm.

\section{The suburban desire for a detached, private home}

The homes provided are not a precise transfer of suburban homes into the city. As already described, they have been distilled. They are reduced in size through the removal of rooms judged as expendable. The resulting housing stock represents a version of the suburban home that reflects the declining number of persons living in private households. At 1200, 1000, and 800 square feet of usable space, these homes are much less grandiose. They all share a similar esthetic on their exteriors which is not about any kind of outward expression or differentiation from one's neighbour's house. These reductions are the main distinction between the suburban house and the private homes offered in this project. If a home-buyer is 
looking only for a large home with extra bedrooms, these homes would not likely appeal to them.

The private homes offered here would also fail under the traditional understanding of a home as 'fully detached.' Despite efforts to retain the image of each unit as its own private entity, which included having no two homes share a party wall, the homes will inevitably be seen as a part of a larger building. They sit in rows along a shared concrete superstructure, they are joined by continuous steel access-ways, and they all sit behind a continuous glass façade that stretches almost from one end of the site to the other. As such, it is difficult to see these homes as an instance of the completely autonomous suburban house, yet, arguably, they are not less distinct than an endless series of detached but identical suburban homes.

Having acknowledged the shortcomings of these units, their redeeming qualities and successes as design alternatives need to be stated. If looked upon as an urban version of the detached house, they offer many positive alternatives to their potential inhabitants. They exist as part of a closely-knit neighbourhood of dwellings that exist in various sizes, in both the private and condominium formats. As a result, the neighbourhood is likely to be a diverse and interesting place; because dwellings of various sizes exist, persons of differing levels of income are likely to live there. As such, this building is an example of an arrangement meant to be free of the class segregation so common in the contemporary urban realm. The space of the automobile, which is essentially the defining spatial element of contemporary urban realm, has been removed from the residential space of this project. These homes are a form of dwelling that offers safety from the dangers of passing cars. The necessity 
of the space of the suburban front lawn, which is a buffer zone between the house and the road, has been eliminated with the road and the parking garage relocated below grade. These homes suffer no lack of sunlight and no lack of direct contact with the exterior space when compared with their suburban counterparts. In addition, these homes offer a series of benefits to their inhabitant by virtue of their location within the city. Shops and stores exist within the building, and all along Rideau Street; as do all of the entertainment, institutional, and civic buildings that would otherwise require a trip in the car in a less dense type of development. As is shown later in the text, these homes are sold at prices cheaper than the typical detached home. ${ }^{3}$ They are admittedly smaller than those homes, but they are not deficient in any way other than having fewer bedrooms than the largest of suburban house plans. Inhabitants would also save money because of the convenient location. Not having to drive to work or to the store represents a major savings in time and money for the typical urban dweller, and in this design these savings are offered to the inhabitant of a private home as well.

\section{The suburban desire for contact with open green space.}

The purpose of the provision of green space within this design was not to question the validity of the suburban desire for contact with green space, or to ask why green space is considered a suburban ideal. It was simply to explore how those yard spaces might look when transferred into the city. As such, the question then becomes: would a suburban dweller be enticed by the green space in this project? If that person requires that their piece of 'land' occurs only at the ground level, then 
likely not. If that person is concerned with the quality of the green space and its ability to sustain plantings of all types, then these gardens might succeed. The gardens provided in this project are not intended as a replacement of nature, as many of the parks and yard spaces provided in suburban development are often marketed. The purpose here is to provide the adjoining piece of 'land' that is an essential part of the image of the private suburban home. These gardens are essentially concrete troughs filled with soil that are automatically irrigated and drained. The soil is deep enough to sustain grasses, flowers, and shrubs, as well as shallow rooting trees which grow as tall as two storeys. Every effort has been made to make these gardens equivalent or better than the yard spaces of suburban developments. They are private in the sense that a neighbour's house is not afforded views into another's garden because each house's glazing is largely oriented to one side. Many of these garden spaces also occur at levels of the building that are far removed from any common spaces, making them increasingly private at each level. The glazed façade that stretches across the front of the building provides a wind barrier for these exterior spaces. The slim garden spaces between units would otherwise have been overly windy. By blocking wind gusts from one side, these exterior spaces become more comfortable. Sun exposure to these gardens is maximized by the building's orientation and also by the use of materials that allow the passage of sunlight. The rear of the building faces south and slightly east, while the steel-grating of the upper access-ways is an assembly of materials that is open enough to allow weather to penetrate to the lowest levels of residential space. 
Although reshaped and somewhat reduced in area, these gardens satisfy the suburban desire for contact with green space. This design provides the inhabitant with direct access to a private piece of land right outside their door, and the freedom to landscape it however they desire.

\section{The suburban expectation of affordability.}

This expectation still survives today, despite the fact that some contemporary suburban homes are actually very expensive and sometimes no cheaper than a similar-sized home in the city. ${ }^{4}$ In order to address the suburban expectation of affordability, this design produced private dwellings that were of comparable value to the equivalent home in a suburban development. In greater Ottawa, many people live outside of the city centre because they can buy a larger house on a smaller mortgage; this project, as a hybrid, bridges that gap.

The goal was to provide the suburban dweller with a viable option for private dwelling within the urban core, or else the suburban side of this hybrid building type would be dramatically flawed. The private residential units offered by this thesis are comparable to suburban homes in many ways, as already discussed, but they go further. It is hoped that whatever an inhabitant of these homes gives up as far as actual living space is made up for by the value added by virtue of the building's location (i.e. proximity to work reduces travel costs, etc.). The building costs that would otherwise have gone into a larger home with more luxurious finishes are instead used to re-create the ground plane on upper levels of this urban building. In these types of trade-offs, the actual dollar value of these items is difficult to pinpoint. 
It thus became necessary to prove the feasibility of this building project based on quantifiable items like constructions costs per square foot, income from the sale of dwelling units, and average lease rates for retail and office space. If this site could be developed in a manner that produced a building that would be profitable based on these tangible qualities, only then would the suburban expectation of affordability become verifiable.

The purpose of this portion of text then is to discuss the economic feasibility of the building design presented in Section 3. As already stated, certain requirements of total square footages and numbers of residential units have been met. In the charts that follow, programmatic elements are listed and their actual physical areas are associated with a dollar amount that reflects the cost to construct one square foot of that type of building. In this section, areas and construction costs are listed in Imperial measurement because this is the accepted format in the cost evaluation industry.

The design presented in Section 3 conveys a building that is primarily made of steel-reinforced concrete. The only aspects of the building that are any different are the steel access-ways at upper levels, the glass curtain-wall that forms the Rideau Street façade and, of course, the assemblies required as part of the intensive green roof areas. The private homes are envisioned as being repetitively formed in place as individual concrete units connected to the larger concrete 'superstructure.' The extent to which certain aspects of the building are provided with interior finishes affects the construction costs, and some areas of the building are purposefully costed as being 'unfinished space.' The retail and office spaces are left without interior finishes because tenants often provide these themselves, and the cost per square foot 
reflects that. Residential spaces, however, are completely finished in order to allow condominium dwellers and homeowners to move right in, which is also how these construction types are usually estimated. Image 4.2.1 shows the costs per square foot of the construction types applicable here. These dollar amounts are upon based the advice of a local quantity surveyor ${ }^{5}$ and the amounts given for each construction type in recent quantity surveyors handbooks. ${ }^{6}$ It should be clarified that the cost associated with the intensive green roof is an amount covering the irrigation systems and drainage assemblies required, as well as the growing medium. The cost of the additional concrete structure required to support the gardens is factored into the cost of the structure below.

\begin{tabular}{|c|c|}
\hline CONSTRUCTION TYPES & $\begin{array}{l}\text { COST } \\
\text { per sq. ft. }\end{array}$ \\
\hline $\begin{array}{l}\text { parking garage } \\
\text { reinforced concrete } \& \text { asphalt }\end{array}$ & $\$ 75$ \\
\hline $\begin{array}{l}\text { retail + office space } \\
\quad \text { reinforced concrete and steel, aluminum partitioning, unfinished space }\end{array}$ & $\$ 60$ \\
\hline $\begin{array}{l}\text { private residential } \\
\text { reinforced concrete superstructure and individual structure, aluminum partitioning, } \\
\text { interior finishes included }\end{array}$ & $\$ 130$ \\
\hline $\begin{array}{l}\text { condominium high-rise residential } \\
\text { reinforced concrete and aluminum partitioning, interior finishes included }\end{array}$ & $\$ 110$ \\
\hline $\begin{array}{l}\text { façade } \\
\text { curtain wall with steel structural elements, fixed to concrete superstructure }\end{array}$ & $\$ 50$ \\
\hline $\begin{array}{l}\text { semi-public access-ways } \\
\text { steel framed with steel grating }\end{array}$ & $\$ 25$ \\
\hline $\begin{array}{l}\text { exterior garden } \\
\quad \text { intensive green roof technology with irrigation, drainage and landscaping }\end{array}$ & $\$ 30$ \\
\hline $\begin{array}{l}\text { interior garden } \\
\quad \text { intensive green roof technology with irrigation, drainage and landscaping }\end{array}$ & $\$ 30$ \\
\hline
\end{tabular}

Image 4.2.1 Chart showing construction values by type of construction. 
The cost to construct this building design is not entirely known due to the fact that the building details are incomplete. To claim that the following cost analysis is fully realistic would be imprudent: only generalized descriptions of the building's assembly have been identified -- more detailed work would be helpful, but time would not allow any further design work to be done. The chart on the following page breaks the building into programmatic elements, lists the areas associated with them, and totals the costs involved in constructing them. It is important to note that the cost of purchasing and servicing the site is not included within chart 4.2.2, but it is included in the cost analysis of the entire project given in chart 4.2.5. Also, when costs are listed in this manner, vertical circulation spaces (elevator cores and stairwells) are counted as part of the assembly that they service, and, as such, not listed separately.

In summary, forty percent of this building's total costs are given over for the underground parking garage, which is too high, and a shortcoming of the design. Also, when the total cost of constructing the individual private homes was divided by fifteen, (the total number of homes) the average construction cost was only about $\$ 125,000$ each. This figure seems on par with the costs involved with wood-framed detached homes around Ottawa and points to a glaring discrepancy: it is reasonable to expect that poured-concrete homes formed at heights of up to 6 storeys in the air, in a very complex manner, should be a much more expensive than wood-framed houses on the ground. This incongruity is likely a result of a basic and generalized the cost analysis. However, as a tool for determining the simple economic feasibility of the design, the following figures serve their purpose. 


\begin{tabular}{|c|c|c|c|}
\hline CONSTRUCTION COSTS & $\begin{array}{l}\text { AREA } \\
\text { (sq. ft.) }\end{array}$ & $\begin{array}{r}\text { COSTS } \\
\text { (per sq. ft.) } \\
\end{array}$ & $\begin{array}{l}\text { TOTAL } \\
\text { COSTS }\end{array}$ \\
\hline \multicolumn{4}{|l|}{$\begin{array}{l}\text { PARKING GARAGE } \\
78 \text { parking spaces and } 33 \text { storage lockers }\end{array}$} \\
\hline \multicolumn{2}{|l|}{$\begin{array}{l}78 \text { parking spaces and } 33 \text { storage lockers } \\
\text { level } \mathrm{P} 1\end{array}$} & & \\
\hline level P2 & 22000 & & \\
\hline level P3 & 22000 & & \\
\hline total: (includes all parking area, circulation, mechanical \& storage) & 65500 & $\$ 75$ & $\$ 4,912,500$ \\
\hline \multicolumn{4}{|l|}{ RETAIL SPACE (ground floor) } \\
\hline \multicolumn{4}{|l|}{$\begin{array}{l}\text { includes } 5 \text { units off of an enclosed sidewalk } \\
\text { unit } 1\end{array}$} \\
\hline & 1130 & & \\
\hline unit 3 & 955 & & \\
\hline unit 4 & 1540 & & \\
\hline unit 5 & 1240 & & \\
\hline subtotal (leasable space) & $\begin{array}{l}1240 \\
6105\end{array}$ & & \\
\hline total: (includes retail promenade space + delivery \& storage) & 9200 & $\$ 60$ & $\$ 552,000$ \\
\hline \multicolumn{4}{|l|}{ OFFICE SPACE (1st floor) } \\
\hline \multicolumn{4}{|l|}{$\begin{array}{l}\text { includes } 3 \text { offices with bathrooms } \\
\text { unit } 1\end{array}$} \\
\hline unit 1 & 2860 & & \\
\hline unit 2 & 1475 & & \\
\hline $\begin{array}{l}\text { unit } 3 \\
\text { subtotal (total leosable snace) }\end{array}$ & 925 & & \\
\hline subtotal (total leasable space) & 5260 & & \\
\hline total: (includes office space + lobby \& bathrooms) & 6550 & $\$ 60$ & $\$ 393,000$ \\
\hline \multirow{2}{*}{\multicolumn{4}{|c|}{$\begin{array}{l}\text { CONDOMINIUM TOWER } \\
\text { includes } 18 \text { condominium units }+ \text { common areas }\end{array}$}} \\
\hline & & & \\
\hline \multicolumn{4}{|l|}{$\begin{array}{l}\text { includes } 18 \text { condominium units }+ \text { common areas } \\
\text { lobby \& ground floor rooms }\end{array}$} \\
\hline exterior green space (roof) & 2500 & $\$ 30$ & $\$ 75,000$ \\
\hline interior green space & 1220 & $\$ 30$ & $\$ 36,600$ \\
\hline enclosed common area (with pool) & 3000 & $\$ 120$ & $\$ 360,000$ \\
\hline residential circulation space & 3600 & $\$ 110$ & $\$ 396,000$ \\
\hline \multicolumn{4}{|l|}{ residential condo units: } \\
\hline $\begin{array}{l}6 @ 1150 \text { sq. ft. } \\
6 \text { @ } 750 \text { sq. ft. }\end{array}$ & $\begin{array}{l}6900 \\
4500\end{array}$ & & \\
\hline $6 @ 650$ sq. ft. & 3900 & & \\
\hline subtotal: & 15300 & $\$ 110$ & $\$ 1,683,000$ \\
\hline total: & & & $\$ 2,721,240$ \\
\hline \multicolumn{4}{|l|}{ PRIVATE RESIDENTIAL UNITS } \\
\hline \multicolumn{4}{|l|}{ includes 15 private residential units + landscaping and circulation } \\
\hline ground floor lobby & 620 & $\$ 60$ & $\$ 37,200$ \\
\hline green space (total) & 12068 & $\$ 30$ & $\$ 362,040$ \\
\hline façade construction & 9494 & $\$ 50$ & $\$ 474,700$ \\
\hline \multicolumn{4}{|l|}{ private residential units: } \\
\hline (3) 1200 sq. ft. units & 3600 & & \\
\hline (6) 1000 sq. ft units & 6000 & & \\
\hline (6) 800 sq. ft. units & 4800 & & \\
\hline subtotal: & 14400 & $\$ 130$ & $\$ 1,872,000$ \\
\hline steel access-ways (total area of all 3 levels) & 3730 & $\$ 25$ & $\$ 93,250$ \\
\hline total: & & & $\$ 2,839,190$ \\
\hline TOTAL COST: & & & $\$ 11,417,930$ \\
\hline
\end{tabular}

Image 4.2.2 Chart showing areas and total construction costs for the building design. 
In Section 3 of this document, the economic profiles of the sites considered for development were compared. Site \#4, for its size and current mortgage value was deemed to be the most affordable. As discussed earlier, the site chosen for development would have to allow for the type of development this project was seeking: a hybrid of urban and suburban building types. Because the density of this building would likely be lower than a typical urban building, the value of the site itself would also determine how profitable the project would be. How, then, does the price attached to this urban site affect proposed development? The current market value of this empty site, which is estimated at $\$ 1,100,000$, has to be considered along with construction costs and sales income. To determine what types of buildings might be 'developable' on this site, compare the following scenarios -- two of which are at the extreme opposite ends of the development spectrum: one urban, and one suburban. The third presents an intermediate scenario (this project or an Urban Suburbanism option), that is meant to fall somewhere in the middle of the two extremes.

\section{1) The Suburban cost scenario (see images 4.2 .3 and 4.2.4)}

Five fully-detached, single family homes based on the model floor plans offered in suburban Ottawa. This is the maximum number of these homes that this site on Rideau Street will physically fit.

\section{2) The Urban cost scenario (see images 4.2.5 and 4.2.6)}

A high-rise slab building consisting of 120 condominium units. This scenario maximizes the zoning envelope and maximum height requirements on this site.

\section{3) The Urban Suburbanism cost scenario (see charts 4.2.7 and 4.2.8)}

Urban requirements for parking and for commercial space facing the street are satisfied, while portions of residential space occur in a suburban format. 


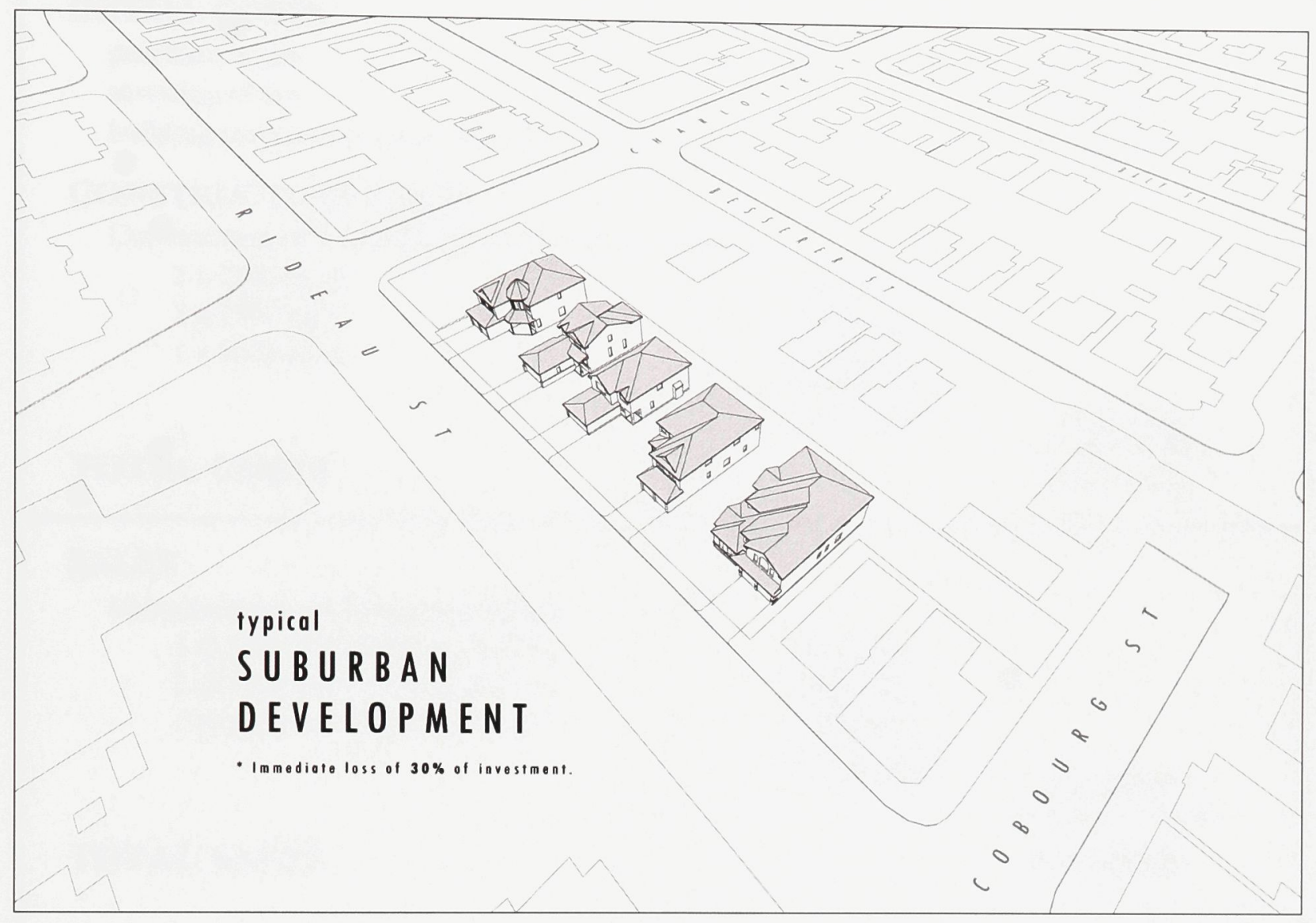

Image 4.2.3 Image showing 'a typical suburban development on the Rideau Street site.' The site would fit five typically-sized suburban homes accessed directly off of Rideau Street. 


\section{Cost Scenario:}

\section{TYPICAL SUBURBAN DEVELOPMENT}

\section{INITIAL COSTS}

purchase of site

$\$ 1,100,000$

servicing of site

$\$ 100,000$

building permit (at $\$ 13.50$ per $\$ 1000$ of construction costs)

$\$ 16,875$

\section{CONSTRUCTION COSTS}

Construction of 5 detached homes (at $\$ 100$ per sq. ft.) *

$$
\begin{aligned}
& 2 \times 2000 \text { sq. ft. } \\
& 2 \times 2500 \text { sq. ft. } \\
& 1 \times 3500 \text { sq. ft. }
\end{aligned}
$$

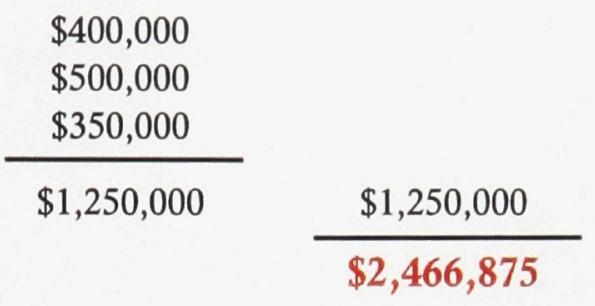

\section{TOTAL COSTS}

\section{SALES}

Immediate sale of 5 detached homes

$$
\begin{aligned}
& 2 @ \$ 300,000(2000 \text { sq. ft. }) * * \\
& 2 @ \$ 350,000 \text { (2500 sq. ft.) } \\
& 1 @ \$ 450,000 \text { (3500 sq. ft.) }
\end{aligned}
$$

$$
\begin{array}{r}
\$ 600,000 \\
\$ 700,000 \\
\$ 450,000 \\
\hline \$ 1,750,000
\end{array}
$$

TOTAL SALES

$\$ 1,750,000$

\section{TOTAL SALES}

TOTAL COSTS

$$
\begin{gathered}
\$ 1,750,000 \\
(\$ 2,466,875) \\
\hline(\$ 716,875)
\end{gathered}
$$

Therefore, the construction and sale of fives homes on this property would yield a loss of $\$ 716,875$ for the developer.

* Although actual values are higher in the Ottawa region, the rate of $\$ 100$ per square foot is assumed for these comparisons. A typical wood-framed residential building in Canada would average between $\$ 90$ and $\$ 140 /$ sq. $\mathrm{ft}$. with basic interior finishes included.

These values are an approximation based on data collected in the greater Ottawa region. These prices reflect the current (2005) values of single-family, fully-detached homes in suburban developments around Ottawa.

Image 4.2.4 Chart showing the cost scenario for a typical suburban development on the Rideau Street site. 


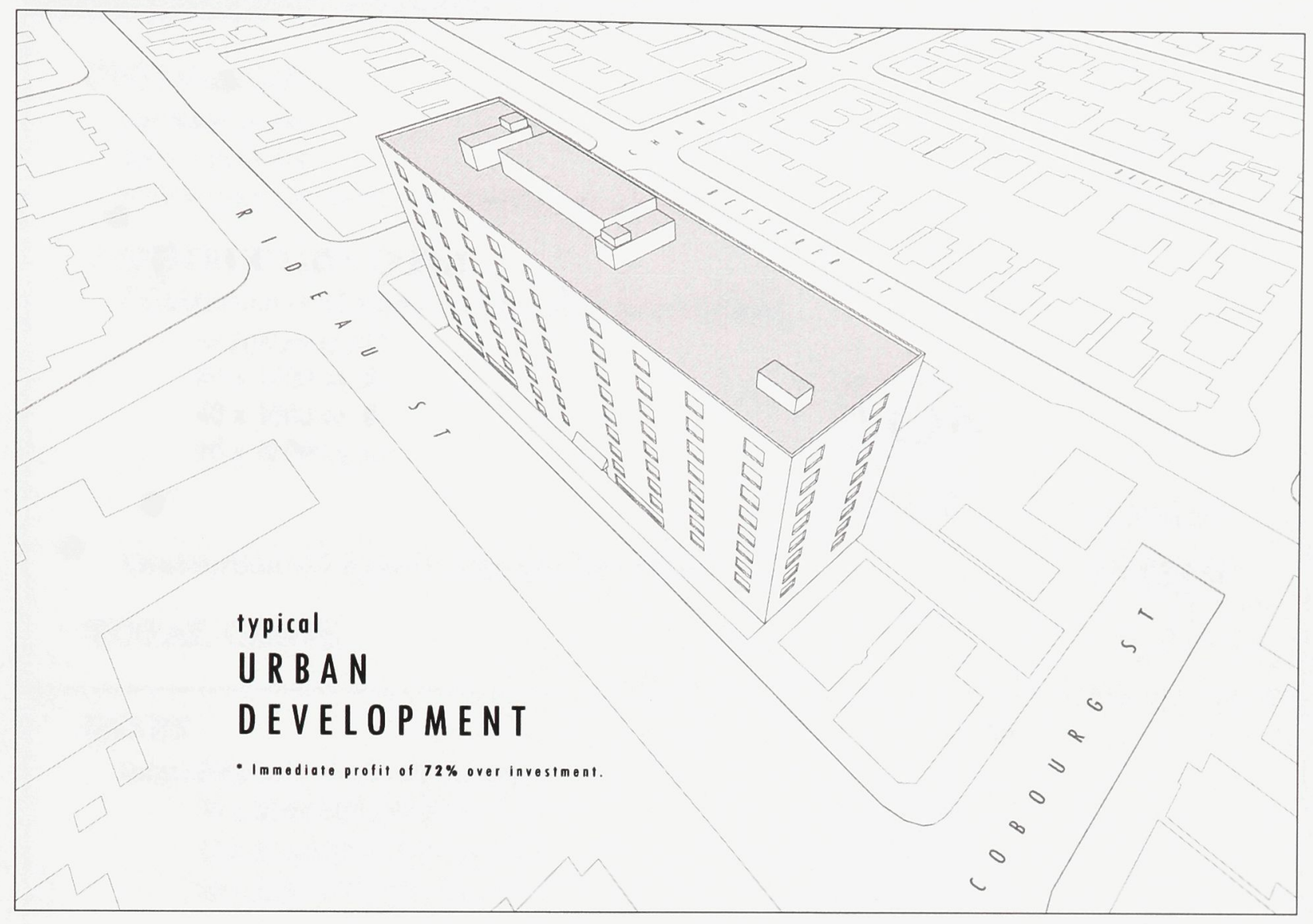

Image 4.2.5 Image showing 'a typical urban development on the Rideau Street site'. This type of building is a maximization of the allowable building envelope, and floor-space index. There would be approximately 120 residential units of various sizes. 
Cost Scenario:

\section{TYPICAL URBAN DEVELOPMENT}

\section{INITIAL COSTS}

purchase of site

servicing of site

building permit (at $\$ 13.50$ per $\$ 1000$ of construction costs)

\section{CONSTRUCTION COSTS}

Construction of 11 storey condominium with 120 units

(at $\$ 100$ per sq. ft) *

$60 \times 1000$ sq. ft.

$40 \times 1500$ sq. ft.

$\$ 6,000,000$

$20 \times 2000$ sq. ft.

$\$ 6,000,000$

$\$ 4,000,000$

$$
\$ 16,000,000
$$

$\$ 16,000,000$

Construction of 3 levels of underground parking

$\$ 4,500,000$

TOTAL COSTS

\section{SALES}

Immediate sale of 120 condo units

$$
\begin{aligned}
& 60 \times \$ 250,000 \text { (1000 sq. ft.) }{ }^{* *} \\
& 40 \times \$ 350,000 \text { (1500 sq. ft.) } \\
& 20 \times \$ 450,000 \text { (2000 sq. ft.) }{ }^{* *}
\end{aligned}
$$

$$
\begin{array}{r}
\$ 15,000,000 \\
\$ 14,000,000 \\
\$ 9,000,000 \\
\hline \$ 38,000,000
\end{array}
$$

$\$ 38,000,000$

TOTAL SALES

TOTAL SALES

\section{Therefore, building a high-rise building that maximizes the allowable building envelope} yields an immediate profit of $72 \%$ over the initial investment.

* This is an approximated value for high-rise residential slab construction based on Handscomb's quantity surveying manual.

** These sale prices are averages taken from comparably-sized condominium properties listed on the Multiple Listing Service at MLS.ca.

Image 4.2.6 Chart showing the cost scenario for a typical urban development on the Rideau Street site. 
In the first scenario, the construction and immediate sale of five suburban homes yields a net loss for the developer. This clearly states that this site is not feasible for a low density development. In the second scenario, where a high-rise was built to maximize the sellable number of units on this site, the developer would enjoy a sizeable immediate profit. This indicates the obvious reasoning behind the popularity of this building type in the urban realm. The exclusion of retail or office space from these types of buildings also points to the desire for immediate pay-back or profit, without any intent of profiting over time later through the income generated from leasable retail or office space. As extreme comparisons, these two development scenarios segue nicely into the third scenario, which is meant to locate a balance between each end of the spectrum. Would this development, which is essentially a combination of these two opposing development types, still achieve profitability? Just how densely developed would this site on Rideau Street have to be to satisfy the existing financial constraints?

The two charts that follow convey this project not only as having met its stated financial goals, but as a development option that strikes a balance between the extreme examples of urban and suburban development given. In the first year after project construction, it is assumed for the purposes of this evaluation that all residential units will sell and all leasable space will be fully occupied. This income, weighed against the value of the site, construction, and other costs results in the net loss of ten percent of the initial investment. However, the project continues to generate income for the developer and all money is recuperated. In fact, five years later the profit is at almost $100 \%$. 


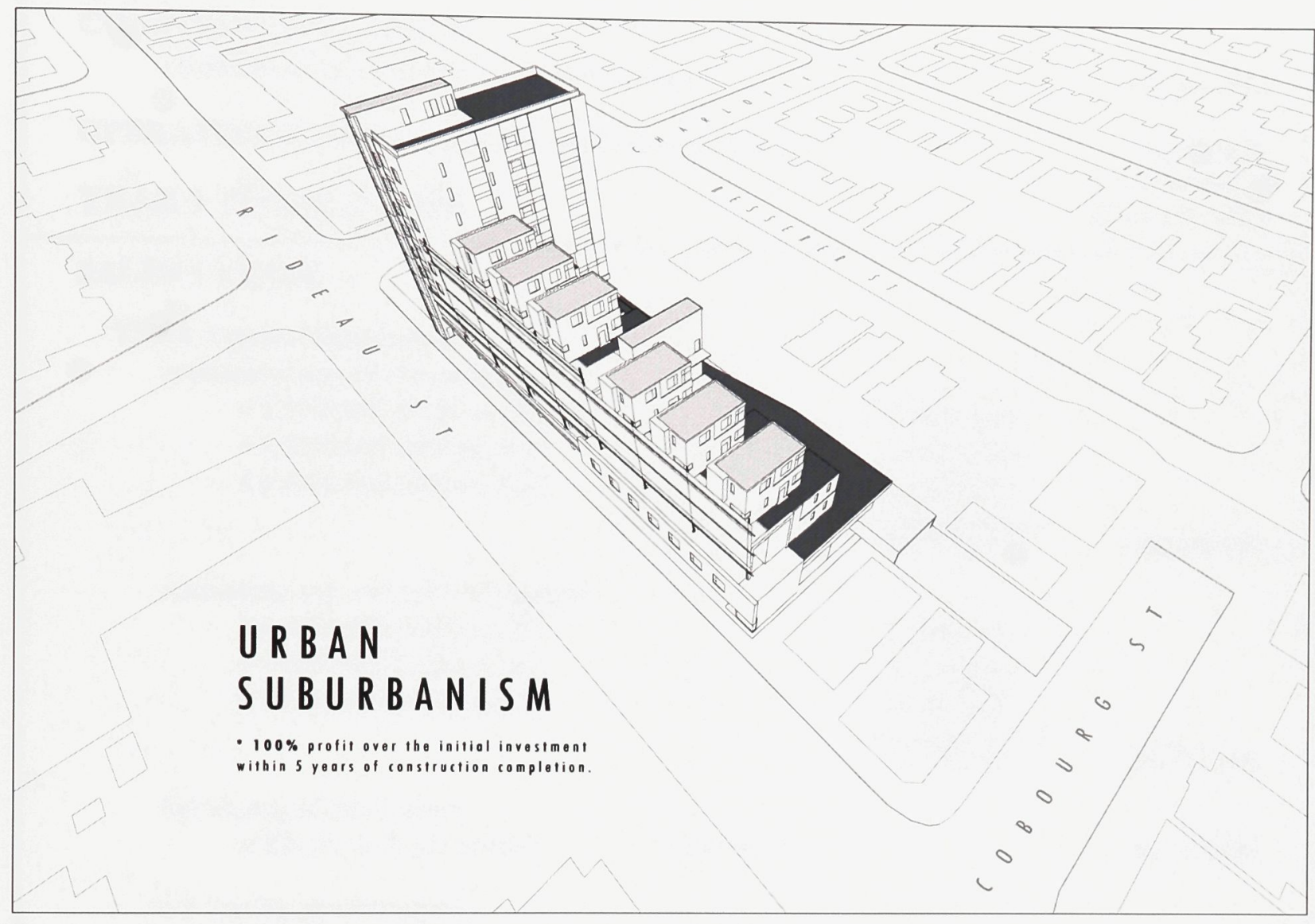

Image 4.2.7 Urban Suburbanism. This development option provides for 5000 square feet of office space, 6000 square feet of retail space, a full parking garage, 15 units of private dwellings, and 18 dwelling units within a condominium tower. 


\section{Cost Scenario:}

\section{URBAN SUBURBANISM}

\section{INITIAL COSTS}

purchase of site

servicing of site

building permit (at $\$ 13.50$ per $\$ 1000$ of construction costs)

\section{CONSTRUCTION COSTS}

construction costs outlined in detail in chart 4.2.2

OPERATING COSTS (estimated, for the first year after construction)

\section{YEAR 1 TOTAL COSTS}

\section{SALES + LEASE}

\section{YEAR 1 (post-construction)}

immediate sale of 18 condo units:

$$
\begin{array}{ll}
6 \times \$ 300,000 \text { (1150 sq. ft.) * } & \$ 1,800,000 \\
6 \times \$ 250,000 \text { (700 sq. ft.) * } & \$ 1,500,000 \\
6 \times \$ 200,000 \text { (600 sq. ft.) * } & \$ 1,200,000 \\
\cline { 2 - 2 } & \$ 4,500,000
\end{array}
$$

immediate sale of 15 private homes:

$$
\begin{aligned}
& 3 \times \$ 350,000 \text { (1200 sq. ft.) } \\
& 6 \times \$ 250,000 \text { (1000 sq. ft.) } \\
& 6 \times \$ 200,000 \text { (800 sq. ft.) }
\end{aligned}
$$

$$
\begin{aligned}
& \$ 1,050,000 \\
& \$ 1,500,000 \\
& \$ 1,200,000 \\
& \hline \$ 3,750,000
\end{aligned}
$$

full leasing of retail space:

$$
\text { at } \$ 30 \text { per sq. ft. per month** }
$$

full leasing of office space:

$$
\text { at } \$ 20 \text { per sq. ft. per month }{ }^{\star * *} \quad 5260 \text { sq. ft. }
$$

* These sale prices are averages taken from comparably-sized condominium properties listed on the Multiple Listing Service at MLS.ca.

** This rate reflects average recent lease rates for prime ground level, street-facing retail space in the Ottawa region.

*** This rate reflects average recent lease rates for prime office space in downtown Ottawa.

Image 4.2.8 Chart showing the 'year one' cost scenario for a the building design this project proposes. 
Long-Term Cost Scenario:

URBAN SUBURBANISM

Assume full occupancy of retail and office space.

Assume annual inflation of lease rates at $2 \%$.

Assume an approximated annual maintenance \& operating budget of $\$ 250,000$.

Running Total:

YEAR 1

total income (office \& retail leases)

$\$ 11,796,600$

total costs (construction \& initial costs + operating costs)

$(\$ 13,072,060)$

$(\$ 1,275,460)$

$(\$ 1,275,460)$

YEAR 2

total income (office \& retail leases)

$\$ 3,617,532$

total costs (maintenance + operating costs)

$(\$ 250,000)$

$\$ 3,367,532$

$\$ 2,092,073$

YEAR 3

total income (office \& retail leases)

$\$ 3,689,883$

total costs (maintenance + operating costs)

$(\$ 250,000)$

$\$ 3,439,883$

$\$ 5,531,955$

YEAR 4

total income (office \& retail leases)

$\$ 3,763,680$

total costs (maintenance + operating costs)

$(\$ 250,000)$

$\$ 3,513,680$

$\$ 9,045,635$

YEAR 5

total income (office \& retail leases)

$\$ 3,838,954$

total costs (maintenance + operating costs)

$(\$ 250,000)$

TOTAL INITIAL INVESTMENT

$\$ 12,822,060$

TOTAL PROFIT (after 5 years)

$\$ 12,634,589$

Therefore, after nearly covering all costs in the first year, the project goes on to achieve a $98.5 \%$ profit at the end of the fifth year post-construction.

Image 4.2.9 Chart showing the long term cost scenario for the building design this project proposes. 


\subsection{Project Conclusions}

The specific goals that were stated initially in the project scope have been largely achieved in this design project. In addition, a case has already been made for the less objective aspects of those goals (the suburban desire for contact with green space, and the suburban ideal of the private home), and, for the most part, those aspects are characteristics in the final design. Still, some of the larger questions remain unanswered, and the purpose of this section is to address those issues.

It is important to ask how this building affects the urban fabric of which it is a part. Does the density of this development detract from or add to the Rideau Street commercial corridor? How does it affect the surrounding residential neighbourhood? First, this design is successful as far as presenting a continuous street front and an edge along the sidewalk that is nearly unbroken. In fact, the sidewalk is extended and enlivened in the winter months by the indoor retail promenade that mirrors the sidewalk inside the building. The façade of this building is continuous above the ground as well; where the private homes present a broken façade against the street, the glass wind barrier provides a constant surface in front of those homes.

If development all along Rideau Street continues to grow in scale, this building will cease to be one of the taller buildings at the street edge in the area. Although there are taller buildings in the immediate vicinity, most of the buildings surrounding this site are low-rise residential buildings. As a result, this project affects the existing urban context by actually increasing the average built density in the area. This is a positive outcome because it occurs in way that is not completely out of scale with the 
context. If every new development would occur in a highly dense arrangement (much like scenario 2, chart 4.2.4), the urban infrastructure would be strained. This project, in its medium-density arrangement, would not contribute to that problem.

At the same time, it must be conceded that this project would fail under the scrutiny of a developer's evaluation. Although it does achieve a profit in reasonable turn-around time, the truth remains that a more profitable option exists. A building which completely maximizes the amount of sellable space would win out over this building design because it would likely offer a less complex type of construction and a much more immediate profit.

Perhaps the question of most importance in the evaluation of this design project is this: how does this building distinguish itself from any other building in the contemporary urban realm? If it is in fact a building that is a hybrid of the urban and suburban realms, does it not contribute to the 'exopolis'? Or, if the merging of city and suburb has caused the problematic nature of today's urban realm, then wouldn't this building only add to it? The simple answer is of course no. The intention here to was not provide a compromised form or either the urban or suburban realms. By choosing a site within the urban core, and by utilizing an empty site, this project is an urban-infill project; it does not contribute to urban sprawl. By creating a multi-use building where residential space co-exists with commercial space, the contemporary notion of single-use zoning is undermined. With that said, this project is not a solution for any urban site in any city, and the same building would not have the same effect on another site. If this building were to be inserted into a more dense area or into another larger metropolis, it likely would detract from the urban fabric 
because it is a medium-density development. For this is reason, this project can only claim distinction from other typical buildings in the contemporary urban realm if it remains tied to this specific site and context. Some of the principles this design exemplifies could be proposed on other urban sites, but they would have to be adjusted to reflect the specific constraints of that site, just as this project is a response designed specifically for this site.

This project delivers a comprehensive alternative building type as a reaction to typical development in the contemporary urban realm. Despite some technical and financial shortcomings, the design presented here supports the search for a hybridized architecture that embodies the ongoing merging of city and suburb in the context of the city of Ottawa. 
Enamaters Setion 40

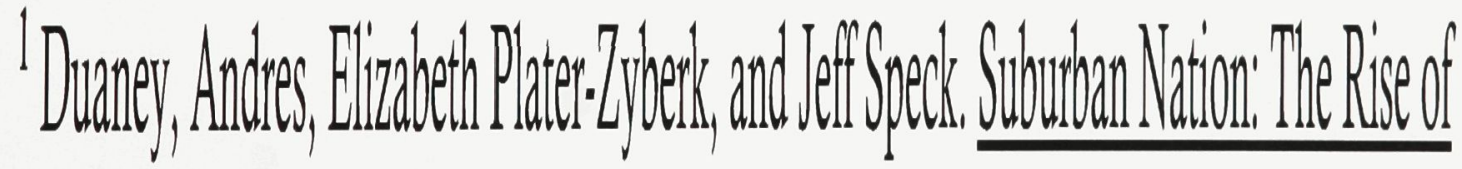

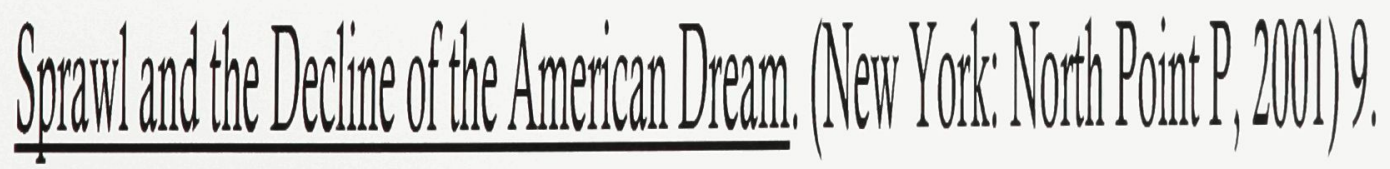

